\title{
Automação de um sistema de pulverização para aplicação de agroquímicos a taxa variada usando injeção direta
}

\author{
Heitor Vinicius Mercaldi
}

Dissertação apresentada à Escola de Engenharia de São Carlos da Universidade de São Paulo, como parte dos requisitos para obtenção do título de Mestre em Ciências, Programa de Engenharia Elétrica.

ORIENTADORA: Profa. Dra. Vilma Alves de Oliveira 
HEITOR VINICIUS MERCALDI

\section{AUTOMAÇÃO DE UM SISTEMA DE PULVERIZAÇÃO PARA APLICAÇÃO DE AGROQUÍMICOS A TAXA VARIADA USANDO INJEÇÃO DIRETA}

Dissertação de Mestrado apresentada ao Programa de Engenharia Elétrica da Escola de Engenharia de São Carlos como parte dos requisitos para obtenção do título de Mestre em Ciências, Programa de Engenharia Elétrica.

Área de Concentração: Sistemas Dinâmicos Orientadora: Profa. Dra. Vilma Alves de Oliveira

São Carlos

2012

Trata-se da versão corrigida da dissertação. A versão original se encontra disponível na EESC/USP que aloja o Programa de Pós-Graduação de Engenharia Elétrica. 
AUTORIZO A REPRODUÇÃO TOTAL OU PARCIAL DESTE TRABALHO, POR QUALQUER MEIO CONVENCIONAL OU ELETRÔNICO, PARA FINS DE ESTUDO E PESQUISA, DESDE QUE CITADA A FONTE.

Mercaldi, Heitor Vinicius

M553a Automação de um sistema de pulverização para aplicação de agroquímicos a taxa variada usando injeção direta. / Heitor Vinicius Mercaldi; orientadora Vilma Alves de Oliveira. São Carlos, 2012.

Dissertação (Mestrado) - Programa de Pós Graduação em Engenharia Elétrica e Área de Concentração em Sistemas Dinâmicos - Escola de Engenharia de São Carlos da Universidade de São Paulo, 2012.

1. agricultura de precisão. 2. automação.

3. controle PID fuzzy. 4. injeção direta. 5. taxa variada. I. Título. 


\section{FOLHA DE JULGAMENTO}

Candidato: Engenheiro HEITOR VINICIUS MERCALDI.

Título da dissertação: "Automação de uma bancada de pulverização para aplicação de agroquímicos a taxa variada usando injeção direta".

Data da defesa: 10/09/2012

\section{Comissão Julgadora:}

Prof ${ }^{\text {a }}$. Titular Vilma Alves de Oliveira (Orientadora) (Escola de Engenharia de São Carlos/EESC)

Prof. Dr. Edson Eiji Matsura

(Universidade Estadual de Campinas/UNICAMP)

Dr. Paulo Estevão CruvineI

(EMBRAPA)

\section{Resultado:}

APROVADO
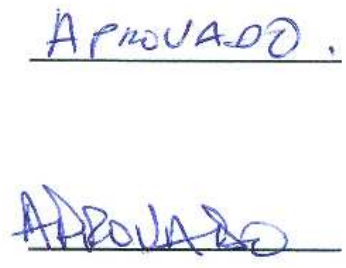

Coordenador do Programa de Pós-Graduação em Engenharia Elétrica e Presidente da Comissão de Pós-Graduação:

Prof. Titular Denis Vinicius Coury 

Aos meus pais Joceli J. Mercaldi e Heraldo J. C. Mercaldi. 
Primeiramente agradeço à Deus pela saúde e as oportunidades que me foram concedidas.

Agradeço também à minha orientadora, Profa. Dra. Vilma A. Oliveira, pelos ensinamentos pertinentes ao trabalho e os ensinamentos fora do laboratório, sempre com sábias palavras em momentos oportunos.

Ao Dr. Paulo E. Cruvinel por participar com discussões e sugestões durante o desenvolvimento desse trabalho.

Ao Prof. Dr. Brian L. Steward pelo apoio no desenvolvimento dos modelos.

Aos companheiros do Laboratório de Controle, em especial ao aluno de doutorando Kleber R. Felizardo, pela amizade e o apoio em todas as etapas desse trabalho.

A minha namorada, Minayana Giacometti, pelo apoio e compreensão.

Aos funcionários do SEL-EESC-USP e da Embrapa Instrumentação pelo pronto atendimento e auxílio nas tarefas que possibilitaram o andamento do trabalho.

Aos colegas de trabalho da UFSCar por incentivarem meu aperfeiçoamento. 


\section{Sumário}

$\begin{array}{ll}\text { Lista de Figuras } & \text { ix }\end{array}$

Lista de Tabelas $\quad$ xiii

$\begin{array}{ll}\text { Lista de Abreviaturas } & \text { Xv }\end{array}$

Lista de Símbolos $\quad$ xvii

Resumo $\quad$ xxi

$\begin{array}{ll}\text { Abstract } & \text { xxiii }\end{array}$

1 Introdução 1

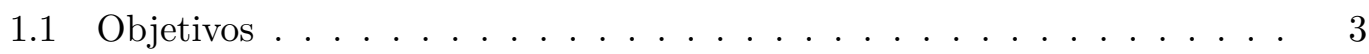

1.2 Organização do Trabalho . . . . . . . . . . . . . . . . 4

2 Revisão Bibliográfica 5

2.1 Introdução a Agricultura de Precisão . . . . . . . . . . . . . . 5

2.2 Aplicação de Agroquímicos por Pulverização . . . . . . . . . . . . . . 7

2.3 Pulverizadores com Injeção Direta . . . . . . . . . . . . . . . . 9

2.4 Controlador de Pulverização . . . . . . . . . . . . . . . . . 11

2.5 Controle Adaptativo com Sistemas Fuzzy . . . . . . . . . . . . . . . 13

3 Instrumentação do Sistema $\quad 21$

3.1 Módulo de Pulverização . . . . . . . . . . . . . . . . . . . . . . . 24

3.2 Módulo de Injeção . . . . . . . . . . . . . . . . . . . . . . . . . . . . . 30

3.3 Módulo de Descarte . . . . . . . . . . . . . . . . . . . . . . . 31

3.4 Características Operacionais do Sistema de Pulverização . . . . . . . 32

4 Modelagem e Simulação dos Módulos 35

4.1 Modelagem do Módulo de Injeção . . . . . . . . . . . . . . . . . 36 
4.2 Modelagem do Módulo de Pulverização . . . . . . . . . . . . . . 38

4.2.1 Validação do modelo matemático do módulo de pulverização . 47

4.3 Ambiente de Simulação . . . . . . . . . . . . . . . . . . . . . . . . . . . 48

5 Controladores para os Módulos 53

5.1 Definição do Período de Amostragem . . . . . . . . . . . . . . . . 54

5.2 Controlador PID no LabVIEW . . . . . . . . . . . . . . . . 55

5.3 Auto-sintonia do PID no LabVIEW . . . . . . . . . . . . . . . . 58

5.4 Controladores Fuzzy no LabVIEW . . . . . . . . . . . . . . . . . . . 62

5.5 Controlador PI do Módulo de Injeção . . . . . . . . . . . . . . . . . . . 68

5.6 Controladores do Módulo de Pulverização . . . . . . . . . . . . . . . 68 5.6.1 Controlador PID . . . . . . . . . . . . . . . . . 68

5.6.2 Controlador PID Fuzzy Adaptativo por Escalonamento de Ganho 69

$\begin{array}{lll}6 & \text { Resultados Experimentais } & 77\end{array}$

7 Conclusões $\quad 83$

8 Propostas para Trabalhos Futuros $\quad 85$

$\begin{array}{lr}\text { A Diagramas Esquemáticos } & 87\end{array}$

$\begin{array}{ll}\text { Referências Bibliográficas } & 93\end{array}$ 


\section{Lista de Figuras}

FIGURA 2.1 Tipos de sistema de injeção de acordo com o ponto de injeção. 10

FIGURA 2.2 Estrutura típica de um controlador PID fuzzy do tipo 1. . . . 14

FIGURA 2.3 Estrutura típica de um controlador PID fuzzy do tipo 2. . . . 15

FIGURA 2.4 Controlador adaptativo baseado em modelo. . . . . . . . . 16

FIGURA 2.5 Controlador fuzzy auto-sintonizável. . . . . . . . . . . . . . 16

FIGURA 2.6 Controlador dual fuzzy para o controle de elevadores. . . . . . 17

FIGURA 2.7 Controlador fuzzy por escalonamento de ganho, tipo $3 . \quad$. . . 18

FIGURA 3.1 Vista frontal da bancada pulverização onde está montado o sistema de aplicação agroquímicos. Ao fundo está o painel com os componentes elétricos, eletrônicos e hidráulicos e à frente as seções de barra com os bicos e pontas de pulverização. . . . . . . . . . . . . . .

FIGURA 3.2 Arquitetura usada para o desenvolvimento da automação da bancada de pulverização mostrando os níveis de programação com o LabVIEW (PC Host), LabVIEW Real-Time e LabVIEW FPGA. . . . . 23

FIGURA 3.3 Ilustração do sistema de pulverização de agroquímicos montado para a aplicação em taxa variada com o módulo de injeção direta central mostrado no detalhe. . . . . . . . . . . . . . .

FIGURA 3.4 Instrumentação usada no acionamento da bomba de pulverização e sensor de nível do tanque de água. . . . . . . . . . . . . . . 
FIGURA 3.5 Válvula de controle VP1 com indicações do êmbolo, terminais elétricos e os sentidos de fluxo da calda de entrada $Q_{B P}$, de saída para as barras $Q_{F}$ e de saída para o retorno $Q_{R} \ldots \ldots \ldots 27$

FIGURA 3.6 Instrumentação usada no acionamento das válvulas VP1, VP2, VS1 e VS2 e encoder na válvula de controle VP1. . . . . . . . . . . . . . 28

FIGURA 3.7 Ligação do fluxômetro eletromagnético. . . . . . . . . . . . . . 28

FIGURA 3.8 Ligação do sensores de pressão. . . . . . . . . . . . . . . . . 29

FIGURA 3.9 Instrumentação do módulo de injeção. No detalhe são indicados os componentes do conjunto QB-3. . . . . . . . . . . . . 30

FIGURA 3.10 Instrumentação do módulo de descarte calda. . . . . . . . . . 32

FIGURA 3.11 Região de operação do sistema de pulverização à taxa variada. A maior e menor taxa de aplicação são respectivamente $R_{\max }=$ $1000 \ell / h a$ e $R_{\text {min }}=6,6 \ell / h a \ldots \ldots 33$

FIGURA 4.1 Diagrama em blocos do módulo de injeção. . . . . . . . . . . . 36

FIGURA 4.2 Arranjo usado para o ensaio do módulo de injeção. . . . . . . 36

FIGURA 4.3 Resultados experimentais e de simulação do modelo do módulo de injeção. . . . . . . . . . . . . . . . . . . . . . . 38

FIGURA 4.4 Circuito hidráulico do módulo de pulverização. . . . . . . . . . 41

FIGURA 4.5 Diagrama em blocos do motor CC da válvula de controle e ponte H. . . . . . . . . . . . . . . . . . . 45

FIGURA 4.6 Diagrama de blocos do módulo de pulverização. . . . . . . . . 46

FIGURA 4.7 Curva $K_{Q V P}$ versus $\theta_{V}(4.27)$ da válvula de controle VP1. . . 47

FIGURA 4.8 Diagrama em blocos do módulo de pulverização com o controlador proporcional com ganho $K_{C}=20 \ldots \ldots$. . . . . . . . . 47

FIGURA 4.9 Respostas reais e de simulação do módulo de pulverização com controlador proporcional usando a ponta modelo ISO-11002. . . . . . . .

FIGURA 4.10 Respostas reais e de simulação do módulo de pulverização com controlador proporcional usando a ponta modelo ISO-11003. . . . . . . . 
FIGURA 4.11 Respostas reais e de simulação do módulo de pulverização com controlador proporcional usando a ponta modelo ISO-11004. . . . . . . . 50

FIGURA 4.12 Respostas reais e de simulação do módulo de pulverização com controlador proporcional usando a ponta modelo ISO-11005 . . . . . . . 50

FIGURA 4.13 Ambiente de simulação mostrando a interface gráfica do controle de vazão do agroquímico. . . . . . . . . . . . . . . . . . . 51

FIGURA 4.14 Ambiente de simulação mostrando a interface gráfica do controle de vazão da calda. . . . . . . . . . . . . . . . . . 51

FIGURA 5.1 Resposta ao degrau do módulo de pulverização com controlador proporcional $\left(K_{C}=20\right)$ usando a ponta modelo ISO-11002. . . . . . 55

FIGURA 5.2 Diagrama de blocos de um sistema de controle a malha fechada. 56

FIGURA 5.3 Função de chaveamento $u$ (linha pontilhada) e saída típica do processo y (linha sólida). . . . . . . . . . . . . . . . . . 59

FIGURA 5.4 Malha de controle com a função de chaveamento no erro. . . . 59

FIGURA 5.5 Malha de controle com a função de chaveamento na referência. 59

FIGURA 5.6 Componentes de um sistema de inferência fuzzy do tipo Mamdani. . . . . . . . . . . . . . . . . . . 63

FIGURA 5.7 Exemplo: definições das funções de pertinência sendo B=baixa, $\mathrm{M}=$ média, $\mathrm{A}=$ alta, $\mathrm{P}=$ pequena, e $\mathrm{G}=$ grande. $\ldots \ldots 664$

FIGURA 5.8 Exemplo: fuzzificação das variáveis de entrada. . . . . . . . . 65

FIGURA 5.9 Exemplo: inferência da região fuzzy de saída através das funções MAX-MIN. . . . . . . . . . . . . . . . . . . 66

FIGURA 5.10 Exemplo: defuzzificação da variável de saída. . . . . . . . . . . 67

FIGURA 5.11 Diagrama em blocos do controlador PID fuzzy adaptativo implementado. . . . . . . . . . . . . . . . . . 69

FIGURA 5.12 Diagrama em blocos do sistema de sintonia fuzzy. . . . . . . . 70

FIGURA 5.13 Representação do sistema fuzzy implementado. . . . . . . . . . 70

FIGURA 5.14 Superfície de ajuste do parâmetro $K_{c} \ldots \ldots \ldots$. . . . . . . . 73 
FIGURA 5.15 Superfície de ajuste do parâmetro $T_{i} \ldots \ldots \ldots$. . . . . . 74

FIGURA 5.16 Superfície de ajuste do parâmetro $T_{d} \ldots \ldots$. . . . . . . 74

FIGURA 5.17 Esquema de avaliação e atualização dos parâmetros do controlador PID . . . . . . . . . . . . . . . . . . 75

FIGURA 6.1 Respostas dos controladores PID e PID fuzzy do módulo de pulverização. (a)Vazão da calda $Q_{F}$ e (b) Erro de aplicação com relação a referência, onde as linhas contínuas indicam a faixa de erro de $\pm 5 \%$. 79

FIGURA 6.2 Adaptação de parâmetros do controlador PID fuzzy por escalonamento de ganho. (a) A variável de entrada E. (b) a (d) Os parâmetros atualizados no controlador PID fuzzy $K_{c}, T_{i}$ e $T_{d} \ldots \ldots$. . . 80

FIGURA 6.3 Respostas da pressão $P_{S}$ do sistema com os controladores PID e PID fuzzy por escalonamento de ganho do módulo de pulverização. . . 81

FIGURA 6.4 Respostas do controlador PI do módulo de injeção. (a)Vazão $Q_{H}$ e (b) Erro de aplicação com relação a referência, onde as linhas contínuas indicam a faixa de erro de $\pm 5 \% \ldots \ldots . \ldots$

FIGURA A.1 Diagrama esquemático da placa de interface com o inversor de frequência. ...................... 88

FIGURA A.2 Diagrama esquemático dos circuitos de acionamento das válvulas VP1, VP2, VS1 e VS2. . . . . . . . . . . . .

FIGURA A.3 Diagrama esquemático dos circuitos do amplificador de potência, condicionamento de sinal e alimentação do encoder do módulo de injeção. . . . . . . . . . . . . . . . . .

FIGURA A.4 Diagrama esquemático da placa de acionamento da bomba de descarte e ligações dos sensores de nível e do fluxômetro. . . . . . . . . . 91 


\section{Lista de Tabelas}

TABELA 2.1 Comparação entre os DIS e um CS. . . . . . . . . . . . . . 11

TABELA 3.1 Tabela verdade para o acionamento das válvulas VP1, VP2, $\mathrm{VS1}$ e VS2. . . . . . . . . . . . . . . . . . . . 29

TABELA 3.2 Características do sistema de pulverização implementado neste trabalho e de um sistema de pulverização comercial. . . . . . . . . . . . 32

TABELA 3.3 Faixas de operação das pontas da pulverização do fabricante

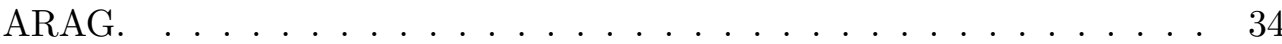

TABELA 4.1 Valores dos parâmetros do modelo do módulo de injeção. . . . 37

TABELA 4.2 Valores dos parâmetros para cálculo da vazão mínima para o escoamento turbulento. . . . . . . . . . . . . . . . . . 40

TABELA 4.3 Valores dos parâmetros do módulo de pulverização. . . . . . . . 46

TABELA 5.1 Fórmulas de sintonia quando o controlador é do tipo P. . . . . 61

TABELA 5.2 Fórmulas de sintonia quando o controlador é do tipo PI ou PID. 62

TABELA 5.3 Exemplo: base de regras para abertura da válvula de alívio. . 66

TABELA 5.4 Parâmetros do PID obtidos por auto-sintonia do modelo do módulo de pulverização. . . . . . . . . . . . . . . . . . . . . 69

TABELA 5.5 Conjuntos fuzzy de entrada e saída. . . . . . . . . . . . . . . 71

TABELA 5.6 Base de regras. . . . . . . . . . . . . . . . . . 72 
TABELA 6.1 Desempenho dos controladores implementados para o módulo de pulverização. . . . . . . . . . . . . . . . . . . .

TABELA 6.2 Desempenho do controlador implementado para o módulo de injeção. . . . . . . . . . . . . . . . . . . . 82 


\section{Lista de Abreviaturas}

AP Agricultura de precisão.

CC Corrente contínua.

CNTP Condições normais de temperatura e pressão.

DIS Sistema de injeção direta - Direct Injection System.

FPGA Circuito integrado de lógica reconfigurável -

- Field Programable Gate Array.

GNSS Sistemas de navegação global via satélite -

- Global Navigation Satellite Systems.

GPS Sistema de posicionamento global - Global Positioning System.

PAC Controlador programável para automação.

PI Controlador proporcional-integral.

PID Controlador proporcional-integral-derivativo.

SIG Sistemas de informação geográfica.

TI Tecnologia de informação.

VRA Aplicação em taxa variada - Variable Rate Application. 


\section{Lista de Símbolos}

$\boldsymbol{Q}_{\boldsymbol{F r e f}}$ Referência de vazão para a calda.

$\boldsymbol{R}$ Taxa de aplicação.

$\boldsymbol{V}$ Velocidade de deslocamento do pulverizador.

$\boldsymbol{L}_{\boldsymbol{B}}$ Comprimento da barra.

$\boldsymbol{y}_{\text {ref }}$ Variável de referência.

y Variável de saída do processo ou variável medida.

e Erro, diferença entre as variáveis de referência e do processo.

$\int \boldsymbol{e d t}$ Integral do erro.

$\boldsymbol{d e} / \boldsymbol{d} \boldsymbol{t}$ Derivada do erro.

$\boldsymbol{u}$ Variável manipulada.

$\sum$ Soma das variáveis.

× Multiplicação das variáveis.

$\boldsymbol{K}_{\boldsymbol{c}}$ Parâmetro de ganho proporcional.

$\boldsymbol{T}_{\boldsymbol{i}} \quad$ Parâmetro de tempo de integração.

$\boldsymbol{T}_{\boldsymbol{d}}$ Parâmetro de tempo derivativo.

$\boldsymbol{Q}_{\boldsymbol{B} \boldsymbol{P}}$ Vazão da bomba de pulverização.

$\boldsymbol{\omega}_{\boldsymbol{P}}$ Rotação da bomba de pulverização.

$\boldsymbol{\omega}_{M P}$ Rotação do motor trifásico.

$\boldsymbol{N A}$ Nível do tanque de água.

$\boldsymbol{V}_{\boldsymbol{N} \boldsymbol{A}}$ Tensão do sensor de nível do tanque de água.

$\boldsymbol{V}_{\boldsymbol{M P}}^{\prime}$ Tensão na placa de interface do inversor de frequência.

$\boldsymbol{V}_{\boldsymbol{M P}}$ Tensão nos módulos conectados ao inversor de frequência.

$\boldsymbol{Q}_{\boldsymbol{F}}$ Vazão da calda.

$\boldsymbol{Q}_{\boldsymbol{R}}$ Vazão da calda no retorno da válvula de controle. 
$\boldsymbol{\theta}_{\boldsymbol{V}}$ Posição angular do embolo da válvula de controle.

$\boldsymbol{V} \mathbf{1}, \boldsymbol{V} \mathbf{2}$ Tensão nas válvulas proporcionais.

$\boldsymbol{V} \mathbf{3}, \boldsymbol{V} \mathbf{3}$ Tensão nas válvulas de seção.

$\boldsymbol{E} \boldsymbol{N}_{\boldsymbol{V} \boldsymbol{P}}$ ou $\boldsymbol{D}_{\boldsymbol{V}}$ Ciclo de trabalho do PWM das válvulas proporcionais.

$\boldsymbol{A F}_{\boldsymbol{V}}$ Seleciona a abertura ou fechamento das válvulas.

$f_{F} \quad$ Frequência de saída do fluxômetro.

$\boldsymbol{P s}, \boldsymbol{P 1}$ Pressão do sistema e da barra, respectivamente.

$\boldsymbol{V}_{\boldsymbol{P} \boldsymbol{s}}, \boldsymbol{V}_{\boldsymbol{P 1}}$ Tensão de saída dos sensores de pressão do sistema e da barra, repectivamente.

$\boldsymbol{\omega}_{\boldsymbol{H}} \quad$ Rotação do motor do módulo de injeção.

$\boldsymbol{i}_{\boldsymbol{H}}$ Corrente de amadura do motor do módulo de injeção.

$\boldsymbol{V}_{\boldsymbol{i} \boldsymbol{H}}$ Tensão proporcional a corrente de amadura do motor do módulo de injeção.

$\boldsymbol{V}_{\boldsymbol{H}}$ Tensão de amadura do motor do módulo de injeção.

$\boldsymbol{D}_{\boldsymbol{H}}$ Ciclo de trabalho do PWM do motor do módulo de injeção.

$\boldsymbol{Q}_{\boldsymbol{H}} \quad$ Vazão do módulo de injeção.

$\boldsymbol{P}_{\boldsymbol{H}}$ Pressão na saída do módulo de injeção.

$\boldsymbol{N}_{\boldsymbol{H} \text { min }}$ Nível mínimo do tanque de agroquímico.

$\boldsymbol{V}_{\boldsymbol{N H} \text { min }}$ Tensão do sensor de nível mínimo do tanque de agroquímico.

$\boldsymbol{N}_{\boldsymbol{D m i n}}, \boldsymbol{N}_{\boldsymbol{D m a x}} \quad$ Nível mínimo e máximo do tanque de descarte, respectivamente.

$\boldsymbol{V}_{\boldsymbol{N} \boldsymbol{H} \boldsymbol{m i n}}$ Tensão do sensor de nível mínimo e máximo do tanque de descarte, respectivamente.

$\boldsymbol{V}_{\boldsymbol{B} \boldsymbol{D}}$ Tensão na bomba de descarte.

$\boldsymbol{V}_{\boldsymbol{B} \boldsymbol{D}}^{\prime}$ Tensão na saída do módulo que aciona a bomba de descarte.

$\boldsymbol{m}$ Número de seções de barra.

n Número de bicos por seção de barra.

$\boldsymbol{E}$ Distância entre os bicos.

$\boldsymbol{D}_{\boldsymbol{H}}$ Ciclo de trabalho do PWM do módulo de injeção.

$\boldsymbol{K}_{\boldsymbol{P}}$ Ganho do amplificador de potencia do módulo de injeção.

$\boldsymbol{K}_{T}$ Constante de torque do motor do módulo de injeção.

$\boldsymbol{K}_{\boldsymbol{E}}$ Força contra-eletromotriz do motor do módulo de injeção.

$\boldsymbol{R}_{\boldsymbol{H}}$ Resistência de armadura do motor do módulo de injeção.

$\boldsymbol{L}_{\boldsymbol{H}}$ Indutância de armadura do motor do módulo de injeção. 
$\boldsymbol{J}$ Momento de inércia do motor do módulo de injeção.

$\boldsymbol{b}$ Coeficiente de atrito viscoso do motor do módulo de injeção.

$\boldsymbol{K}_{\boldsymbol{B}}$ Deslocamento volumétrico da bomba do módulo de injeção.

$\boldsymbol{R}_{\boldsymbol{e}} \quad$ Número de Reynolds.

$\boldsymbol{\rho}$ Densidade absoluta do fluído.

$\boldsymbol{d}_{\boldsymbol{i}}$ Diâmetro interno do conduto.

$\boldsymbol{v}$ Velocidade média do fluído.

$\boldsymbol{\delta}$ Viscosidade dinâmica absoluta do fluído.

$\boldsymbol{A}_{\boldsymbol{i}}$ Área transversal interna do conduto.

$\boldsymbol{C}_{\boldsymbol{D}} \quad$ Coeficiente de descarga do elemento hidráulico.

$\boldsymbol{K}_{\boldsymbol{Q}}$ Resistência fluídica do elemento hidráulico.

$f_{a}$ Coeficiente de perda de carga distribuída.

$\boldsymbol{\Delta} \boldsymbol{P}$ Queda de pressão.

$\boldsymbol{Q}_{\boldsymbol{A}}$ Vazão da água.

$\boldsymbol{Q}_{\boldsymbol{S}}$ Vazão da calda em uma seção de barra.

$\boldsymbol{Q}_{\boldsymbol{T}}$ Vazão da calda em um trecho da seção de barra.

$\boldsymbol{Q}_{\boldsymbol{P}} \quad$ Vazão nas pontas de pulverização.

$\boldsymbol{K}_{\boldsymbol{P H}}$ Ganho da ponte $\mathrm{H}$ que aciona a válvula de controle da calda.

$Z_{M}$ Zona morta.

$\boldsymbol{K}_{\boldsymbol{M}}$ Constante de ganho do modelo do motor da válvula de controle da calda.

$\boldsymbol{T}_{\boldsymbol{M}}$ Constante de tempo do modelo do motor da válvula de controle da calda.

$\boldsymbol{u}^{2}$ Operação de potenciação da variável - eleva ao quadrado.

$\boldsymbol{\tau}$ Tempo de resposta do fluxômetro.

$\boldsymbol{\omega}_{\boldsymbol{A}}$ Frequência de amostragem.

$\boldsymbol{T}$ Período de amostragem.

$\boldsymbol{\omega}_{b m a}$ Banda de passagem de malha fechada.

$\boldsymbol{t}_{\boldsymbol{r}}$ Tempo de subida.

$\tau_{\boldsymbol{d}}$ Constante de tempo dominante.

$\omega_{n} \quad$ Frequência natural.

$\mathcal{U}$ Universo de discurso de uma variável fuzzy. 


\section{Resumo}

MERCALDI, H. V. Automação de um sistema de pulverização para aplicação de agroquímicos a taxa variada usando injeção direta. Dissertação (Mestrado) - Escola de Engenharia de São Carlos da Universidade de São Paulo, São Carlos, 2012.

Neste trabalho, a automação de um sistema de pulverização a taxa variada com injeção direta é apresentado. A automação do sistema de pulverização montado em uma bancada laboratorial estática foi baseado em um controlador programável com capacidade de tempo real. Os sistemas de pulverização com injeção direta possibilitam o uso de diferentes agroquímicos em uma mesma aplicação, e adicionalmente reduzem os impactos toxicológico e ambiental relacionados com o preparo e descarte da mistura de agroquímico e água. A automação deste sistema envolve o desenvolvimento de placas de interface, a modelagem do pulverizador e o controle das vazões. Um ambiente de simulação baseado no LabVIEW permitiu que os códigos fonte e as rotinas desenvolvidas fossem utilizadas diretamente no controlador programável, exigindo pouca ou nenhuma modificação. Para regular a vazão de injeção do agroquímico, que é dada por uma bomba de pistão, é utilizado um controlador proporcional-integral (PI). Já para regular a vazão da mistura de agroquímico e água, que é dada por uma válvula de controle proporcional de três vias, são implementados dois controladores: um controlador proporcional-integral-derivativo (PID) e um controlador adaptativo do tipo PID fuzzy por escalonamento de ganho. O desempenho dos controladores implementados são analisados via os resultados do erro de aplicação e das vazões.

Palavras-chave: Agricultura de precisão, automação, controle PID fuzzy, injeção direta, taxa variada. 


\section{Abstract}

MERCALDI, H. V. Automation of a direct injection sprayer system for variable rate application of agrochemicals. Dissertação (Mestrado) - Escola de Engenharia de São Carlos da Universidade de São Paulo, São Carlos, 2012.

In this work, the automation of a direct injection sprayer system for variable rate application of agrochemicals is presented. The automation of the sprayer system assembled on a laboratory static bench is based on a programmable controller with real time capabilities. Variable rate sprayer with direct injection systems allow multiple agrochemical application and additionally reduces the toxicologic and environmental risks associated with the carrier-agrochemical mix preparation and discard. The automation of this system comprises the development of interface boards, the sprayer modeling and the control of flow rates. Using a simulation environment based on LabVIEW, the developed source code and routines could be implemented directly in the programmable controller, requiring few or no changes. For the injection flow rate, which is set by a piston pump, a proportional-integral (PI) controller is used. And, to regulate the carrier-agrochemical mix flow rate, which is set by a three-way proportional control valve, two controllers are used: a proportional-integral-derivative (PID) controller and a fuzzy gain scheduling of PID controller. The performance of the implemented controllers is analyzed via the flow rates and the application error results.

Keywords: Automation, direct injection, PID fuzzy control, precision agriculture, variable rate. 
xxiv 


\section{Capítulo 1}

\section{Introdução}

O homem iniciou sua jornada no cultivo de plantas e criação de animais no período neolítico, há cerca de 10.000 anos, desde então a agricultura conquistou o mundo, e tornou-se o principal fator de transformação da ecosfera. O aumento da sua capacidade de produção e de produtividade condicionam o aumento da população mundial e o desenvolvimento de categorias sociais (MAZOYER et al., 2010). A mecanização agrícola teve início por volta de 1830, com o desenvolvimento das segadoras ${ }^{1}$. No entanto, somente por volta de 1910, houve a disseminação do uso dos primeiros tratores acionados por motores de combustão interna. Desde então, a mecanização agrícola esteve em constante evolução, provocando grande aumento na produtividade do trabalho rural (QUEIROZ; DIAS; MANTOVANI, 2006).

Antes mesmo da mecanização os benefícios da aplicação diferenciada de insumos, como o esterco, já eram conhecidos pelos agricultores, mas foi por volta de 1938 que surgiram os primeiros trabalhos sobre a variabilidade espacial das culturas, dando início aos primeiros conceitos do que se entende hoje por agricultura de precisão (AP) (COELHO, 2005). Segundo Coelho (2005): "Agricultura de precisão engloba aspectos da variabilidade dos solos, clima, diversidade de culturas, performance de máquinas agrícolas e insumos (físicos, químicos e biológicos) naturais ou sintéticos, usados na produção das culturas". Os principais conceitos da AP são apresentados no próximo capítulo deste trabalho.

Apesar das pesquisas sobre a variabilidade dos solos e das culturas terem se ini-

\footnotetext{
${ }^{1}$ máquina empregada na colheita ou ceifa de grãos e cereais
} 
ciado na década de 1930, foi somente com os avanços da tecnologia na década de 1980 que a AP ganhou força (INAMASU et al., 2011). Neste sentido, os processadores e microcontroladores, o sistema de posicionamento global (GPS), os sistemas de informação geográfica (SIG), o sensoriamento remoto e os sensores podem ser consideradas tecnologias precursoras para o desenvolvimento da AP (COELHO, 2005) (MANTOVANI, 1999-2002 apud JUNIOR et al., 2006).

A partir de 1993, com o final da implantação dos satélites GPS e sua disponibilidade para uso civil, houve um grande aumento no número de pesquisas voltadas para a agricultura de precisão (QUEIROZ; DIAS; MANTOVANI, 2006). No Brasil, as primeiras iniciativas de adoção de práticas e pesquisa em AP surgiram na segunda metade da década de 1990 (RESENDE et al., 2010; BAIO; ANTUNIASSI, 2011).

Ainda hoje, os grandes centros produtores do país não adotaram extensivamente as técnicas da AP, desta forma a agricultura ainda é praticada sem considerar os efeitos da variabilidade (MOLIN, 2004; RESENDE et al., 2010), refletindo no consumo excessivo de agroquímicos (fertilizantes, herbicidas, inseticidas, fungicidas, reguladores do crescimento, entre outros). Somente no ano 2011, foram consumidos no Brasil por volta de 800 mil toneladas de agroquímicos, onde $48 \%$ é de herbicidas (FERREIRA; CAMARGO; VEGRO, 2012). Esse consumo elevado é justificado porque sem a adoção de práticas de plantas invasoras as perdas na produtividade da lavoura podem variar de $10 \%$ a $100 \%$ (KROPFF; LAAR, 1993).

Considerando a necessidade de controle de plantas invasoras através do uso herbicidas, além dos benefícios para o produtor rural e para o ambiente proporcionadas pela adoção da AP o Laboratório de Controle $^{2}$ e a Embrapa Instrumentação ${ }^{3}$ formaram um grupo de pesquisa, com o apoio do Prof. Dr. Brian L. Steward da Iowa State University (ISU) para as modelagens, visando a formação de mão de obra qualificada e a expansão do conhecimento acerca da tecnologia de aplicação de agroquímicos líquidos. Com o apoio financeiro do $\mathrm{CNPq}^{4}$ e a parceria no âmbito da Rede de Agricultura de Precisão ${ }^{5}$, esta equipe implantou um laboratório situado na Embrapa Instrumentação, com uma plataforma flexível para o desenvolvimento de pulverizadores, chamada aqui

\footnotetext{
${ }^{2}$ LAC - Departamento de Engenharia Elétrica - EESC - USP - São Carlos

${ }^{3}$ Unidade XV de Novembro - São Carlos

${ }^{4}$ Processos: 306988/2007-0, 479306/2008-7 e 143452/2008-8

${ }^{5}$ Macro Programa 1, Processo 01.09.01.002.01
} 
de bancada de pulverização (CRUVINEL et al., 2011).

Esse trabalho de pesquisa, envolve a instrumentação, a obtenção dos modelos matemáticos e a implementação de controladores para a automação de um sistema de pulverização. Especificamente, o sistema estudado é um pulverizador de barras com injeção direta de agroquímicos, caracterizado por apresentar reservatórios separados para o diluente (água) e o agroquímico. São apresentados a instrumentação para o acionamento e condicionamento de sinal, um ambiente de simulação baseado nos modelos obtidos e a implementação dos controladores, sendo um para regular a vazão de injeção (módulo de injeção) do agroquímico e outros dois para regular vazão de pulverização (módulo de pulverização) da calda (mistura de agroquímico e água). O ambiente de simulação desenvolvido a partir dos modelos obtidos é utilizado para facilitar o ajuste dos controladores durante seu desenvolvimento. Ao final do trabalho, são apresentados os resultados experimentais dos controladores implementados e comparados os resultados dos controladores usados para regular a vazão de pulverização da calda.

\section{$1.1 \quad$ Objetivos}

O objetivo geral deste trabalho é automação de um sistema de pulverização para aplicação de agroquímicos a taxa variada usando injeção direta. Para atender ao objetivo geral, os seguintes objetivos específicos são delineados:

- Implementação da instrumentação do sistema de pulverização;

- Obtenção dos modelos matemáticos do pulverizador com injeção direta montado na bancada de pulverização;

- Avaliação do sistema de pulverização usando um controlador proporcional-integral (PI) para o módulo de injeção e outros dois controladores para o módulo de pulverização, sendo o primeiro um controlador proporcional-integral-derivativo (PID) e o outro um controlador adaptativo do tipo PID fuzzy por escalonamento de ganho. 


\subsection{Organização do Trabalho}

O trabalho está organizado em oito capítulos. No Capítulo 2, seguindo esta introdução, é apresentada a revisão bibliográfica abordando os conceitos iniciais acerca do desenvolvimento de sistemas de pulverização a taxa variada com injeção direta, incluindo também os conceitos e trabalhos recentes sobre os controladores eletrônicos usados nesses sistemas. No Capítulo 3, são apresentados o sistema de pulverização para aplicação de agroquímicos a taxa variada usando injeção direta e a instrumentação desse sistema. No Capítulo 4, são apresentados os modelos matemáticos obtidos e o ambiente de simulação desenvolvido. No Capítulo 5, são apresentadas as ferramentas e os controladores implementados para os módulos de pulverização da calda e de injeção direta de agroquímicos. No Capítulo 6, são apresentados os resultados experimentais e a análise desses resultados. No Capítulo 7, são apresentadas as conclusões. No Capítulo 8, são apresentadas as propostas para trabalhos futuros, baseadas nos trabalhos que vem sendo desenvolvidos. 


\section{Capítulo 2}

\section{Revisão Bibliográfica}

\subsection{Introdução a Agricultura de Precisão}

Uma ampla diversidade de plantas, insetos e patógenos, chamados aqui de pragas, podem causar perdas consideráveis em qualidade e quantidade nas plantações. Essas pragas devem ser monitoradas e gerenciadas, com o intuito de reduzir seu impacto negativo na produção de alimentos, rações, fibras e matéria prima para combustíveis.

O crescimento da população mundial, que recentemente atingiu sete bilhões de pessoas, juntamente à busca por fontes de recursos renováveis, têm tornado, cada vez mais, necessário o aumento da produção e da produtividade agrícola. Para atender a esta demanda, as plantações devem ser protegidas das pragas de modo efetivo, eficiente, sem prejudicar o meio ambiente e o homem. Para isso, podem ser utilizadas ferramentas mecânicas, biológicas, químicas ou a combinação destas.

Quanto à forma de utilização dessas ferramentas, é importante considerar que as pragas se distribuem dentro de uma plantação, de forma heterogênea tanto no espaço quanto no tempo. O mesmo acontece com as características do solo, como os nutrientes e a água. Esses fatores, que se distribuem de forma não uniforme, afetam o crescimento da lavoura, influenciando em sua produção e produtividade (OERKE et al., 2010).

Para combater estas pragas é preciso mapeá-las para estudar sua interação com a cultura ao longo dos anos a fim de tomar a melhor decisão do ponto de vista econômico. As ferramentas que proporcionam esta análise e os equipamentos para o combate das pragas fazem parte da AP. 
São diversos os autores que definem a agricultura de precisão, de modo geral, a AP consiste de um conjunto de conceitos, tecnologias e equipamentos voltados ao manejo da variabilidade espacial e temporal associada à produção agrícola empregados para a redução dos custos de produção através da otimização do uso de recursos, levando ao aumento da produtividade das culturas e da qualidade ambiental (PIERCE; NOWAK, 1999; MOLIN, 2004; MANTOVANI; QUEIROZ; DIAS, 1998).

A AP é constituída por um ciclo composto de basicamente por três etapas: (i) coleta de informações, (ii) interpretação das informações e (iii) aplicação de insumos (agroquímicos, sementes e irrigação). Na primeira etapa são obtidas amostras georeferenciadas do solo e da planta, na segunda etapa são analisados os dados obtidos a fim de obter mapas com a distribuição espacial dos atributos analisados (produtividade, nutrientes, disponibilidade de água, densidade de plantas invasoras, etc) a interpretação desses mapas pode servir como base para gerar mapas de prescrição localizada de insumos e agroquímicos, finalmente ocorre a aplicação à taxa variável de insumos e agroquímicos. O ciclo se reinicia com os dados obtidos com a aplicação para a geração de mapas de rastreabilidade (mapas georeferenciados contendo os dados reais da aplicação). Nesse processo é importante o acompanhamento da lavoura durante o ciclo das culturas, a investigação das relações de causa e efeito, a análise econômica e o replanejamento das atividades de manejo visando à otimização dos recursos (MANTOVANI, 2006; AMADO et al., 2006).

Considerando o ciclo da AP, o gerenciamento de uma lavoura utilizando suas técnicas pode incluir o uso de ferramentas de tecnologia de informação (TI), sistemas globais de navegação via satélite (GNSS), sistemas de informação geográfica (SIG), sensoriamento remoto, sistemas de gerenciamento de banco de dados, sistemas de telecomunicações e de maquinário especializado (MOLIN, 1997; MENEGATTI; MOLIN, 2004).

Assim, a AP não consiste somente na habilidade de aplicar agroquímicos (fertilizantes, herbicidas, inseticidas, fungicidas, reguladores do crescimento, entre outros) de forma localizada, mas sim em uma metodologia para a compreensão do processo produtivo da lavoura visando otimizar o uso de recursos e o retorno financeiro. Como consequência as técnicas de AP podem ser compreendidas como uma forma de manejo sustentável da lavoura (QUEIROZ; DIAS; MANTOVANI, 2006; ZHANG; WANG; WANG, 2002). 
No Brasil, as recomendações de agroquímicos, como herbicidas e pesticidas, têm sido estabelecidas com uma margem de segurança do volume de aplicação, levando à utilização de doses até duas vezes maiores que o mínimo (ANDREI, 2005; RAETANO, 2011). Adicionalmente, apesar dos avanços tecnológicos e do conhecimento da heterogeneidade das culturas, em geral em nosso país, a aplicação de agroquímicos é feita pela média sem considerar as variabilidades espacial e temporal (MOLIN, 2004).

Segundo Raetano (2011), a tendência das aplicações é pela diminuição do volume aplicado, reduzindo o consumo de água, principal diluente desses produtos. Em contrapartida, para proporcionar uma cobertura equivalente, é necessário fracionar o volume aplicado em gotas menores, o que aumenta o risco da aplicação devido ao fenômeno de deriva das gotas.

Desta forma, é importante que os equipamentos voltados a aplicação de agroquímicos desenvolvidos atualmente atendam as necessidades da AP.

\subsection{Aplicação de Agroquímicos por Pulverização}

A AP também engloba as técnicas de manejo da lavoura como a semeadura, a colheita, o combate às pragas, entre outras. Dessa forma o manejo fitossanitário, visando o combate à pragas, deve ser realizado de acordo com a variabilidade espacial do alvo.

Neste sentido, quando a opção é pelo controle químico, envolvendo a pulverização de produtos potencialmente danosos ao meio ambiente, como os herbicidas, há um desafio para a agricultura devido aos riscos associados à aplicação destes agroquímicos, que incluem, mas não limitam-se, a contaminação ambiental de áreas não alvo devido a deriva, a lixiviação ${ }^{1}$ e a evaporação.

Dentre os riscos citados, o tamanho das gotas formadas no processo de pulverização tem influência direta com a deriva e a evaporação, sendo objeto de estudos que visam o desenvolvimento de pontas pulverização que reduzem a deriva e adjuvantes para reduzir a evaporação. Na aplicação de agroquímicos, a deriva é a distância horizontal percorrida pelas gotas formadas no processo de pulverização, sendo influenciada pelo seu tamanho/volume e pelas condições climáticas. Para avaliar a propensão à deriva

\footnotetext{
${ }^{1}$ processo de lavagem das folhas da plantas alvo pelas chuvas
} 
utiliza-se a análise do espectro de gotas, onde é determinado a distribuição percentual do diâmetro das gotas formadas. Diferentes pesquisadores consideram que gotas menores que $100 \mu m$ são facilmente carregadas pelo vento (CUNHA, 2008).

Na prática, através do estudo do espectro de gotas são determinadas as condições nas quais o efeito da deriva é reduzido, aumentando a eficiência da pulverização e reduzindo o risco de contaminação de áreas não alvo. Para herbicidas, é recomendada a aplicação nas condições de temperatura ambiente inferior a $30^{\circ} \mathrm{C}$, umidade relativa do ar superior a $55 \%$ e velocidade do vento entre 3 e $10 \mathrm{Km} / \mathrm{h}$ (CAVENAGHI, 2011).

Dentro do conceito da AP, a pulverização deve ser feita de forma localizada, ou seja, o agroquímico deve ser aplicado na quantidade necessária e atingir somente o alvo desejado. Isso leva ao conceito de aplicação em taxa variada que consiste em variar o volume do produto aplicado por hectare. A aplicação de agroquímicos em taxa variada pode ser baseada em mapas de prescrição ou baseada em sensores.

Aplicação baseada em mapas: referem-se aos sistemas de aplicação nos quais a referência da dose é dada por um mapa georeferenciado. Para isso são coletadas amostras no campo agrícola de forma sistemática. Essas amostras são analisadas e os dados obtidos são usados para criação do mapa de prescrição (ESS; PARSONS; MEDLIN, 2001). Os resultados obtidos nessa abordagem mostram o controle de até $98 \%$ das plantas invasoras (plantas daninhas) com redução do uso de herbicidas entre $20 \%$ e $90 \%$, se comparado à aplicação em taxa constante (TIMMERMANN; GERHARDS; KüHBAUCH, 2003; DICKE; KüHBAUCH, 2006; GERHARDS; OEBEL, 2006).

Aplicação baseada em sensores: referem-se aos sistemas de aplicação nos quais a referência da dose é obtida somente no momento da aplicação. Para isso são usados sensores capazes de monitorar alguma característica importante do alvo. Os sensores usados podem ser de diferentes tipos, de acordo com as caraterísticas do produto a ser aplicado e do alvo. Na aplicação baseada em sensores, em geral, é usada uma unidade de processamento dos sinais ou imagens com o objetivo de inferir a dose durante a aplicação. Weis et al. (2008), com um sistema baseado em visão computacional, obteve uma economia de herbicidas de $42 \%$, comparado à aplicação uniforme.

Apesar dos trabalhos citados mostrarem uma economia maior de agroquímicos na 
abordagem utilizando a aplicação baseada em mapas de prescrição não há evidencias, quanto a eficiência, que justifique a adoção de uma abordagem em detrimento da outra. Assim, na prática o importante é a capacidade do controlador regular a taxa de aplicação.

\subsection{Pulverizadores com Injeção Direta}

A pulverização de agroquímicos em taxa variada pode ser feita por via terrestre (SHIRATSUCHI; FONTES, 2002), aérea (BOUSE; CARLTON; MORRISON, 1981) ou aquática (ANTUNIASSI et al., 2003). O pulverizador de barras com sistema de injeção direta $(\mathrm{DIS})^{2}$, usado neste trabalho, encontra-se entre as tecnologias de aplicação por via terrestre. A principal característica dos pulverizadores com DIS é o uso de reservatórios separados para os agroquímicos e o diluente (em geral água), dessa forma a mistura para a formação da calda ocorre em tempo real, imediatamente antes da pulverização (LAMMERS; VONDRICKA, 2008).

Segundo Lammers e Vondricka (2010), a principal motivação do desenvolvimento dos DIS é aumentar a flexibilidade do pulverizador, devido à capacidade da aplicação de diferentes produtos ao mesmo tempo e a possibilidade de variar tanto a taxa como a concentração da calda, além de propiciar maior segurança ao operador, pois não é necessária a manipulação do agroquímico para o preparo da calda.

Os DIS podem ser divididos de acordo com o local onde ocorre a injeção. Lammers e Vondricka (2010) definem três tipos básicos de DIS: os sistemas com injeção direta central (CDIS), sistemas com injeção direta nas barras de seção (BDIS) e sistemas com injeção direta nos bicos (NDIS). Baseado nestas definições foi elaborada a Figura 2.1, que ilustra os pontos de injeção.

Sistemas com injeção direta central (CDIS): o agroquímico é injetado entre o reservatório de água e as seções de barra. Na Figura 2.1, isso corresponde aos pontos de injeção 1 e 2. As vantagens de injeção antes da bomba de pulverização, ponto 1, são a uniformidade da mistura e a possibilidade de utilização de bombas de injeção de baixa pressão. Quanto à injeção após a bomba de pulverização, ponto 2 e seguintes, são

\footnotetext{
${ }^{2}$ do inglês: direct injection system
} 


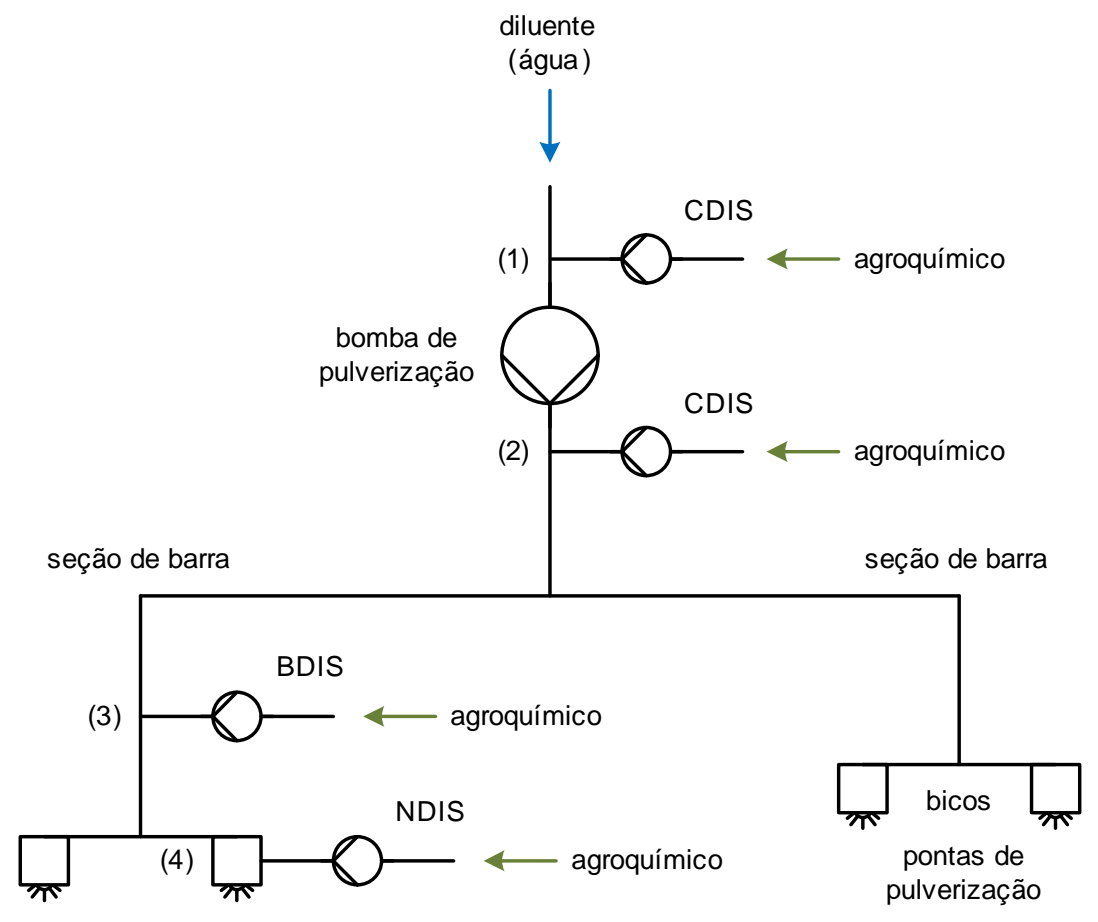

Figura 2.1: Tipos de sistema de injeção de acordo com o ponto de injeção.

usados misturadores estáticos para homogenizar a calda. A principal desvantagem dessa abordagem é o elevado atraso de transporte (em alguns casos, mais de 20 segundos), em decorrência da distância entre o ponto de injeção e as pontas de pulverização (WALKER; BANSAL, 1999; SUDDUTH; BORGELT; HOU, 1995).

Sistemas com injeção direta na barra (BDIS): cada seção de barra do pulverizador possui um sistema para a injeção do agroquímico. Na Figura 2.1 isso corresponde ao ponto de injeção 3. Comparados aos CDIS, a distância entre o ponto de injeção e as pontas é menor, assim o atraso de transporte também é menor (OERKE et al., 2010).

Sistemas com injeção direta nos bicos (NDIS): o agroquímico é injetado diretamente em cada bico de pulverização. Na Figura 2.1 isso corresponde ao ponto de injeção 4. Em comparação com os DIS anteriores, essa abordagem apresenta um atraso de transporte muito pequeno. Por outro lado, também é reduzido o tempo para a formação da calda, assim são reportados problemas com relação a homogeneidade da mistura (ROCKWELL; AYERS, 1996; ZHU et al., 1998).

Na Tabela 2.1, são comparadas as principais características dos DIS em relação a um 
sistema de pulverização convencional (CS) ${ }^{3}$ sem variação da taxa (OERKE et al., 2010). O custo e a complexidade dos sistemas são os principais fatores para a comercialização das tecnologias (LAMMERS; VONDRICKA, 2010).

Tabela 2.1: Comparação entre os DIS e um CS.

\begin{tabular}{lcccc}
\hline Fatores & CS & CDIS & BDIS & NDIS \\
\hline Flexibilidade & pequena & média & média & alta \\
Tempo de resposta & rápido & lento & médio & rápido \\
Qualidade da mistura & excelente & excelente & boa & satisfatória \\
Complexidade & baixa & média & média & alta \\
Custo & baixo & médio & elevado & muito elevado \\
\hline
\end{tabular}

Dentre a configurações dos sistemas de pulverização com injeção direta apresentados um CDIS será montado neste trabalho, isso devido principalmente à disponibilidade e ao custo dos componentes utilizados para sua montagem.

\subsection{Controlador de Pulverização}

O uso da eletrônica embarcada em sistemas de pulverização é justificada pela necessidade do controle da taxa de aplicação, de modo a garantir precisão no volume de agroquímico aplicado por área, compensando ainda as variações na velocidade de deslocamento do pulverizador. A essa função básica nos controladores eletrônicos de pulverização, mais recentemente, vem sendo associadas outras, que em pulverizadores de barras podem incluir entre outras a abertura e fechamento das seções barras e o controle de altura da barra.

Em sua configuração básica o controlador é conectado aos sensores de vazão e de velocidade de deslocamento do pulverizador e com o atuador que regula a vazão da calda. A referência dessa vazão é obtida através dos mapas de prescrição ou de sensores de campo, sendo calculada a partir destes por:

$$
Q_{\text {Fref }}=\frac{R V L_{B}}{60000}
$$

onde $Q_{F r e f}$ é a referência de vazão para a calda em $\ell / m i n, R$ é a taxa de aplicação em $\ell / h a, V$ é a velocidade de deslocamento do pulverizador em $K m / h, L_{B}$ é o comprimento

\footnotetext{
${ }^{3}$ do inglês: common sprayer.
} 
da barra em $\mathrm{cm}$ e o número 60000 é uma constante de ajuste das unidades. Uma vez calculada a variável de referência $Q_{\text {Fref }}$ e utilizando um fluxômetro ${ }^{4}$ para medir a vazão instantânea da calda, pode-se implementar um controlador em malha fechada para regular a vazão da calda.

Os tipos mais simples de controladores em malha fechada são os baseados na ações proporcional, integral e derivativa (controladores PID). Esses controladores apresentam uma ação de controle baseada em operações de integração, diferenciação e multiplicação (proporcional ou ganho) do erro, dado pela diferença entre a variável de referência e a variável medida (ASTROM; HAGGLUND, 2006; KATSUHIKO, 2003).

Rosseto (2008) utilizou o protótipo de um sistema de pulverização em taxa variada para a aplicação baseada em mapas de prescrição. No qual a vazão é regulada através de uma válvula de três vias e para medi-la é usado um fluxômetro. São comparados os desempenhos de um controlador PID convencional com um controlador fuzzy com ação de controle do tipo PID e os resultados mostram que o controlador fuzzy apresentou melhor desempenho.

Queiros (2010) desenvolveu um sistema para a pulverização de reguladores de crescimento em taxa variada baseada em sensores. A vazão, medida através de um fluxômetro, é regulada pelo uso de um controlador do tipo PID. A referência da taxa de aplicação ou dose é obtida através de sensores de ultrassom, usados para monitorar a altura da planta.

Yin et al. (2011) desenvolveram um robô de pulverização. Um controlador PID fuzzy adaptativo com escalonamento de ganho é usado nos sistemas de pulverização e no de controle de trajetória. Segundo o autor essa abordagem é adotada devido à complexidade e à dinâmica não linear (histerese) do sistema de pulverização. Os resultados mostram a melhoria da reposta transitória e a redução do erro estacionário.

Paice, Miller e Day (1996) apresentaram um estudo sobre os requisitos de um sistema para aplicação de herbicidas a taxa variada e concluíram que os sistemas de pulverização devem ser capazes de aplicar diferentes herbicidas com concentrações variadas, e os principais fatores que influenciam na eficiência da aplicação são: a precisão, a velocidade de resposta e a faixa de trabalho do sistema de controle da taxa de apli-

\footnotetext{
${ }^{4}$ sensor de vazão
} 
cação.

Os trabalhos experimentais na área de máquinas agrícolas voltados a aplicação localizada mostram que é possível manter o erro estacionário em uma faixa inferior a $\pm 5 \%$ (PAICE; MILlER; BODLE, 1995). Este valor, para o erro estacionário, vem sendo adotado como padrão para avaliar a precisão de sistemas de pulverização comerciais (STEWARD; HUMBURG, 2000; ANTUNIASSI; GANDOLFO; SIQUEIRA, 2011).

Os controladores fuzzy tem apresentado bons resultados em sistemas de pulverização, desta forma, é proposto o uso de um controlador deste tipo para controlar a vazão da calda neste trabalho.

\subsection{Controle Adaptativo com Sistemas Fuzzy}

A lógica fuzzy, também conhecida como lógica nebulosa ou difusa, introduzida por Zadeh (1965), foi a base para o desenvolvimento de diversas aplicações voltadas a identificação de padrões, processamento de sinais e imagens e controle de processos.

Na teoria clássica de conjuntos, os elementos pertencem ou não a um conjunto. A lógica fuzzy permite relaxar essa condição, de modo que, os elementos possam pertencer aos conjuntos em diferentes graus. Assim a lógica fuzzy aproxima a linguagem matemática da linguagem natural através do uso de termos linguísticos, por exemplo: quando diz-se quente, morno e frio não existem definições rígidas do limiar entre estas temperaturas.

A lógica fuzzy proporciona ainda ferramentas para realizar operações diversas como união, intersecção, complemento, entre outras. Com o uso da lógica fuzzy e suas ferramentas é possível implementar um sistema fuzzy, com a capacidade de aproximar a decisão computacional da decisão humana, o que leva a inserção destes sistemas entre os sistemas de inteligência artificial (SUMATHI; PANEERSELVAM, 2010).

Em geral quando um sistema fuzzy é utilizado no controle de processos, como a temperatura de fornos e a temperatura e a pressão em caldeiras, este é chamado de controlador fuzzy e foi inicialmente proposto por Mamdani e Assilian (1975), baseado no trabalho de Zadeh (1973).

Os controladores fuzzy não se limitam a topologias específicas e podem ser imple- 
mentados através de diversas abordagens (CHEN; PHAM, 2001). Dentre essas, algumas implementações descritas na literatura se baseiam no controlador PID, sendo chamadas de controladores PID fuzzy. Controladores PID fuzzy têm sido aplicados para melhorar o desempenho da malha de controle em processos lineares de ordem elevada e não lineares, processos variantes no tempo e sistemas onde o modelo matemático não é bem definido. Segundo (CHEN; PHAM, 2001), para sistemas lineares de baixa ordem não é justificável o uso do PID fuzzy, pois esse e o PID convencional apresentam desempenhos semelhantes.

As topologias dos controladores PID fuzzy, encontrados na literatura, podem ser divididas em três:

Tipo 1 O sistema fuzzy substitui o PID;

Tipo 2 O sistema fuzzy e o PID são independentes, mas trabalham em conjunto;

Tipo 3 O sistema fuzzy modifica a dinâmica do controlador PID.

Os sistemas do tipo 1, ilustrado na Figura 2.2, têm sido usados com sucesso em processos como: sistemas de freio anti-blocante (sistema não linear) (CHEN; SHIH, 2004), biorreatores para produção de levedura (zona morta e não linear) (REIS, 2009), controle de posição em motores de corrente contínua (aumento da velocidade de resposta e da precisão) (NATSHEH; BURAGGA, 2010), sistema de levitação magnética (não linear) (YADAV; TIWARI; NAGAR, 2012) e secadora de vapor aquecido (não linear, zona morta e variante no tempo) (LIAN; MESSOM; KONG, 1999).

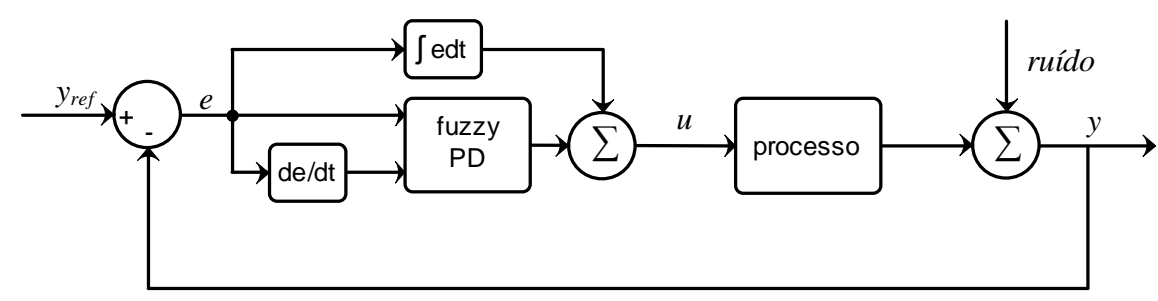

Figura 2.2: Estrutura típica de um controlador PID fuzzy do tipo 1.

Os sistemas do tipo 2, ilustrado na Figura 2.3, têm sido usados com sucesso em processos como: sistema supervisório para problemas de estacionamento autônomo (RIID; RUSTERN, 2001), compensação de zona morta em motores de corrente contínua 
(JANG, 2001) e no sistema hidráulico de veículos para remoção de neve (HUI; YONGBO; MEIYU, 2009).

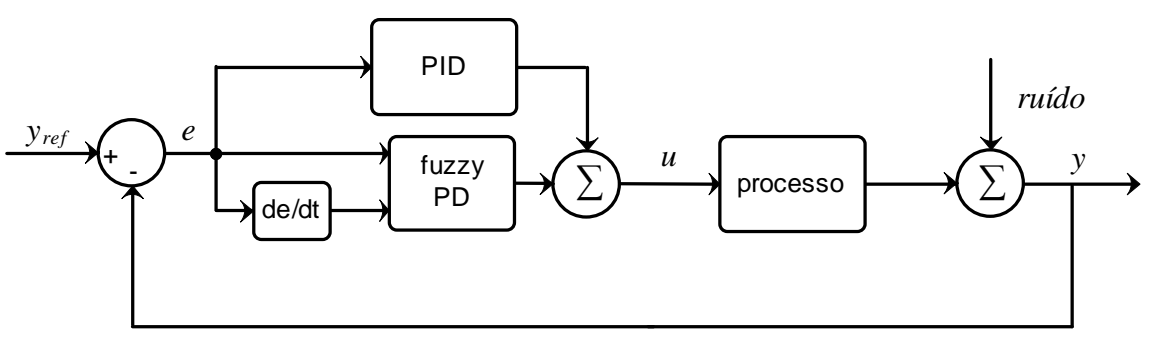

Figura 2.3: Estrutura típica de um controlador PID fuzzy do tipo 2.

Os sistemas do tipo 3, são um tipo de controle adaptativo usando sistemas fuzzy. Segundo Chen e Pham (2001), o controle fuzzy adaptativo é uma extensão da teoria de controle fuzzy que permite expandir a aplicabilidade dos controladores fuzzy, seja para uma classe mais ampla de sistemas ou para fazer o ajuste dos parâmetros do modelo de um processo ou de um controlador. Os controladores fuzzy adaptativos têm sido usados para melhorar o desempenho da malha de controle. As abordagens mais comuns desses tipos de controladores são: o controlador adaptativo baseado em modelo, o controlador auto-sintonizável, o controlador dual e o controlador por escalonamento de ganho.

Controlador adaptativo baseado em modelo: baseia-se na implementação de um modelo fuzzy do processo e um mecanismo para ajustar o ganho da malha de controle. Nesta abordagem, o sinal de referência $y_{r e f}$ é aplicado tanto no modelo fuzzy quanto no processo real, um algoritmo calcula o ganho da malha de controle de modo a minimizar o erro $e$ entre as saídas do processo $y$ e do modelo $y_{m}$. A Figura 2.4, adaptada de Chen e Pham (2001), ilustra o conceito desse controlador. Associadas a essa abordagem são usadas técnicas numéricas para calcular o ganho adaptativo (CHEN; PHAM, 2001).

Controlador fuzzy auto-sintonizável: baseia-se no projeto de um controlador fuzzy com parâmetros ajustáveis. Os parâmetros do controlador fuzzy dependem da dinâmica do processo, representado por um conjunto de regras. Através de técnicas para a identificação do processo (ex: curva de reação ou resposta em frequência de Ziegler Nichols) e para o cálculo dos parâmetros do controlador, a cada iteração são atualizados os parâmetros do controlador com os novos parâmetros. A Figura 2.5, adaptada de 


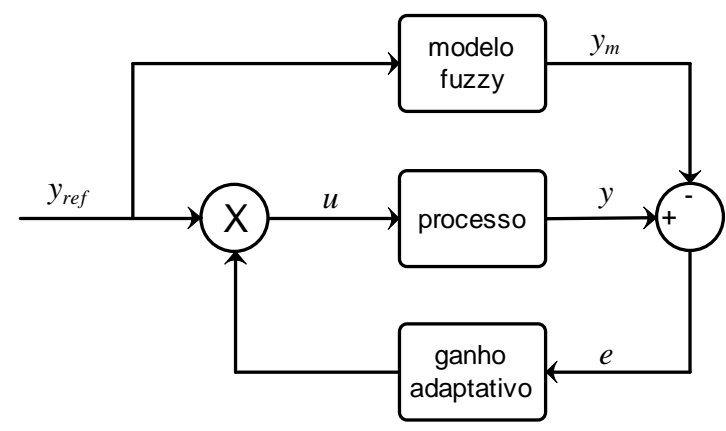

Figura 2.4: Controlador adaptativo baseado em modelo.

Chen e Pham (2001), ilustra este conceito onde $y_{\text {ref }}$ é a entrada de referência, $u$ e $y$ são respectivamente a entrada e saída do processo.

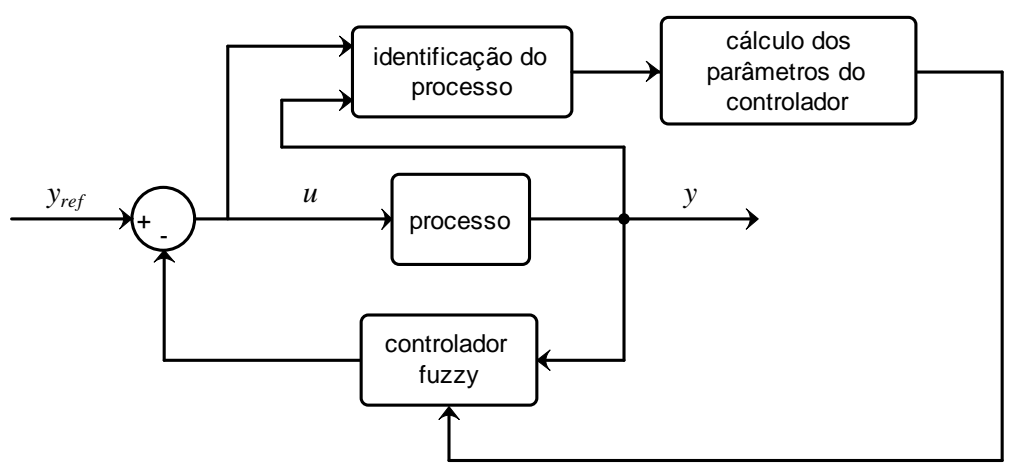

Figura 2.5: Controlador fuzzy auto-sintonizável.

Controlador dual: baseia-se no projeto de um controlador e um estimador para as características do processo. O estimador fornece informações estatísticas para o controlador que será ajustado. Aplicado em sistemas fuzzy, esse conceito pode ser entendido como uma forma a projetar um estimador que atua na definição dos conjuntos fuzzy do controlador, modificando suas funções de pertinência continuamente (CHEN; PHAM, 2001).

Kim (2001) propõe o uso de um controlador fuzzy dual para o controle de um grupo de elevadores de alta velocidade. O objetivo desse controlador dual é minimizar o tempo de espera em um prédio. Quando ocorre uma nova chamada o controlador dual fuzzy avalia o tráfego e modifica as funções de pertinência associadas ao conjunto de regras. Os controladores utilizam um mecanismo de inferência do tipo Mamdani. 
Os resultados mostram que o controlador dual reduziu o tempo de espera médio em até $30 \%$. A Figura 2.6, adaptada de Kim (2001), ilustra o esquema utilizado no controlador dual.

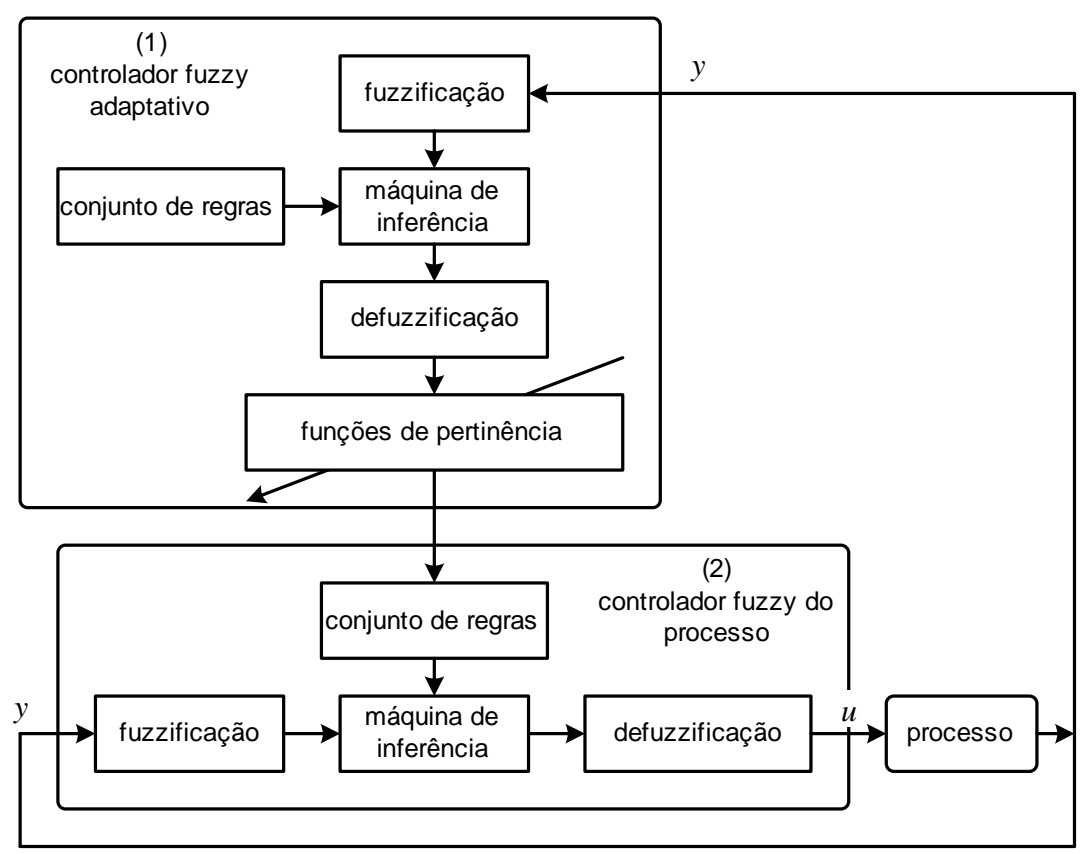

Figura 2.6: Controlador dual fuzzy para o controle de elevadores.

Controlador fuzzy por escalonamento de ganho: baseia-se na combinação diferentes controladores em apenas um. Isso significa substituir diversos controladores, cada um é ajustado para um ponto de operação do processo, por um único controlador que atenda os requisitos de desempenho em diferentes pontos de operação. Isso exige uma condição para determinar qual controlador está ativo. Usando sistemas fuzzy, isso pode ser feito através de um conjunto de regras. Não existe um método formal de definição do conjunto de regras que, em geral, são concebidas heuristicamente (CHEN; PHAM, 2001). A Figura 2.7 ilustra esta abordagem aplicada na adaptação dos parâmetros de um controlador PID.

$\mathrm{Pu}$ e Zhang (2009) propõem o uso de um controlador fuzzy por escalonamento de ganho (Figura 2.7), para o controle de um válvula solenoide de alta velocidade,usada em motores aeronáuticos. A aplicação é justificada pela baixa precisão e interferência, obtida com o uso de outros tipos de controladores. O sistema fuzzy, do tipo Mamdani, calcula a variação dos parâmetros $K_{c}, T_{i}$ e $T_{d}$ do controlador PID, baseado no erro e 


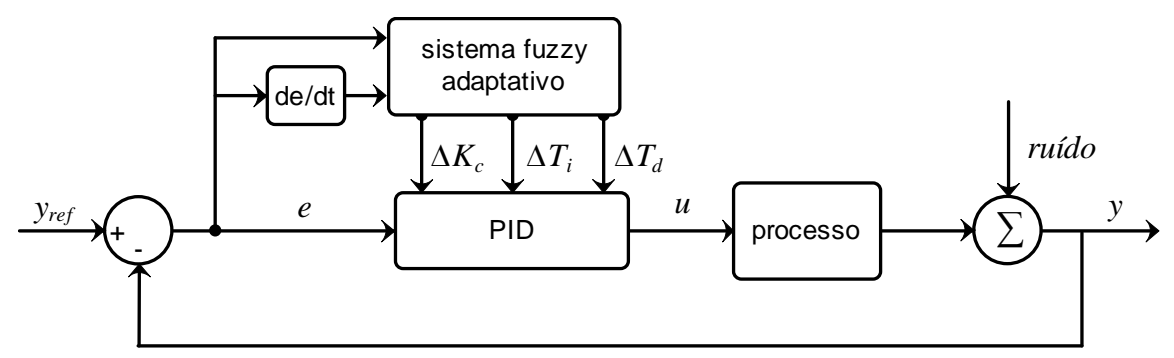

Figura 2.7: Controlador fuzzy por escalonamento de ganho, tipo 3.

na sua variação. Os valores dos parâmetros, previamente sintonizados, são somados ou subtraídos dos valores calculados. As variáveis de entrada e saída do sistema fuzzy são divididas em sete termos linguísticos. Os resultados obtidos mostram que o controlador PID fuzzy com adaptação de parâmetros apresenta um aumento significativo do desempenho com relação ao sobressinal e ao tempo de resposta.

Bae et al. (2011) propõem o uso de um controlador fuzzy com escalonamento de ganho, combinado com um filtro de Kalman, para o regular o deslocamento de cargas em trilhos usando levitação magnética (MagLev). A estrutura sem contato e de baixo ruído é apropriada para utilização em ambientes extremamente limpos. A aplicação é justificada devido as características não lineares do sistema, a variação da carga, e o baixo desempenho obtido com o uso dos controladores do tipo PID e de realimentação de estado. O sistema fuzzy, do tipo Mamdani, calcula a variação dos parâmetros $K_{c}$, $T_{d}$ do PID, baseado no erro e na sua variação. Esses valores são somados aos valores dos parâmetros sintonizados previamente no PID. As variáveis de entrada do sistema fuzzy são divididas em sete termos linguísticos e as de saída em dois. Um filtro de Kalman é usado para eliminar o ruído do sinal do sensor de distância entre o trilho e a estrutura. Os resultados das simulações mostram que o controlador proposto apresenta um melhor desempenho com relação ao tempo de resposta e ao erro estacionário com relação ao PID convencional.

Os controladores fuzzy tem sido utilizados com sucesso em diferentes tipos de processos, melhorando o desempenho da malha de controle. Entre os controladores fuzzy apresentados, o controlador fuzzy por escalonamento de ganho, possibilita a implementação paralela aos controladores PID, utilizados em muitos processos. Dessa forma, sua implementação requer apenas uma adaptação nas rotinas de controle dos contro- 
ladores eletrônicos de pulverização já existentes, sem a necessidade de uma completa reformulação do código. 


\section{Capítulo 3}

\section{Instrumentação do Sistema}

A bancada de pulverização usada neste trabalho (Figura 3.1), foi desenvolvida para atuar como um plataforma flexível para o desenvolvimento de pulverizadores, aplicadores de fertilizantes líquidos e maturadores (CRUVINEL et al., 2011). Esta plataforma de desenvolvimento está instalada em uma infraestrutura compartilhada entre a Embrapa Instrumentação e o Laboratório de Controle da Escola de Engenharia de São Carlos, da Universidade de São Paulo.

A automação desse sistema é realizada com um Controlador Programável para Automação (PAC) (modelo cRIO-9073, empresa National Instruments). O PAC é constituído por um chassi para a conexão de até oito módulos de entrada ou saída (E/S), possui um processador industrial de $266 \mathrm{MHz}$ e um chip de lógica reconfigurável Field Programmable Gate Array (FPGA) de 2 milhões de portas. As características do controlador cRIO permitem o controle de processos independente de um computador, o monitoramento e desenvolvimento de interfaces com comunicação através das portas ethernet 10/100 Mbps ou serial RS-232, disponíveis no chassi.

Para a automação e modelagem do sistema montado na bancada de pulverização, foi desenvolvida uma interface com o usuário a fim de monitorar e gravar as variáveis do processo, bem como permitir a interação com o sistema. Dessa forma, a automação da bancada envolve o desenvolvimento de rotinas em três níveis de programação (Figura 3.2). No primeiro nível está a programação do chip FPGA, através do LabVIEW FPGA. Nesse nível são implementadas as rotinas para a leitura dos sensores conectados aos módulos de entrada e para gerar os sinais para os atuadores conectados nos módulos de 


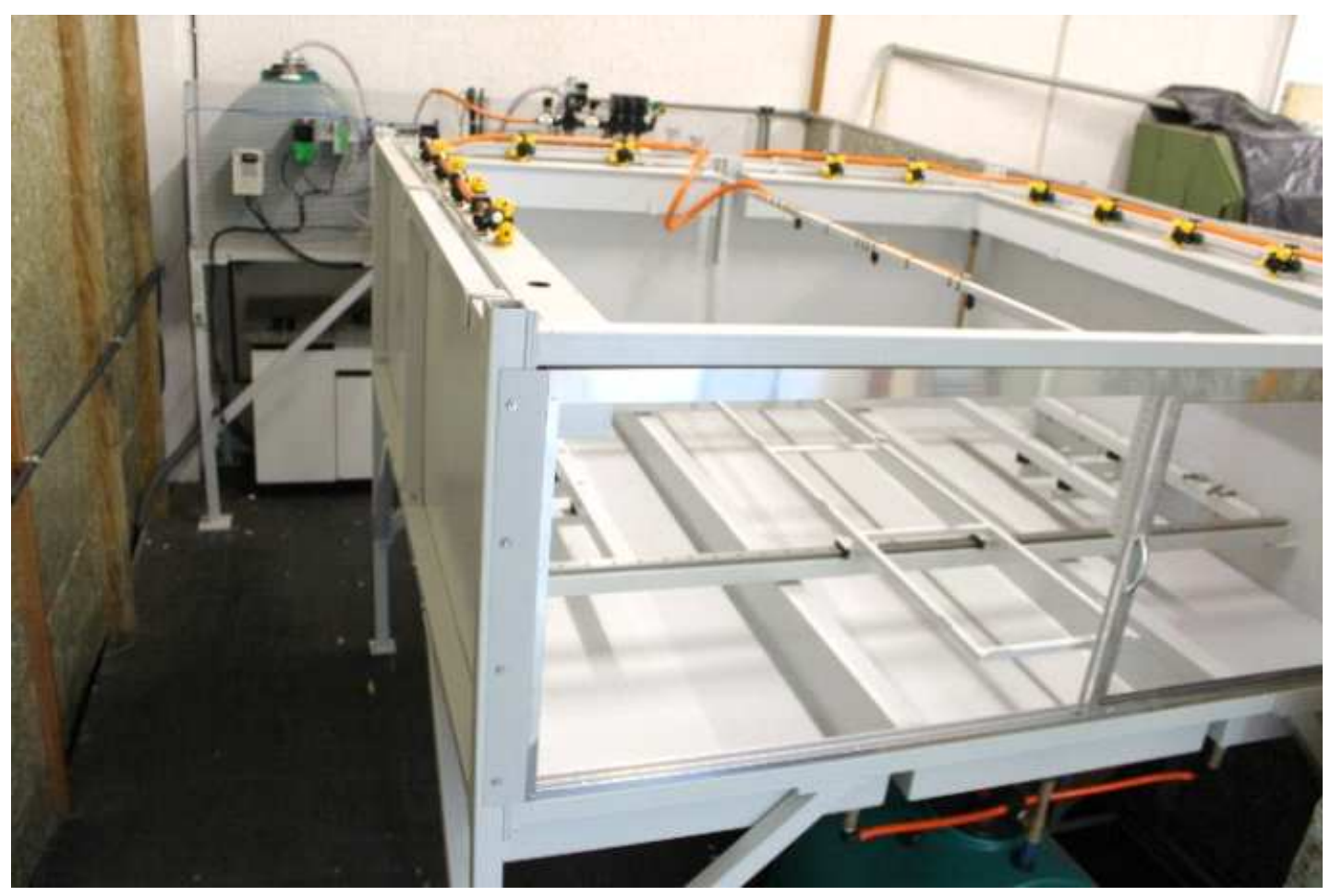

Figura 3.1: Vista frontal da bancada pulverização onde está montado o sistema de aplicação agroquímicos. Ao fundo está o painel com os componentes elétricos, eletrônicos e hidráulicos e à frente as seções de barra com os bicos e pontas de pulverização.

saída. As rotinas implementadas com o LabVIEW FPGA são executadas em paralelo e os sinais gerados ou lidos pelos módulos de E/S são atualizados a cada $10 \mathrm{~ms}$.

No segundo nível está a programação do processador industrial, que executa um sistema operacional em tempo real (RTOS) com capacidade de execução de rotinas de tempo crítico (rotinas determinísticas). Nesse nível, através do LabVIEW RealTime, são implementadas as rotinas para os controladores, as rotinas para as conversões de unidades e as rotinas de supervisão dos estados dos sensores de nível e pressão. A comunicação entre o processador industrial e o chip FPGA ocorre através de um barramento de alta velocidade. Através do sistema RTOS as variáveis referentes aos sinais gerados ou lidos são transferidas entre o processador e o FPGA a cada $50 \mathrm{~ms}$.

No terceiro nível, usando o LabVIEW 2009, é implementada a interface com o usuário. A interface desenvolvida para executar no sistema operacional Windows 7 permite ajustar as referências dos controladores, a gravação das variáveis do processo, o monitoramento da pressão e vazão através de gráficos e a seleção das seções de barra ativas. A comunicação entre esse nível e o anterior é feita através da interface Ethernet a cada $50 \mathrm{~ms}$. 


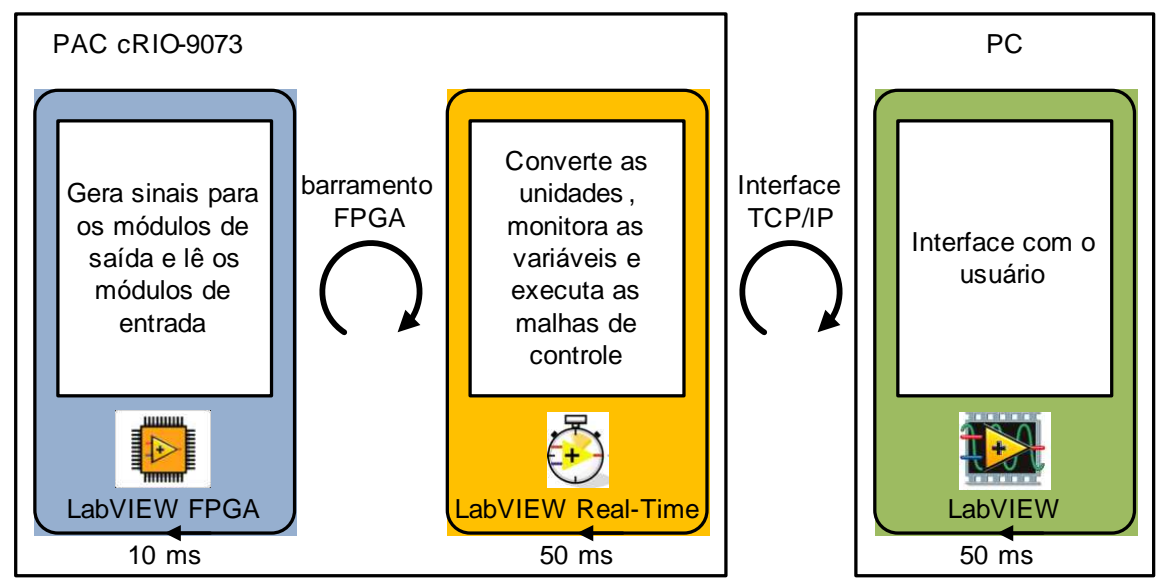

Figura 3.2: Arquitetura usada para o desenvolvimento da automação da bancada de pulverização mostrando os níveis de programação com o LabVIEW (PC Host), LabVIEW Real-Time e LabVIEW FPGA.

Para a leitura dos sinais dos sensores são usados três módulos de entrada, e para geração dos sinais para os atuadores são usados dois módulos de saída, todos conectados ao chassi do PAC. Os módulos utilizados e suas características são descritas a seguir.

NI 9474: módulo com 8 saídas digitais de alta velocidade (atualização a cada $1 \mu s$ ) e capacidade de corrente de até 1 A/canal. Esse módulo deve ser alimentado por uma fonte externa de $5 \mathrm{~V}$ a $30 \mathrm{~V}$;

NI 9411: módulo de entradas digitais dedicado para leitura de velocidade e posição de até 2 encoders (leitura a cada 500 ns);

NI 9421: módulo com 8 entradas digitais de baixa velocidade (leitura a cada $100 \mu s$ );

NI 9263: módulo com 4 saídas analógicas $( \pm 10 \mathrm{~V})$, resolução de 16 bits e taxa de amostragem de 100.000 amostras/s;

NI 9201: módulo com 8 entradas analógicas $( \pm 10 \mathrm{~V})$, resolução de 12 bits e taxa de amostragem de 500.000 amostras/s.

O sistema de pulverização para a aplicação de agroquímicos a taxa variada usando injeção direta central é ilustrado na Figura 3.3. Esse sistema de pulverização é dividido em três partes: módulo da pulverização em taxa variada da calda (mistura de água e agroquímico), módulo de injeção do agroquímico e módulo de descarte da calda. 


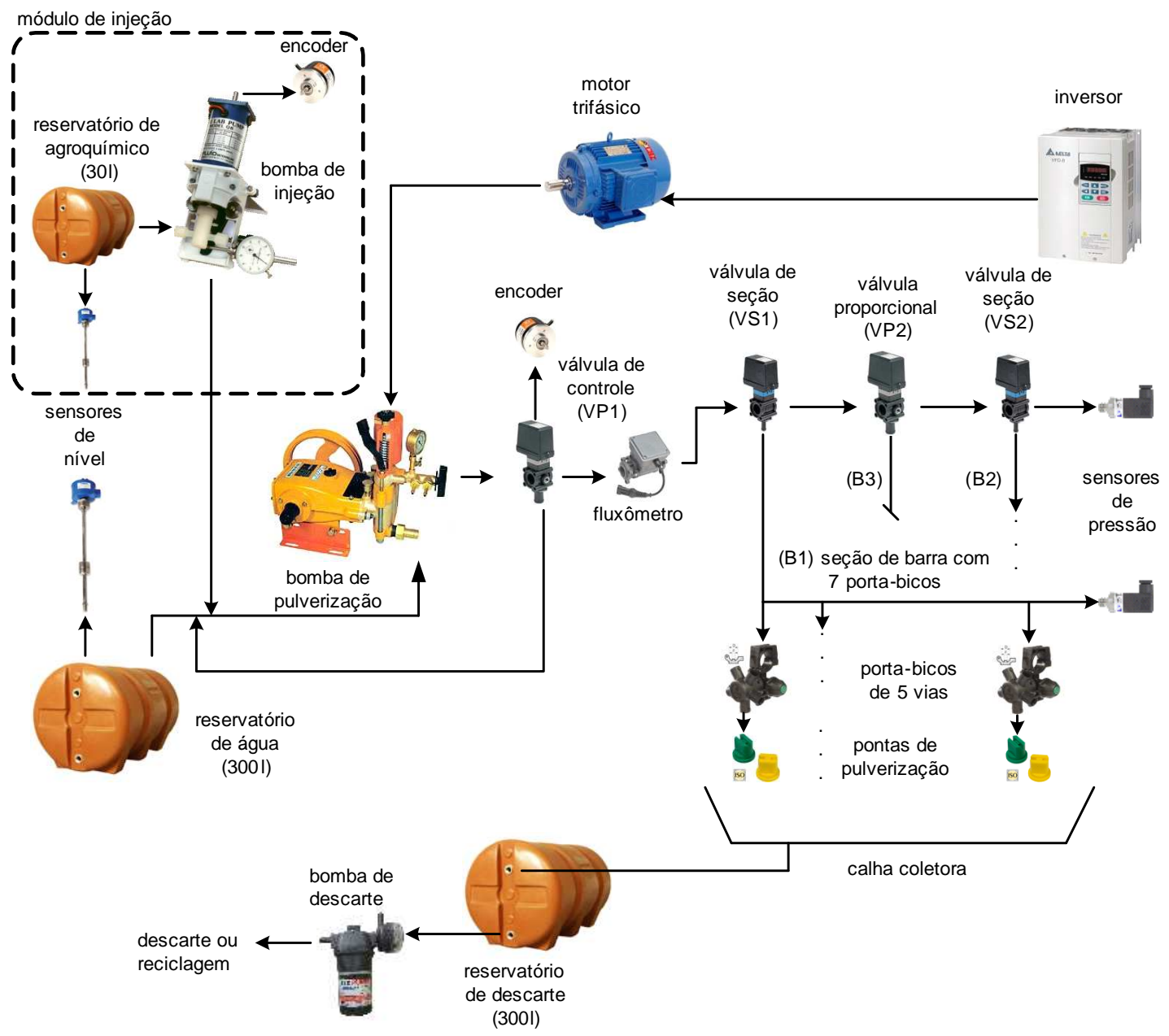

Figura 3.3: Ilustração do sistema de pulverização de agroquímicos montado para a aplicação em taxa variada com o módulo de injeção direta central mostrado no detalhe.

\subsection{Módulo de Pulverização}

O módulo de pulverização é responsável pelo controle da vazão da calda que será aplicada (taxa de aplicação). Como o principal diluente dos agroquímicos é a água, é usado um reservatório de água de 300 $\ell$, com sensores de nível máximo $N_{A m a x}$ e mínimo $N_{A m i n}$ do tipo reed-switch (empresa CONTECH). Os sensores de nível são usados para supervisão durante a operação do sistema de pulverização. O módulo NI-9421 retorna os níveis lógicos correspondentes à leitura das tensões do sensores de nível $V_{N A m a x}$ e $V_{N A m i n}$ (Figura 3.4) . O diagrama esquemático de ligação dos sensores de nível é apresentado no Apêndice A.

O bombeamento da calda é feito por uma bomba de pulverização do tipo pistão (modelo MB-42, empresa Jacto) acoplada a um motor de indução trifásico de $2,2 \mathrm{KW}$, 


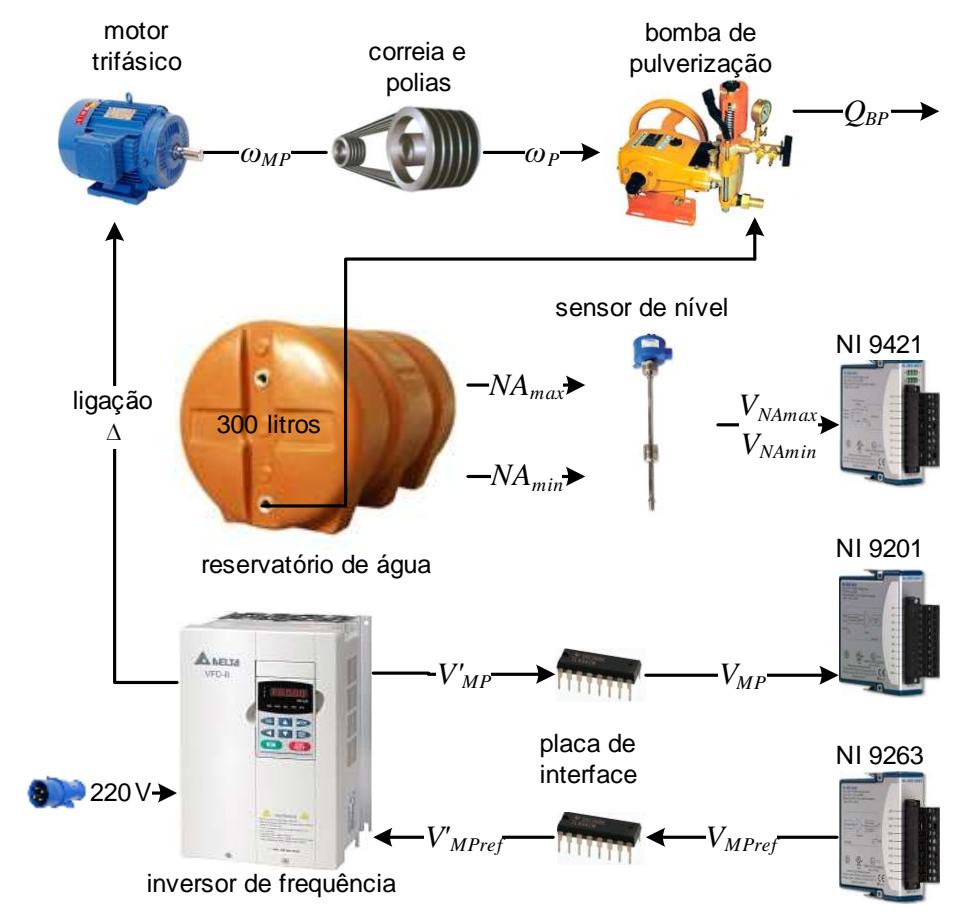

Figura 3.4: Instrumentação usada no acionamento da bomba de pulverização e sensor de nível do tanque de água.

4 pólos, $\triangle-220 \mathrm{~V}, 60 \mathrm{~Hz}$ (modelo 90L, empresa Kohlbach) acionado por um inversor de frequência de 4,2 KVA (modelo VFD022B23A, empresa Delta Electronics).

A bomba de pulverização possui uma capacidade de vazão $Q_{B P}$ de $42 \ell /$ min para uma rotação $\omega_{P}$ de $800 R P M$ e sua pressão de trabalho máxima é de $4000 \mathrm{KPa}$ (40bar). Essa bomba possui em seu eixo uma polia com diâmetro $d=250 \mathrm{~mm}$. O motor trifásico, acoplado à MB-42, possui uma polia com diâmetro $D=104 \mathrm{~mm}$ e sua rotação $\omega_{M P}$ máxima é de 1800 RPM. Considerando a relação de transmissão, a rotação da bomba é dada em função da rotação do motor:

$$
\omega_{P}=\omega_{M P} \frac{D}{d}
$$

A relação, obtida experimentalmente, entre a rotação bomba de pulverização $\omega_{P}$ em $R P M$ e sua vazão $Q_{B P}$ em $\ell / \min$ é:

$$
Q_{B P}=0,0519 \omega_{P}
$$

O inversor usado para controlar a velocidade do motor trifásico possui uma entrada analógica cuja tensão $V_{M P r e f}^{\prime}$ de $0-8 V$ é usada como referência de rotação para 
o motor $\omega_{\text {MPref }}$. Uma saída analógica desse inversor, com tensão de saída $V_{M P}^{\prime}$ de $0-5 V$, é usada para medir a rotação atual do motor $\omega_{M P}$. As relações, obtidas experimentalmente, entre as tensões nos canais analógicos e a rotação do motor são respectivamente:

$$
\begin{gathered}
\omega_{M P r e f}=225 V_{M P r e f}^{\prime} \\
V_{M P}^{\prime}=\omega_{M P} / 360 .
\end{gathered}
$$

Os canais analógicos do inversor são conectados ao PAC através de uma placa de interface que isola eletricamente os circuitos (Figura 3.4). Essa placa é constituída por acopladores ópticos (4N25), conversores tensão-PWM ${ }^{1}$ (TL494) e filtros passa-baixa. O diagrama esquemático da interface é apresentado no Apêndice A. As tensões de saída da placa de interface $V_{M P}$ e $V_{M P r e f}^{\prime}$ são proporcionais as tensões de entrada $V_{M P}^{\prime}$ e $V_{M P r e f}$, respectivamente. Essas relações, obtidas experimentalmente, são dadas por:

$$
\begin{gathered}
V_{M P}=-1,59 V_{M P}^{\prime}+8,44 \\
V_{M \text { Pref }}^{\prime}=-3,48 V_{M \text { Pref }}+9,22 .
\end{gathered}
$$

A referência de vazão da bomba de pulverização $Q_{B P r e f}$ é ajustada através da tensão de saída $V_{M P r e f}$ do módulo NI-9263 e essa relação, obtida experimentalmente, é:

$$
V_{M P r e f}=\frac{44,81-Q_{B P r e f}}{16,91}
$$

A vazão $Q_{B P}$ da bomba é monitorada através da tensão $V_{M P}$, medida pelo módulo NI-9201 e essa relação, obtida experimentalmente, é:

$$
Q_{B P}=4,89\left(8,44-V_{M P}\right)
$$

As tensões dos módulos analógicos são acessadas diretamente na programação do FPGA do PAC e as relações (3.7) e (3.8) são programadas no seu RTOS, de modo a ficarem transparentes para o usuário.

A vazão da bomba de pulverização é mantida constante durante a operação do

\footnotetext{
${ }^{1}$ modulação por largura de pulso.
} 
sistema e a vazão da calda $Q_{F}$ é controlada pela válvula VP1 (modelo 463022S, empresa ARAG)(Figura 3.5). A válvula de controle proporcional VP1 é do tipo agulha com 3 vias e seu êmbolo é acionado por um motor de corrente contínua (motor CC) de $12 \mathrm{~V} / 0,5 \mathrm{~A}$. Essa válvula, usada em sistemas de pulverização da ARAG, pode controlar vazões de até $150 \ell / \min$ a uma pressão de até 20 bar e o possui um tempo de resposta de 7 segundos. Acoplado ao eixo do motor CC da VP1, está um encoder incremental de 1024 pulsos por revolução (ppr) (modelo HTR-W2-1024-3-PP, empresa Hontko) (Figura 3.6), usado na etapa de modelagem da VP1, para obter a posição angular $\theta_{V}$ do eixo do motor CC que aciona seu êmbolo.

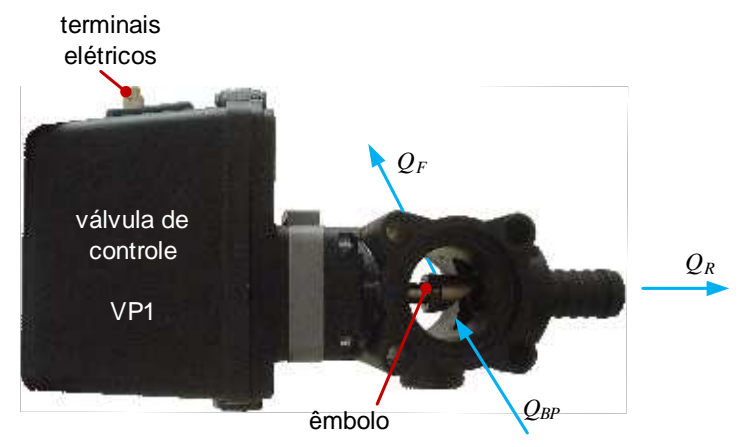

Figura 3.5: Válvula de controle VP1 com indicações do êmbolo, terminais elétricos e os sentidos de fluxo da calda de entrada $Q_{B P}$, de saída para as barras $Q_{F}$ e de saída para o retorno $Q_{R}$.

A válvula proporcional VP2, do mesmo modelo da VP1, faz o direcionamento da calda para a seção de barra B3. Essa válvula é usada na etapa de modelagem de VP1, permanecendo fechada durante a operação normal do sistema. A velocidade das válvulas VP1 e VP2 são controladas, durante a abertura ou fechamento, através da aplicação de um sinal PWM com frequência de $500 \mathrm{~Hz}$.

As válvulas de seção de 3 vias VS1 e VS2 (modelo 463001S, empresa ARAG) são do tipo solenoide (aberta/fechada) e direcionam a calda para as seções de barra B1 e B2, respectivamente. A abertura e fechamento das válvulas (VP1, VP2, VS1 e VS2) são feitos através da inversão da polaridade da tensão aplicada em seus terminais elétricos. Para isso, é usada uma placa de acionamento com pontes H (L298) e isoladores ópticos (4N25). Na Figura 3.6, são ilustrados os circuitos da placa de acionamento das válvulas de controle, bem como a conexão do encoder na válvula VP1. O diagrama esquemático da placa de acionamento das válvulas pode ser visto no Apêndice A. A Tabela 3.1 mostra o acionamento dos circuitos das válvulas.

Cada seção de barra B1 ou B2 possui sete porta-bicos de 5 vias, com seleção manual 


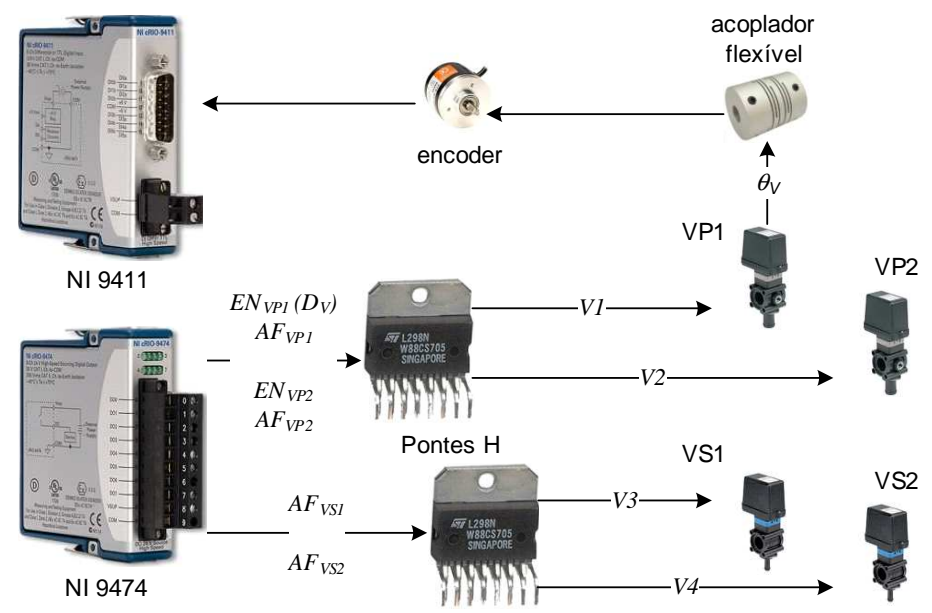

Figura 3.6: Instrumentação usada no acionamento das válvulas VP1, VP2, VS1 e VS2 e encoder na válvula de controle VP1.

das vias, para a instalação de até 5 pontas de pulverização. Nesses porta bicos são instaladas 4 pontas de pulverização de jato plano com leque de $110^{\circ}$ (modelos ISO 110(02,03,04,05), empresa ARAG)(Tabela 3.3).

A vazão da calda é medida por um fluxômetro eletromagnético (modelo 4621AA30000, empresa ORION) que possui uma faixa de medição de 5 a $100 \ell / \min$, para pressões de até $4000 \mathrm{KPa}\left(40 \mathrm{bar}\right.$ ) e temperatura máxima de $50^{\circ} \mathrm{C}$. O fluxômetro possui saída em coletor aberto e constante de calibração de 600 pulsos por litro. Na Figura 3.8, é ilustrada a ligação do fluxômetro com o módulo NI-9421. O diagrama esquemático da ligação do fluxômetro é apresentado no Apêndice A. A vazão da calda $Q_{F}$ em $\ell /$ min é obtida a partir da frequência $f_{F}$ em $\mathrm{Hz}$ dos pulsos gerados:

$$
Q_{F}=600 f_{F} \text {. }
$$

Os pulsos medidos pelo módulo são convertidos em frequência $f_{F}$ no FPGA do PAC cRIO. No RTOS, baseado na relação (3.9), é realizada a conversão da frequência em vazão.

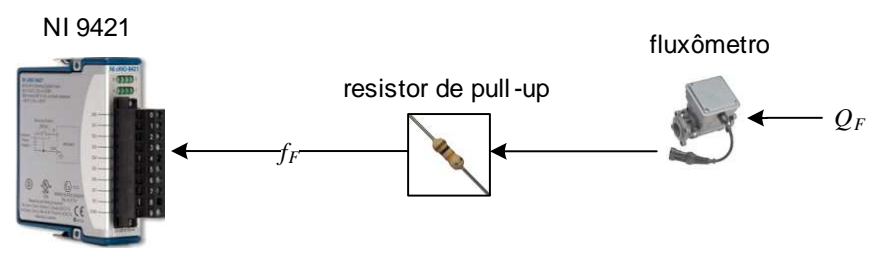

Figura 3.7: Ligação do fluxômetro eletromagnético. 
Tabela 3.1: Tabela verdade para o acionamento das válvulas VP1, VP2, VS1 e VS2.

\begin{tabular}{|c|c|c|c|}
\hline Entrada & Estado & Resultado & Saída \\
\hline$E N_{V P 1}\left(D_{V}\right)$ & ciclo de trabalho do PWM & Velocidade da VP1 & \\
\hline \multirow{2}{*}{$A F_{V P 1}$} & $\mathrm{H}$ & Abre VP1 & $\begin{array}{l}\mathrm{V} 1(+)=\mathrm{PWM} \\
\mathrm{V} 1(-)=\mathrm{GND}\end{array}$ \\
\hline & $\mathrm{L}$ & Fecha VP1 & $\begin{array}{l}\mathrm{V} 1(+)=\mathrm{GND} \\
\mathrm{V} 1(-)=\mathrm{PWM}\end{array}$ \\
\hline$E N_{V P 2}$ & ciclo de trabalho do PWM & Velocidade da VP2 & \\
\hline \multirow{2}{*}{$A F_{V P 2}$} & $\mathrm{H}$ & Abre VP2 & $\begin{array}{l}\mathrm{V} 2(+)=\mathrm{PWM} \\
\mathrm{V} 2(-)=\mathrm{GND}\end{array}$ \\
\hline & $\mathrm{L}$ & Fecha VP2 & $\begin{array}{l}\mathrm{V} 2(+)=\mathrm{GND} \\
\mathrm{V} 2(-)=\mathrm{PWM}\end{array}$ \\
\hline \multirow{2}{*}{$A F_{V S 1}$} & $\mathrm{H}$ & Abre VS1 & $\begin{array}{l}\mathrm{V} 3(+)=12 \mathrm{~V} \\
\mathrm{~V} 3(-)=\mathrm{GND}\end{array}$ \\
\hline & $\mathrm{L}$ & Fecha VS1 & $\begin{array}{l}\mathrm{V} 3(+)=\text { GND } \\
\mathrm{V} 3(-)=12 \mathrm{~V}\end{array}$ \\
\hline \multirow{2}{*}{$A F_{V S 2}$} & $\mathrm{H}$ & Abre VS2 & $\begin{array}{l}\mathrm{V} 4(+)=12 \mathrm{~V} \\
\mathrm{~V} 4(-)=\mathrm{GND}\end{array}$ \\
\hline & $\mathrm{L}$ & Fecha VS2 & $\begin{array}{l}\mathrm{V} 4(+)=\text { GND } \\
\mathrm{V} 4(-)=12 \mathrm{~V}\end{array}$ \\
\hline
\end{tabular}

$\mathrm{H}=$ nível lógico alto, $\mathrm{L}=$ nível lógico baixo.

Dois sensores de pressão piezoelétricos (modelo A-10, empresa WICA) são utilizados no sistema de pulverização, um monitora a pressão do sistema hidráulico $P_{S}$ no ponto de distribuição da calda para as barras e o outro monitora a pressão $P_{1}$ no final da barra B1. Os sensores possuem uma saída em tensão $V_{P s, 1}$ de 0 a $10 \mathrm{~V}$ proporcional sua faixa de medida de $P_{S, 1} 0$ a 16 bar dada por :

$$
P_{S, 1}=0,625 V_{P s, 1}
$$

Como características, esses sensores apresentam erro de leitura e de linearidade máximo de 0,016 bar e resistem sem danos à sobre-pressões contínuas de até 32 bar e intermitentes de até 120 bar. A Figura 3.8 ilustra a ligação dos sensores de pressão com o módulo NI-9421.

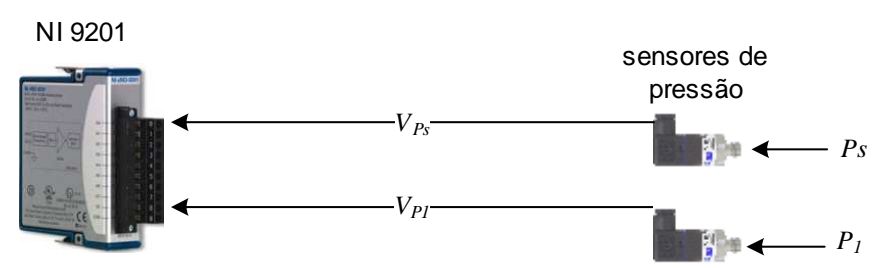

Figura 3.8: Ligação do sensores de pressão. 


\subsection{Módulo de Injeção}

O módulo de injeção é responsável pela injeção do agroquímico na linha de entrada da bomba de pulverização. Um conjunto (modelo QB-3, empresa Fluid Metering Inc.) composto por uma bomba de pistão, de curso variável com ajuste manual, acoplada a um motor CC de 12V/4A, é usado para a injeção (em destaque na Figura 3.9).

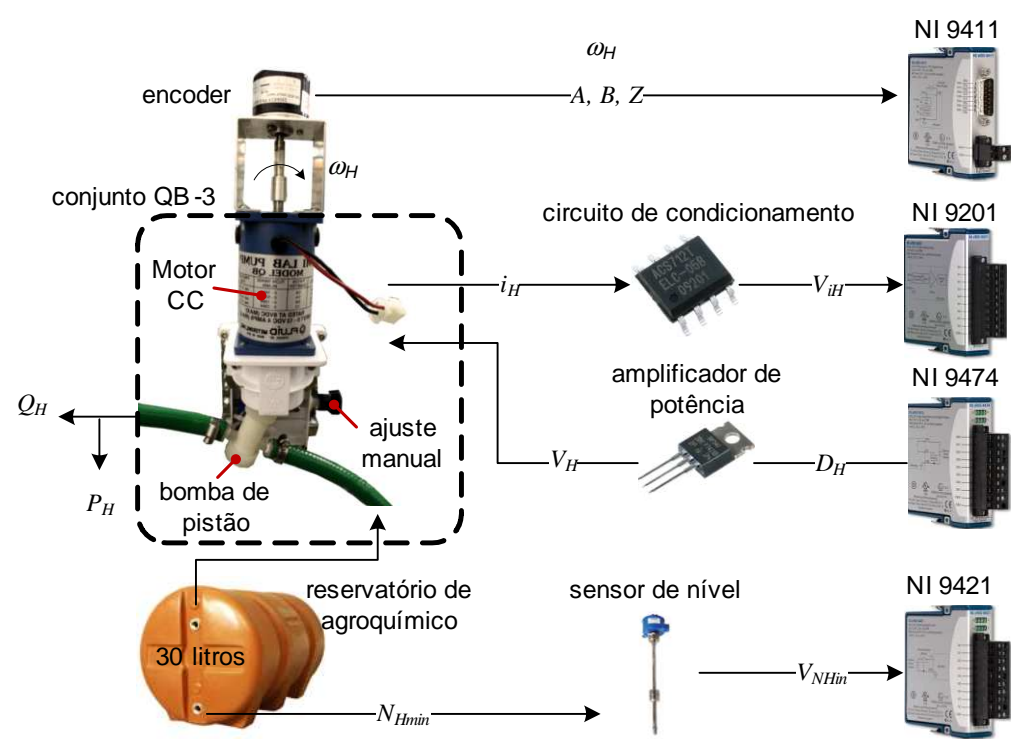

Figura 3.9: Instrumentação do módulo de injeção. No detalhe são indicados os componentes do conjunto QB-3.

A bomba de pistão, do conjunto QB-3, possui capacidade de vazão $Q_{H}$ de $2,304 \ell /$ min para uma rotação $\omega_{H}$ de $1800 R P M$ e pressão de trabalho máxima de $172 \mathrm{KPa}$ $(1,72$ bar $)$. Essa bomba é conectada ao reservatório de agroquímico de 30 , equipado com um sensor de nível mínimo $N_{H m i n}$ do tipo reed-switch (empresa CONTECH). O sensor de nível é usado na supervisão da operação do módulo, que deve parar seu funcionamento para evitar danos à bomba em caso de falta de líquido. O módulo NI-9421 faz a leitura da tensão do sensor de nível $V_{N H \min }$ (Figura 3.9), retornado o nível lógico correspondente. O diagrama esquemático da ligação dos sensores de nível é apresentado no Apêndice A.

O motor CC do conjunto é acionado por um amplificador de potência isolado, composto por um transistor (mosfet IRFZ48N) e um acoplador óptico (4N25). A velocidade angular do motor é controlada através do ciclo de trabalho $D_{H}$ do sinal PWM, com frequência de $500 \mathrm{~Hz}$ (Figura 3.9). 
A corrente do motor CC é medida pelo módulo NI-9201 (Figura 3.9) através de um circuito de condicionamento de sinal, composto por um sensor de efeito hall (modelo ACS712, empresa Allegro MicroSystems) e um amplificador operacional (LM358). A tensão $V_{I h}$ proporcional à corrente $I_{H}$ no motor $\mathrm{CC}$ é:

$$
V_{I h}=0,49 I_{H}
$$

A velocidade angular do motor $\omega_{H}$ em RPM é obtida através de um encoder incremental de 1024 ppr (modelo HTR-W2-1024-3-PP, empresa Hontko) acoplado a seu eixo (Figura 3.9) O diagrama esquemático dos circuitos do amplificador de potência, de condicionamento de sinal e de alimentação do encoder é apresentado no Apêndice A.

\subsection{Módulo de Descarte}

O módulo de descarte é responsável pelo destino dado à calda resultante da pulverização (Figura 3.10). As gotas formadas pelas pontas de pulverização nas barras B1 e B2 são direcionadas para calhas coletoras. A calda pulverizada é armazenada em um reservatório de $300 \ell$ com sensores de nível máximo $N_{D \max }$ e mínimo $N_{D \min }$ do tipo reed-switch (empresa CONTECH). Os sensores de nível são usados para supervisão do sistema evitando vazamento da calda pulverizada e para parar a bomba de descarte (modelo 8411001, empresa GeoPump).

A bomba de descarte, do tipo diafragma, possui capacidade de vazão de $12 \ell /$ min e é acionada através de um relé. O relé é acionado por um circuito amplificador de corrente conectado a uma saída analógica do módulo NI-9263. No Apêndice A, é apresentado o diagrama esquemático da placa de acionamento da bomba descarte e do sensor de nível do módulo de descarte. A calda armazenada pode ser descartada ou reciclada para o tanque de água através da bomba de descarte. Para o direcionamento da calda são usadas conexões tipo engate rápido na parte hidráulica. 


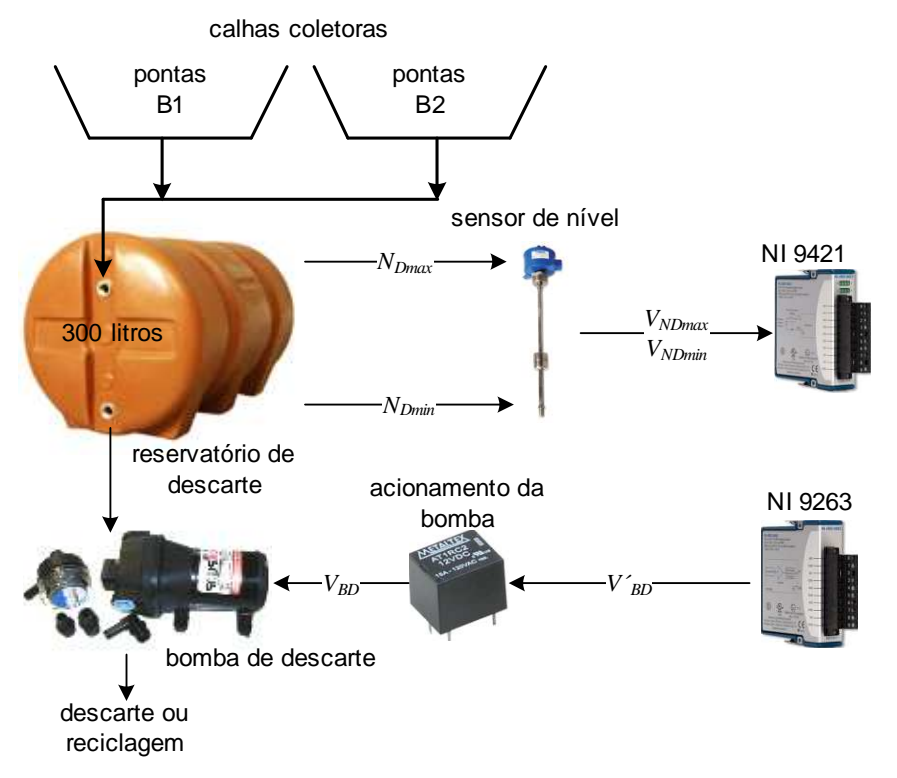

Figura 3.10: Instrumentação do módulo de descarte calda.

\subsection{Características Operacionais do Sistema de Pulveri- zação}

A taxa de aplicação de um pulverizador em taxa variada depende de três fatores: a faixa de vazão da bomba de pulverização, a faixa de velocidade de deslocamento e a largura da barra de pulverização. Na Tabela 3.2, são apresentadas as caraterísticas do pulverizador montado para este trabalho e de um pulverizador comercial da Jacto, modelo Uniport 3030.

Tabela 3.2: Características do sistema de pulverização implementado neste trabalho e de um sistema de pulverização comercial.

\begin{tabular}{lcc}
\hline Características & Este Trabalho & Uniport 3030 \\
\hline Velocidade máxima $(K m / h)$ & teórico* & 65 \\
Reservatório - água $(\ell)$ & 300 & 3000 \\
Reservatório - agroquímico $(\ell)$ & 20 & $2 \times 100$ \\
Bomba de pulverização $(\ell /$ min $)$ & max. 42 & 300 \\
Tipo da bomba de pulverização & pistão & pistão \\
Bomba de injeção $(\ell /$ min $)$ & max. 2,304 & - \\
Tipo da bomba de injeção & pistão & - \\
Espaçamento entre as pontas $(m)$ & 0,5 & 0,5 \\
Largura das seções barra $(m)$ & 3,5 & 8 \\
Número de seções de barra & 2 & 4 \\
Quantidade total de bicos & 14 & 64 \\
$R_{\text {max }}(\ell / h a)$ a $3,6 \mathrm{Km} / h$ & 1000 & 1562 \\
\hline$*$ trata-s & &
\end{tabular}

*trata-se de uma bancada estática, porém o deslocamento pode ser simulado. 
As características do sistema são utilizadas para determinar a região de operação do sistema e pulverização. Dessa forma, considerando o pulverizador utilizado neste trabalho, com as características apresentadas na Tabela 3.2, a leitura mínima do fluxômetro de $5 \ell / \min$, e que a velocidade de deslocamento (baseando-se no pulverizador autopropelido da Jacto) varie entre 3,6 e $65 \mathrm{Km} / \mathrm{h}(1$ e $18 \mathrm{~m} / \mathrm{s})$, obtém-se a região de operação (Figura 3.11) do sistema de pulverização implementado, utilizando:

$$
R=\frac{60000 Q_{F}}{V m n E}
$$

onde $R$ é a taxa de aplicação em $\ell / h a, Q_{F}$ é a vazão total da calda em $\ell / \min , V$ é a velocidade de deslocamento do pulverizador em $K m / h, n$ é o número de bicos por barra, $m$ é o número de seções de barra, $E$ é o espaçamento entre os bicos em $\mathrm{cm}$ e o número 60000 é uma constante de ajuste das unidades.

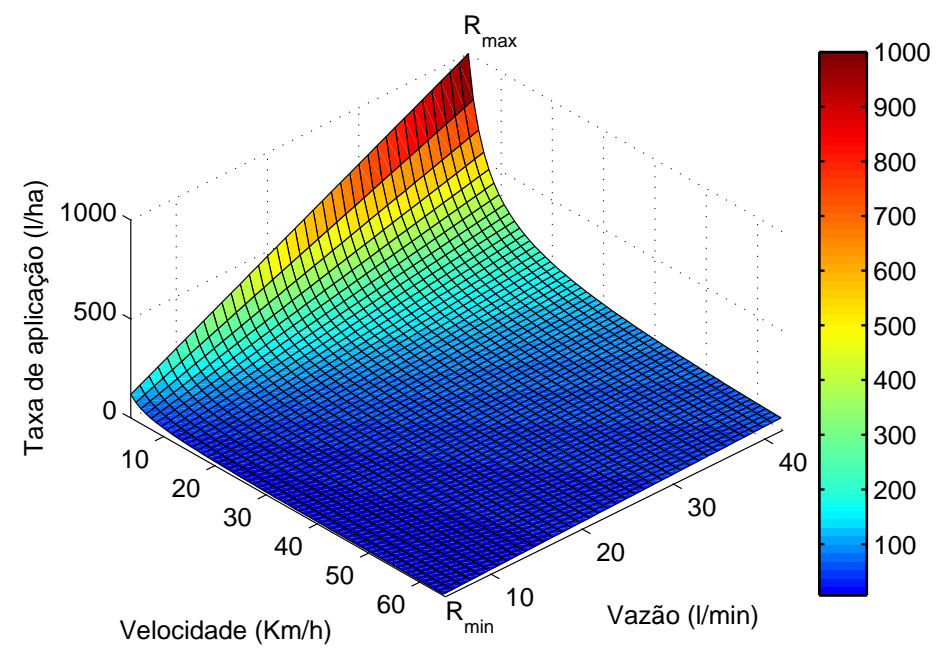

Figura 3.11: Região de operação do sistema de pulverização à taxa variada. A maior e menor taxa de aplicação são respectivamente $R_{\max }=1000 \ell / \mathrm{ha}$ e $R_{\min }=6,6 \ell / \mathrm{ha}$.

As pontas de pulverização utilizadas têm suas características operacionais apresentadas na Tabela 3.3. Por (3.12) são calculadas as taxas de aplicação mínima $\left(R_{\min }\right)$ a $65 \mathrm{Km} / \mathrm{h}$ e máxima $\left(R_{\max }\right)$ a $3,6 \mathrm{Km} / \mathrm{h}$ para a maior e menor pressão recomendadas para cada modelo. As pressão recomendadas pelo fabricante das pontas (ARAG), correspondem a faixa de pressão onde não ocorre variação no espectro de gotas.

Em geral a aplicação de agroquímicos a taxa variada é realizada baseando-se em uma velocidade de deslocamento constante, apesar de existir proposta para a variação da 
Tabela 3.3: Faixas de operação das pontas da pulverização do fabricante ARAG.

\begin{tabular}{|c|c|c|c|c|}
\hline Modelo da ponta & Pressão $(K P a)$ & Vazão $(\ell / \min )$ & $\begin{array}{l}R_{\min }(\ell / h a) \\
(\text { a } 65 \mathrm{Km} / \mathrm{h})\end{array}$ & $\begin{array}{c}R_{\max }(\ell / h a) \\
(\text { a } 3,6 \mathrm{Km} / \mathrm{h})\end{array}$ \\
\hline \multirow{5}{*}{ ISO 11002} & 200 & 0,65 & 12 & 217 \\
\hline & 250 & 0,73 & & \\
\hline & 300 & 0,80 & & \\
\hline & 350 & 0,86 & & \\
\hline & 400 & 0,92 & 17 & 307 \\
\hline \multirow{5}{*}{ ISO 11003} & 200 & 0,98 & 18 & 327 \\
\hline & 250 & 1,10 & & \\
\hline & 300 & 1,20 & & \\
\hline & 350 & 1,30 & & \\
\hline & 400 & 1,39 & 26 & 463 \\
\hline \multirow{5}{*}{ ISO 11004} & 200 & 1,31 & 24 & 437 \\
\hline & 250 & 1,46 & & \\
\hline & 300 & 1,60 & & \\
\hline & 350 & 1,73 & & \\
\hline & 400 & 1,85 & 34 & 617 \\
\hline \multirow{5}{*}{ ISO 11005} & 200 & 1,63 & 30 & 543 \\
\hline & 250 & 1,83 & & \\
\hline & 300 & 2,00 & & \\
\hline & 350 & 2,16 & & \\
\hline & 400 & 2,31 & 42 & 770 \\
\hline
\end{tabular}

velocidade a fim de se variar a taxa de aplicação (WERNER et al., 2007). Considerando a forma tradicional, com aplicação em velocidade constante, verifica-se através dos dados apresentados na Tabela 3.3 que os bicos de pulverização limitam a faixa de operação do sistema de pulverização. 


\section{Capítulo 4}

\section{Modelagem e Simulação dos}

\section{Módulos}

O desenvolvimento e parametrização de modelos para a simulação de processos dinâmicos, permite estudar as interações entre as várias partes do sistema, explorar o arranjo físico dos componentes do sistema e projetar a estratégia de controle (GARCIA, 2005). Neste trabalho, o desenvolvimento dos modelos para a simulação do sistema de pulverização com injeção direta visa principalmente a estratégia de controle. Adicionalmente, o desenvolvimento de um ambiente de simulação, com os modelos obtidos, na mesma linguagem de programação (Linguagem G ou Gráfica) utilizada na automação do sistema, permite que os códigos fonte ou programas desenvolvidos no LabVIEW para computador sejam transportados para LabVIEW Real-Time no PAC cRIO com poucas modificações.

Para fins de modelagem e desenvolvimento do ambiente para simulação são considerados os módulos de pulverização e de injeção. A recomendação para a pulverização de agroquímicos como o herbicida RoundUP Original ${ }^{\circledR}$ é para a dissolução do herbicida em água em uma concentração de 0,5 a $4 \%$ dependendo da planta invasora. A baixa concentração de agroquímico implica pequena variação nas propriedades físicas do fluído (densidade e viscosidade) considerado para a aproximação dos modelos. Todos os ensaios são realizados com água de torneira proveniente da rede de distribuição de água da cidade de São Carlos. 


\subsection{Modelagem do Módulo de Injeção}

O módulo de injeção é descrito através do modelo tradicional de um motor CC (OLIVEIRA; AGUIAR; VARGAS, 2005), adicionando os elementos correspondentes à bomba de pistão e ao amplificador de potência. O diagrama em blocos na Figura 4.1, mostra o modelo completo deste módulo. Os parâmetros do motor CC são a constante de torque $K_{T}$, a constante da força contra-eletromotriz $K_{E}$, a resistência de armadura $R_{H}$, a indutância de armadura $L_{H}$, o momento de inércia $J$ e o coeficiente de atrito viscoso $b$.

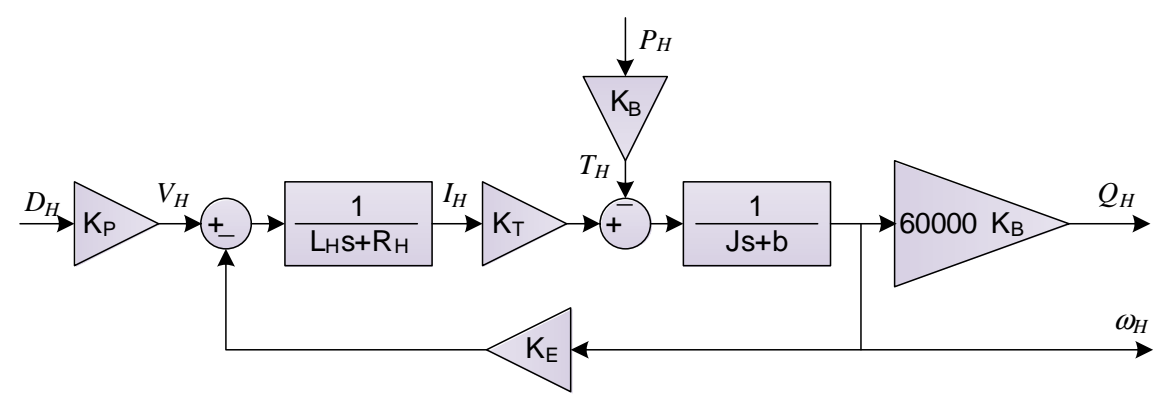

Figura 4.1: Diagrama em blocos do módulo de injeção.

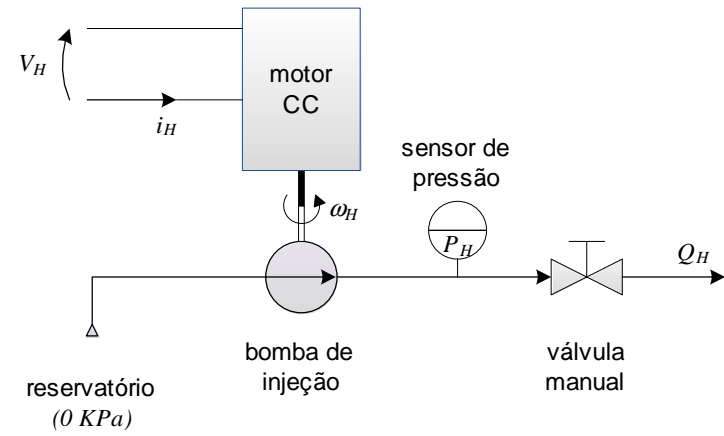

Figura 4.2: Arranjo usado para o ensaio do módulo de injeção.

As relações constitutivas para bomba de injeção (QB-3) são:

$$
\begin{aligned}
Q_{H} & =60000 K_{B} \omega_{H} \\
T_{H} & =K_{B} P_{H}
\end{aligned}
$$

onde, $Q_{H}$ é a vazão da bomba em $\ell / \min , K_{B}$ o deslocamento volumétrico do pistão em $\mathrm{m}^{3} / \mathrm{rad}, \omega_{H}$ a velocidade angular no eixo em $\mathrm{rad} / \mathrm{s}, T_{H}$ o torque demandado pela bomba em $N m, P_{H}$ a pressão na saída da bomba em Pascal $\left(N . m^{-2}\right)$ (MERRITT, 1967). 
A rotação $\omega_{H}$ do motor $\mathrm{CC}$ da bomba de injeção depende da tensão $V_{H}$, que é proporcional ao ciclo de trabalho sinal PWM $D_{H}$ aplicado no amplificador de potência:

$$
V_{H}=K_{P} D_{H}
$$

sendo $K_{P}$ o ganho do amplificador de potência.

Para obter os valores dos parâmetros do modelo (Figura 4.1) é montado o arranjo mostrado na Figura 4.2. Através de uma interface com o usuário, desenvolvida no LabVIEW, são gravados os dados referentes a tensão aplicada no motor $V_{H}$, a corrente de armadura $I_{H}$ a rotação $\omega_{H}$ e a pressão na saída da bomba $P_{H}$.

Uma fonte de tensão CC ajustável é utilizada para variar a tensão $V_{H}$ e para o ajuste de $P_{H}$ é utilizada uma válvula de 2 vias conectada na saída da bomba, com abertura e fechamento manual. O experimento é conduzido em duas etapas, na primeira etapa até o tempo $50 s$ varia-se a tensão $V_{H}$ com a válvula manual totalmente aberta, após isso são aplicados valores aleatórios de $V_{H}$ e $P_{H}$, através da fonte de tensão e da abertura e fechamento da válvula manual.

O valor do parâmetro $K_{B}$ é obtido pelos dados fornecidos pelo fabricante da bomba, o parâmetro $K_{P}$ é o valor teórico do ganho do amplificador de potência e os valores dos parâmetros $R_{H}, L_{H}, K_{E}, K_{T}, J$ e $b$ são estimados através da ferramenta Simulink Design Optimization, utilizando os dados obtidos a cada $1 \mathrm{~ms}$. Esta ferramenta do Matlab/Simulink permite estimar e ajustar os parâmetros de um modelo desenvolvido no Simulink a partir de dados de entrada/saída reais.

Tabela 4.1: Valores dos parâmetros do modelo do módulo de injeção.

\begin{tabular}{cl}
\hline Parâmetro & Valor \\
\hline$R_{H}$ & $6,8610^{-1} \Omega$ \\
$L_{H}$ & $1,0010^{-3} \mathrm{H}$ \\
$K_{T}$ & $3,7510^{-2} \mathrm{Nm} / \mathrm{A}$ \\
$K_{E}$ & $3,7510^{-2} \mathrm{Vs} / \mathrm{rad}$ \\
$J$ & $4,7410^{-4} \mathrm{Kgm}^{2}$ \\
$b$ & $4,5910^{-4} \mathrm{Kgm}^{2} / \mathrm{s}$ \\
$K_{B}$ & $2,0710^{-7} \mathrm{~m}^{3} / \mathrm{rad}$ \\
$K_{P}$ & $0,12 \mathrm{~V}$ \\
\hline
\end{tabular}

A Tabela 4.1 mostra os valores numéricos dos parâmetros do modelo, implementado no Simulink (Figura 4.1), ajustado a partir dos dados experimentais. 
As respostas obtidas do modelo simulado e as respostas experimentais, referentes ao ensaio preparado conforme a Figura 4.2, podem ser observadas na Figura 4.3. A análise gráfica mostra boa concordância entre as curvas real e simulada. Outras abordagens para a modelagem deste módulo podem ser encontradas nos trabalhos Mercaldi et al. (2011a, 2011b).
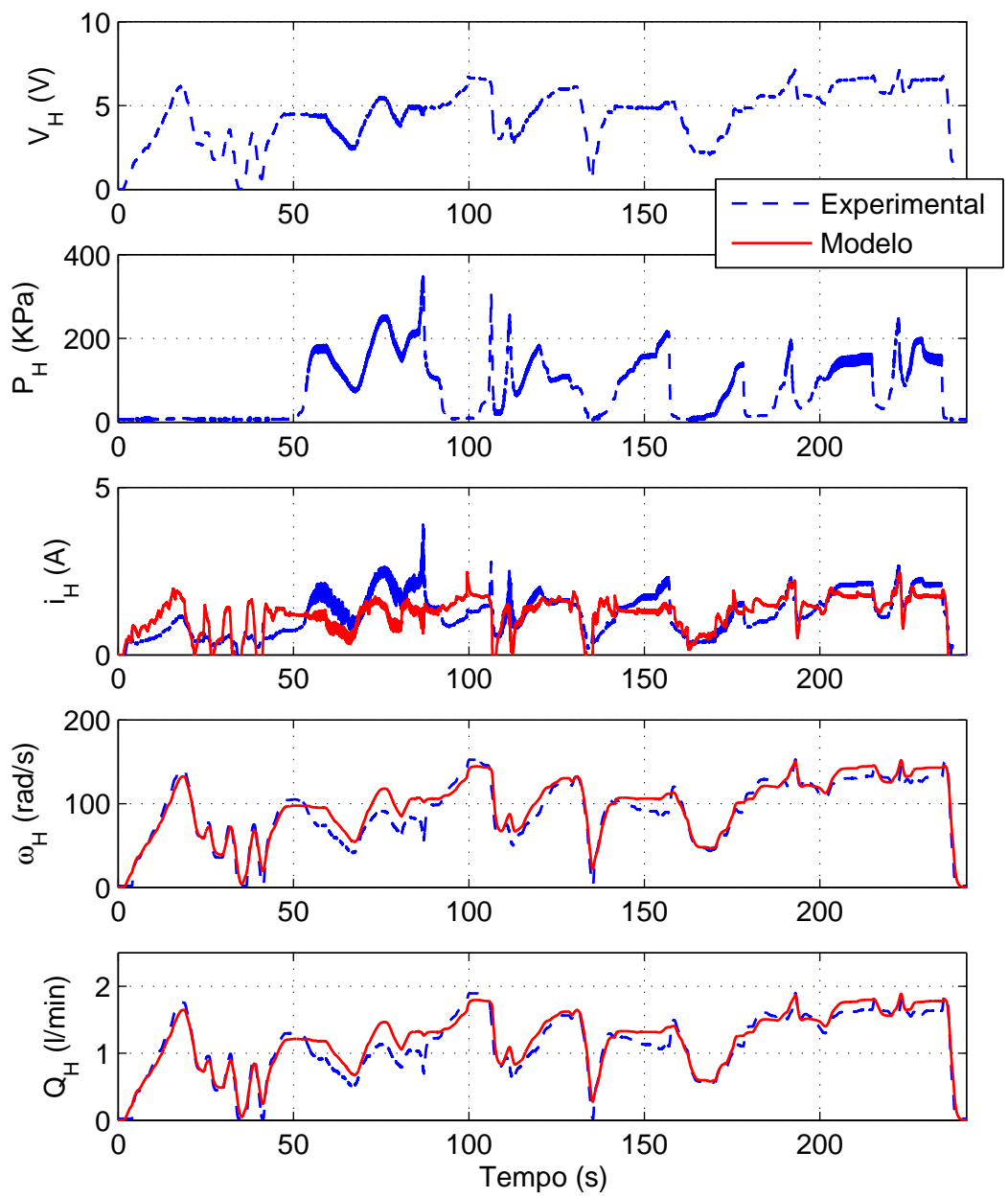

Figura 4.3: Resultados experimentais e de simulação do modelo do módulo de injeção.

\subsection{Modelagem do Módulo de Pulverização}

O módulo de pulverização possui diferentes elementos hidráulicos como as válvulas proporcionais e de seção, as mangueiras e as pontas de pulverização. Esses elementos se opõem a passagem do fluído (calda) criando uma diferença de pressão através do 
elemento, esse efeito é conhecido como resistência hidráulica ou resistência fluídica (GARCIA, 2005).

O perfil da velocidade de escoamento de um fluído tem um efeito significativo na relação entre a diferença de pressão a vazão através de um elemento hidráulico (HUGHES, 2002). Para a classificar o escoamento em um conduto é usada uma constante adimensional, o número de Reynolds dado por:

$$
R_{e}=\frac{\rho d_{i} v}{\delta}
$$

em que $\rho$ é a densidade absoluta do fluído, $d_{i}$ é o diâmetro interno do conduto, $v$ é a velocidade média do fluído e $\delta$ a viscosidade dinâmica absoluta do fluído. Um escoamento é dito laminar $(R e<1100)$ quando o seu perfil de velocidade é parabólico e turbulento $(R e>3500)$ quando seu perfil de velocidade é achatado (GARCIA, 2005).

Na prática a velocidade do fluído em um conduto aproxima-se de zero nas proximidades das paredes e varia com o diâmetro. A velocidade média do escoamento é:

$$
v=\frac{Q}{A_{i}}
$$

onde $Q$ é a vazão e $A_{i}$ é a área transversal interna do conduto.

O módulo de pulverização, em sua maior parte, utiliza mangueiras com diâmetro interno de $d_{i}=1 / 2$ pol $\left(1,27010^{-2} \mathrm{~m}\right)$. Considerando as características dessa tubulação e do fluído para as condições de $\mathrm{CNTP}^{1}$ e para a temperatura máxima do fluxômetro, apresentadas na Tabela 4.2, através de (4.4) e (4.5) são calculadas as vazões mínimas $Q_{\min }$ na tubulação para que o escoamento seja turbulento $\left(R_{e}=4000\right)$ :

$$
\begin{gathered}
Q_{\min }(C N T P)=4,26 \ell / \min \left(7,1110^{-5} \mathrm{~m}^{3} / \mathrm{s}\right) \\
Q_{\min }\left(50^{\circ} \mathrm{C}\right)=1,32 \ell / \min \left(2,2110^{-5} \mathrm{~m}^{3} / \mathrm{s}\right) .
\end{gathered}
$$

A partir dos valores de $Q_{\min }$ na faixa de $0-50^{\circ} C$ pode-se assumir que o escoamento da calda na maior parte da tubulação do módulo de pulverização é turbulento, uma vez que não são usadas vazões inferiores a $5 \ell / \min$ devido a faixa de leitura do fluxômetro.

\footnotetext{
${ }^{1}$ temperatura $=0^{\circ} \mathrm{C}$ e pressão $=1 \mathrm{~atm}$
} 
Tabela 4.2: Valores dos parâmetros para cálculo da vazão mínima para o escoamento turbulento.

\begin{tabular}{|c|c|c|c|}
\hline Parâmetro & Valor & Parâmetro & Valor \\
\hline$\rho_{a g}$ & $9,99810^{2} \mathrm{Kg} / \mathrm{m}^{3}$ & $\rho_{\text {ag }}$ & $9,88010^{2} \mathrm{Kg} / \mathrm{m}^{3}$ \\
\hline$\delta_{a g u a(C \Lambda}$ & 1, $78110^{-3}$ Pa.s & $\delta_{\text {agua }\left(50^{\circ} \mathrm{C}\right)}$ & $0,54710^{-3}$ Pa.s \\
\hline$d_{i}$ & $1,27010^{-2} \mathrm{~m}$ & $A_{i}$ & $1,26710^{-4} \mathrm{~m}^{2}$ \\
\hline
\end{tabular}

Para o escoamento turbulento de um líquido que passa através de elementos hidráulicos, tais como as válvulas e as pontas de pulverização, a relação entre a queda de pressão $\Delta P$ e a vazão $Q$ é dada por:

$$
Q=C_{D} A_{i} \sqrt{\frac{2}{\rho} \Delta P}
$$

onde $C_{D}$ é o coeficiente de descarga do elemento hidráulico, $A_{i}$ é a área da seção transversal do conduto e $\rho$ é a densidade absoluta do fluído. Resolvendo (4.6) em termos de $\Delta P$ em $K P a$ para a vazão em $\ell / \min$ têm-se:

$$
\Delta P=K_{Q} Q^{2}
$$

sendo $K_{Q}=C_{1} \frac{\rho}{2 C_{D}^{2} A_{i}^{2}}$ a resistência fluídica do componente hidráulico, $C_{1}=2,8.10^{-13}$ o fator de conversão de unidades.

Para as mangueiras da tubulação, a resistência hidráulica em $K P a /(\ell / m i n)^{2}$ é:

$$
K_{Q}=C_{2} \frac{f_{a} L \rho}{2 d_{i} A_{i}^{2}}
$$

sendo $C_{2}=1,67.10^{-11}$ o fator de conversão de unidades, $f_{a}$ o coeficiente de perda de carga distribuído, $L$ o comprimento do trecho em $m, d_{i}$ o diâmetro interno em $m$, $A_{i}=\frac{\pi d_{i}^{2}}{4}$ a área da seção transversal em $m^{2}$ e $\rho$ a densidade absoluta do líquido em $\mathrm{Kg} / \mathrm{m}^{3}$ (GARCIA, 2005).

O módulo de pulverização da calda é modelado através do conceito da resistência fluídica, a mesma abordagem adotada por Steward e Humburg (2000). Assim o valor numérico de $K_{Q}$ em $K \mathrm{~Pa} /(\ell / \mathrm{min})^{2}$ é obtido experimentalmente através das medidas da diferença de pressão $\Delta P$ em $K P a$ e da vazão $Q$ em $\ell / \min$. Na Figura 4.4, é apresentado o circuito hidráulico do módulo de pulverização com a representação dos elementos através de resistências hidráulicas.

Assumindo que: 


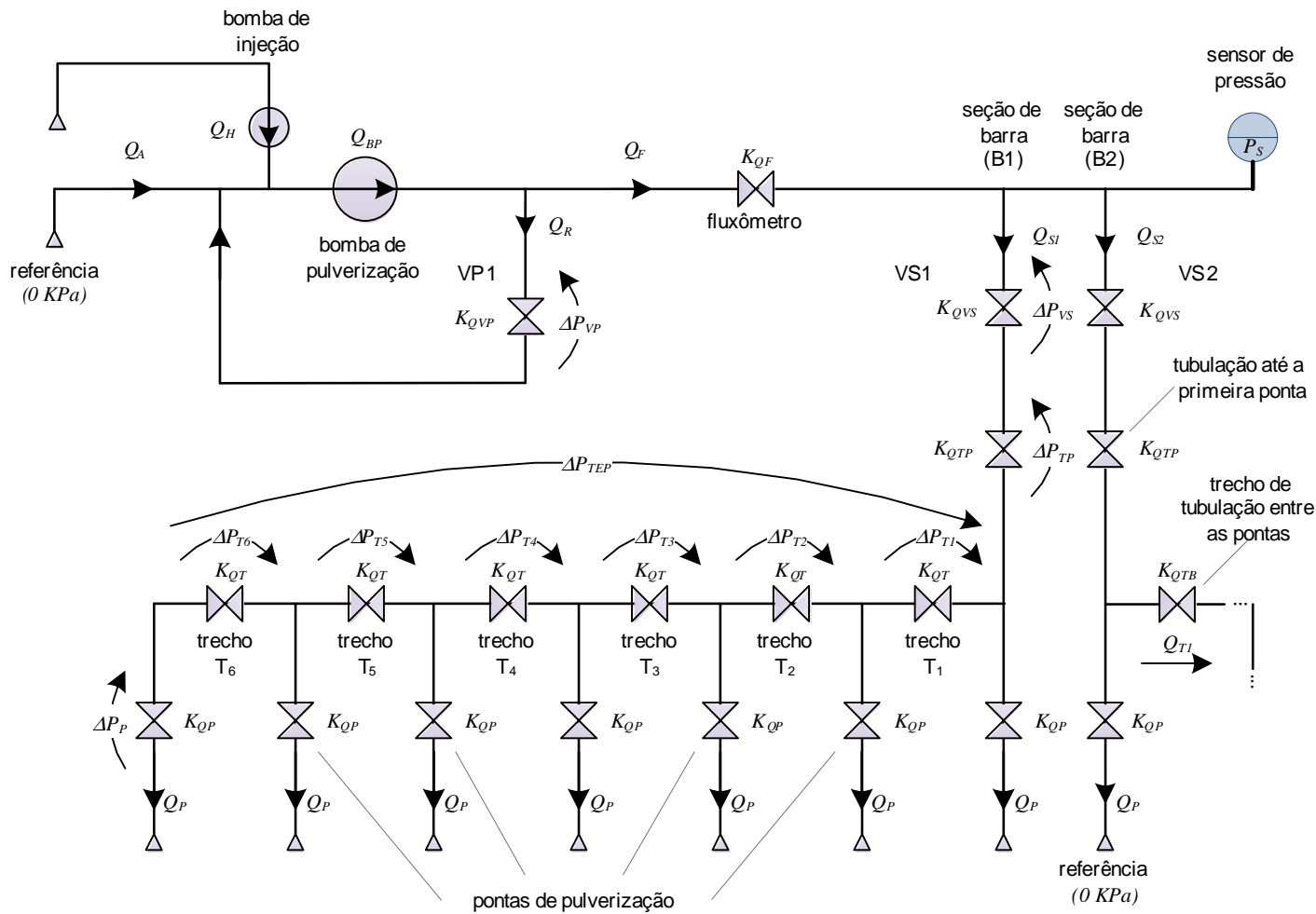

Figura 4.4: Circuito hidráulico do módulo de pulverização.

1. a vazão $Q_{P}$ nas pontas de pulverização são iguais; (A regra prática para substituição das pontas é quando a diferença entre a vazão estipulada pelo fabricante e a real é superior a 10\%) (WILES; SHARP; MATTHEWS, 2001; BOLLER; RAETANO, 2011);

2. as tubulações entre as pontas de pulverização possuem a mesma resistência fluídica $K_{Q T}$

3. as válvulas de seção possuem a mesma resistência fluídica $K_{Q V S}$;

4. as tubulações que vão da saída da válvula de seção VS1 ou VS2 até a primeira ponta de pulverização de cada barra B1 ou B2 possuem a mesma resistência fluídica $K_{Q T P}$;

5. a queda de pressão no fluxômetro é desprezível (determinado através de ensaios);

então pode-se afirmar que a vazão da calda se divide igualmente entre as barras e que 
a vazão da barra se distribui igualmente entre as pontas de pulverização:

$$
\begin{aligned}
Q_{S 1} & =\frac{Q_{F}}{m} \\
Q_{P} & =\frac{Q_{S 1}}{n}
\end{aligned}
$$

onde $Q_{S 1}$ é a vazão na seção de barra $B 1, m$ é a quantidade de seções de barra, $n$ é a quantidade de pontas de pulverização da barra $B 1$ e $Q_{P}$ é a vazão nas pontas de pulverização.

De acordo com o circuito hidráulico (Figura 4.4), a pressão do sistema $P_{S}$ é dada pela soma das quedas de pressão nos elementos hidráulicos de cada seção de barra:

$$
P_{S}=\Delta P_{V S}+\Delta P_{T P}+\Delta P_{T E P}+\Delta P_{P}
$$

sendo $\Delta P_{V S}$ a queda de pressão da válvula de seção $\mathrm{VS} 1, \Delta P_{T P}$ a queda de pressão no trecho de tubulação que vai da saída de VS1 até a primeira ponta de pulverização, $\Delta P_{T B}$ a soma das quedas de pressão da tubulação entre as pontas de pulverização e $\Delta P_{P}$ a queda de pressão da ponta de pulverização.

A partir da relação de pressão (4.11), para obter o modelo hidráulico que representa a relação entre a vazão $Q_{F}$ medida do fluxômetro e a pressão $P_{S}$ medida pelo sensor de pressão, são analisadas as quedas de pressão no elementos hidráulicos das seções de barra.

Para as válvulas de seção, pontas de pulverização e os trechos de tubulação até a primeira ponta de pulverização, utilizando (4.9) e (4.10), as quedas de pressão são respectivamente:

$$
\begin{gathered}
\Delta P_{V S}=\frac{K_{Q V S}}{m^{2}} Q_{F}^{2}=K_{Q V S e q} Q_{F}^{2} \\
\Delta P_{P}=\frac{K_{Q P}}{m^{2} n^{2}} Q_{F}{ }^{2}=K_{Q P e q} Q_{F}{ }^{2} \\
\Delta P_{T P}=\frac{K_{Q T P}}{m^{2}} Q_{F}^{2}=K_{Q T P e q} Q_{F}^{2}
\end{gathered}
$$

onde $K_{Q V S e q}, K_{Q P e q}$ e $K_{Q T P e q}$ são as resistências hidráulicas equivalentes dos respectivos elementos hidráulicos e $K_{Q T P}=C_{2} \frac{f_{a} L_{1} \rho}{2 d_{i} A_{i}^{2}}$ é a resistência fluídica do trecho de tubulação até a primeira ponta da seção de barra B1, com comprimento $L_{1}$. 
Para obter a queda de pressão $\Delta P_{T E P}$ da tubulação entre as pontas de pulverização é desenvolvido o equacionamento para os dois primeiros trechos e por indução é obtida a equação da resistência fluídica equivalente. A queda de pressão nos trechos de tubulação T1 e T2 (Figura 4.4), utilizando (4.9) e (4.10) são respectivamente:

$$
\begin{gathered}
\Delta P_{T 1}=K_{Q T}\left(Q_{S 1}-Q_{P}\right)^{2}=K_{Q T}\left(\frac{Q_{F}}{m}-\frac{Q_{F}}{m n}\right)^{2} \\
\Delta P_{T 2}=K_{Q T}\left(Q_{S 1}-2 Q_{P}\right)^{2}=K_{Q T}\left(\frac{Q_{F}}{m}-\frac{2 Q_{F}}{m n}\right)^{2}
\end{gathered}
$$

sendo $K_{Q T}=C_{2} \frac{f_{a} E \rho}{2 d_{i 2} A_{i 2}^{2}}$, onde $E$ o espaçamento entre as pontas de pulverização.

A partir de (4.15) e (4.16) se obtém que para o iésimo trecho de tubulação a queda de pressão é:

$$
\Delta P_{T i}=K_{Q T}\left[\frac{1}{m}\left(1-\frac{i}{n}\right)\right]^{2} Q_{F}^{2}
$$

sendo i o trecho de tubulação. Como a queda de pressão total $\Delta P_{T E P}$ dos trechos entre as pontas é a soma das quedas individuais $\Delta P_{T i}$, pode-se escrever:

$$
\begin{aligned}
\Delta P_{T E P} & =K_{Q T} \sum_{i=1}^{n-1}\left[\frac{1}{m}\left(1-\frac{i}{n}\right)\right]^{2} Q_{F}{ }^{2} \\
& =K_{Q T e q} Q_{F}{ }^{2}
\end{aligned}
$$

A pressão do sistema é obtida substituindo os resultados (4.12), (4.13), (4.14) e (4.19) em (4.11):

$$
\begin{aligned}
P_{S} & =\left(K_{Q V S e q}+K_{Q T P e q}+K_{Q T e q}+K_{Q P e q}\right) Q_{F}^{2} \\
& =K_{Q e q} Q_{F}^{2}
\end{aligned}
$$

onde $K_{Q e q}$ é a resistência hidráulica equivalente de todo o circuito hidráulico do módulo de pulverização.

A vazão da calda $Q_{F}$ medida pelo fluxômetro é regulada na válvula de controle VP1 (Figuras 3.5 e 4.4) através da vazão de retorno $Q_{R}$, considerando que a vazão da bomba $Q_{B P}$ é mantida constante, então a vazão e a queda de pressão através da válvula são 
respectivamente:

$$
\begin{array}{r}
Q_{R}=Q_{B P}-Q_{F} \\
\Delta P_{V P}=K_{Q V P} Q_{R}^{2}
\end{array}
$$

onde $K_{Q V P}$ é a resistência fluídica da válvula VP1.

Uma vez que a queda de pressão no fluxômetro é desprezível e considerando que a pressão na entrada da bomba relativa a pressão atmosférica é nula, então substituindo (4.22) em (4.23) e igualando ao resultado anterior (4.21) obtém-se:

$$
\left(K_{Q V P}-K_{Q e q}\right) Q_{F}^{2}-2 K_{Q V P} Q_{B P} Q_{F}+K_{Q V P} Q_{B P}^{2}=0
$$

onde a raiz positiva é a solução procurada. Assim a vazão $Q_{F}$ medida pelo fluxômetro é dada em função dos parâmetros $K_{Q e q}, K_{Q V P}$ e $Q_{B P}$ por:

$$
Q_{F}=\frac{Q_{B P}\left(\sqrt{K_{Q e q} K_{Q V P}}-K_{Q V P}\right)}{K_{Q e q}-K_{Q V P}}
$$

ou seja, $Q_{F}=f\left(K_{Q e q}, K_{Q V P}, Q_{B P}\right)$.

O valor de $K_{Q V P}$ é função da posição do êmbolo no interior da via de retorno da válvula, obtida através a posição angular $\theta_{V}$ do eixo do motor CC que aciona o êmbolo:

$$
K_{Q V P}=f\left(\theta_{V}\right)
$$

Nessa relação, a posição angular $\theta_{V}$ do eixo do motor CC da válvula de controle VP1 é obtida através do modelo do motor CC que aciona o êmbolo e do circuito de potência com ponte $\mathrm{H}$ que aciona o motor. O diagrama em blocos da Figura 4.5 mostra esse modelo. Neste diagrama, $D_{V}$ representa o valor do ciclo de trabalho do sinal PWM. A ponte $\mathrm{H}$ é representado pelo bloco de ganho $K_{P H}$. O motor $\mathrm{CC}$ é representado por um sistema de primeira ordem mais um integrador, com os parâmetros de ganho $K_{M}$ e constante de tempo $T_{M}$. Esse motor só atua quando o ciclo de trabalho do PWM é maior que sua zona morta $Z_{M}<D_{V}$. O efeito da zona morta é modelado com o 
amplificador de potência, assim a tensão no motor CC da válvula VP1 é:

$$
V 1= \begin{cases}0, & \text { se } \quad D_{V} \in\left[-Z_{M}, Z_{M}\right] \\ K_{P H} D_{V}, & \text { caso contrário. }\end{cases}
$$

O êmbolo possui um curso limitado pelas dimensões da válvula e para representar esse efeito é usado um bloco de saturação na posição angular do eixo $\theta_{V}$. Adotando-se $\theta_{V \min }=0$ como o limite inferior da saturação, para a válvula totalmente aberta, então o limite superior é $\theta_{V \max }$ ocorre para a válvula totalmente fechada.

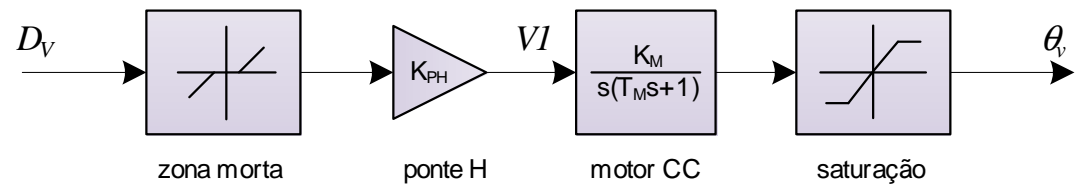

Figura 4.5: Diagrama em blocos do motor $\mathrm{CC}$ da válvula de controle e ponte $\mathrm{H}$.

O diagrama de blocos do modelo completo do módulo de pulverização da calda é apresentado na Figura 4.6, onde o bloco $\tau$ representa o tempo de resposta do fluxômetro. Os valores numéricos dos parâmetros do módulo de pulverização são mostrados na Tabela 4.3. Os parâmetros $L_{1}, E, d_{i}, Q_{B P}, Z_{M}$ e $K_{P H}$ são conhecidos.

Os valores de $f_{a 1}$ e $f_{a 2}$ foram ajustados empiricamente através dos dados experimentais de pressão $P_{S}$ e vazão $Q_{F}$. O valor de $K_{Q V S}$ é obtido através da curva de pressão por vazão fornecida pelo fabricante. O valor de $K_{Q P}$ é obtido através dos dados fornecidos pelo fabricante das pontas (Tabela 3.3).

Os valores dos parâmetros $K_{m}, T_{m}$ e $\theta_{V \max }$ foram obtidos medindo-se a posição angular $\theta_{V}$ do eixo do motor submetido a um degrau correspondente a um ciclo de trabalho de $D_{V}=100 \%$ no PWM. Utilizando os dados obtidos a cada $50 \mathrm{~ms}$ da curva de reação ao degrau são estimados os valores dos parâmetros através da ferramenta Simulink Design Optimization.

O parâmetro $K_{Q V P}$ é obtido experimentalmente através das medidas de vazão $Q_{F}$ e pressão $P_{V}$ para quatorze diferentes posições angulares $\theta_{V}$ da válvula VP1. Nesse experimento as seções de barra B1 e B2 são fechadas. A válvula VP2, partindo da posição totalmente aberta, é acionada para fechamento até que a pressão atinja o valor de $700 \mathrm{KPa}$ (7 bar), a partir daí a valvula é aberta. A vazão $Q_{R}$, na via de retorno 


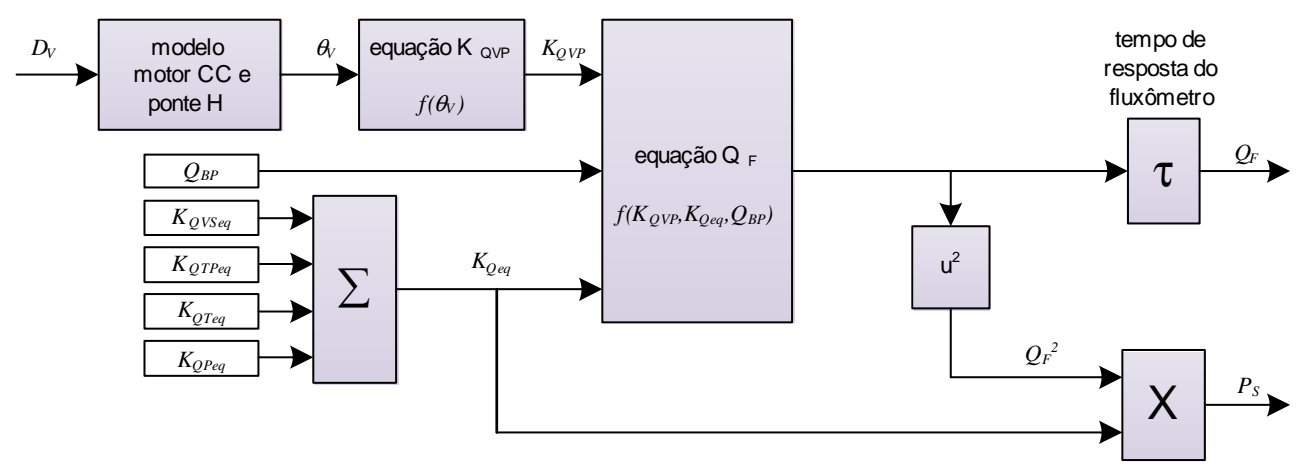

Figura 4.6: Diagrama de blocos do módulo de pulverização.

Tabela 4.3: Valores dos parâmetros do módulo de pulverização.

\begin{tabular}{cl}
\hline Parâmetro & Valor \\
\hline$Q_{B P}$ & $4,2010^{1} \ell / \mathrm{min}$ \\
$m$ & 2,00 \\
$n$ & 7,00 \\
$K_{M}$ & $1,10 \mathrm{rad} / \mathrm{V}$ \\
$T_{M}$ & $5,0010^{-2} \mathrm{~s}$ \\
$Z_{M}$ & $2,0010^{1} \%$ \\
$K_{P H}$ & 0,12 \\
$\tau$ & $0,60 \mathrm{~s}$ \\
$\theta_{V \max }$ & $9,4210^{1} \mathrm{rad}$ \\
$f_{a}$ & $8,2010^{-2}$ \\
$L_{1}$ & $1,35 \mathrm{~m}$ \\
$E$ & $0,50 \mathrm{~m}$ \\
$d_{i}$ & $1,2710^{-2} \mathrm{~m}$ \\
$K_{Q V S}$ & $4,0810^{-2} \mathrm{KPa} /(\ell / \mathrm{min})^{2}$ \\
$K_{Q P}($ ponta 11002) & $4,7110^{2} \mathrm{KPa} /(\ell / \mathrm{min})^{2}$ \\
$K_{Q P}($ ponta 11003) & $2,0710^{2} \mathrm{KPa} /(\ell / \mathrm{min})^{2}$ \\
$K_{Q P}($ ponta 11004) & $1,1710^{2} \mathrm{KPa} /(\ell / \mathrm{min})^{2}$ \\
$K_{Q P}($ ponta 11005) & $7,5010^{1} \mathrm{KPa} /(\ell / \mathrm{min})^{2}$ \\
$K_{Q V P}$ & $0 \mathrm{a} 1,80 \mathrm{KPa} /(\ell / \mathrm{min})^{2}$ \\
\hline
\end{tabular}

da válvula, é calculada por (4.22). Dessa forma é obtida a curva de $K_{Q V P}$ versus $\theta_{V}$, mostrado na Figura 4.7. Os dados experimentais dessa curva são usados para ajustar os parâmetros da expressão:

$$
K_{Q V P}=A_{0}+A_{1} e^{\frac{\theta_{V}}{B_{1}}}
$$

sendo $A_{0}=2,99.10^{-2}, A_{1}=2,81.10^{-6}$ e $B_{1}=6,53$ constantes.

Na saída da bomba de pulverização têm-se a relação (4.22), já na sua entrada a vazão $Q_{B P}$ é dada por:

$$
Q_{B P}=Q_{R}+Q_{A}+Q_{H}
$$




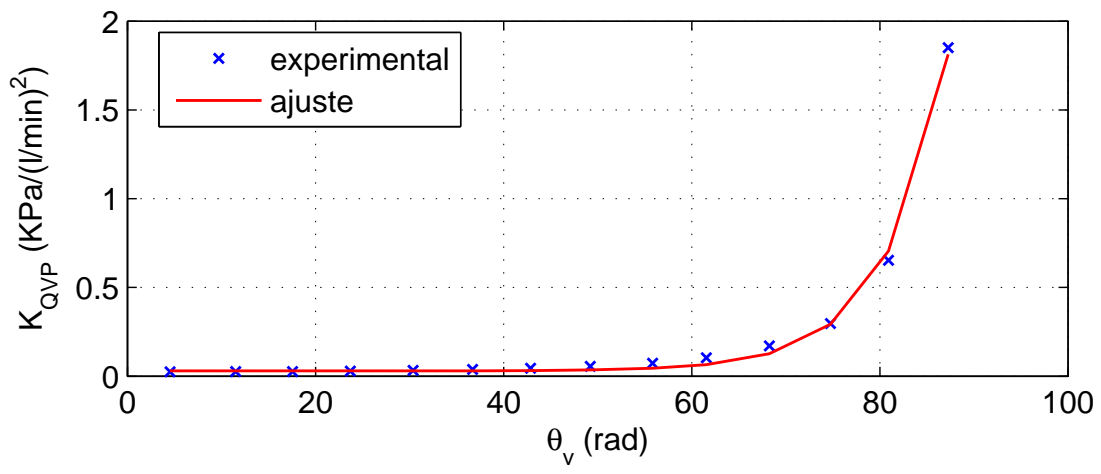

Figura 4.7: Curva $K_{Q V P}$ versus $\theta_{V}(4.27)$ da válvula de controle VP1.

Isolando $Q_{F}$ em (4.22) e substituindo em (4.28) obtém-se a vazão da calda:

$$
Q_{F}=Q_{A}+Q_{H}
$$

onde $Q_{A}$ é a vazão de água do reservatório.

\subsubsection{Validação do modelo matemático do módulo de pulverização}

Para validação do modelo, devido ao processo em malha aberta deste módulo ser instável, foi implementado um controlador proporcional ilustrado na Figura 4.8.

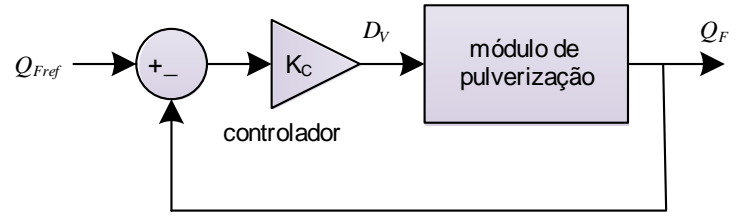

Figura 4.8: Diagrama em blocos do módulo de pulverização com o controlador proporcional com ganho $K_{C}=20$.

Os dados do processo, referentes as respostas da vazão $Q_{F}$, pressão $P_{S}$ e posição angular $\theta_{V}$, são gravados e comparados com os resultados do modelo em malha fechada. Para isso, tanto no processo quanto no modelo, são aplicadas referências de vazão $Q_{\text {Fref }}$ (Figuras 4.9c a 4.12c). Os resultados do processo e do modelo para as pontas de pulverização 11002 a 10005 são apresentados nas Figuras 4.9 a 4.12, respectivamente. Nota-se através dos gráficos que existe uma boa aproximação das curvas do modelo simulado e do processo. 


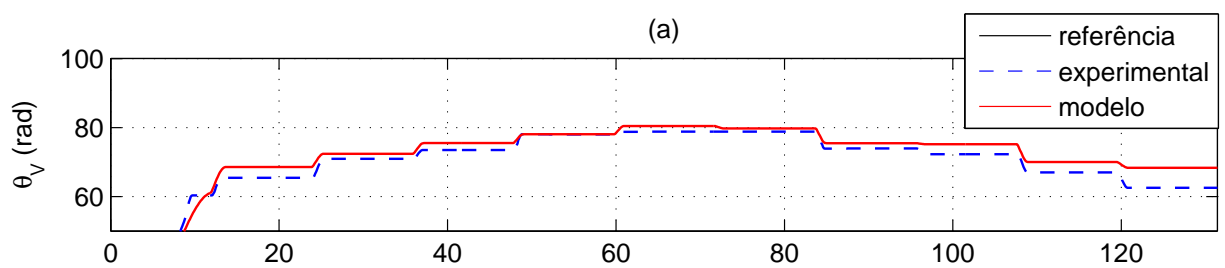

(b)

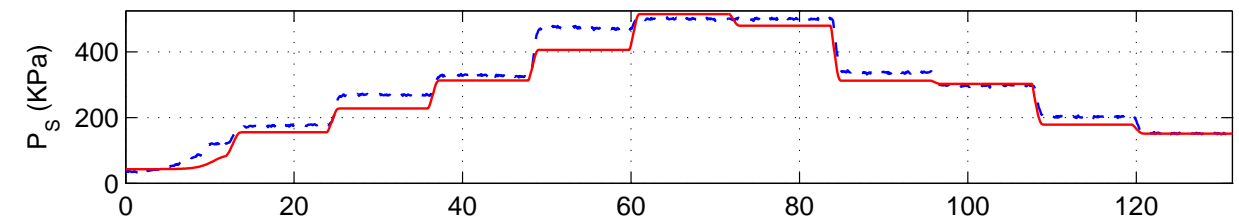

(c)

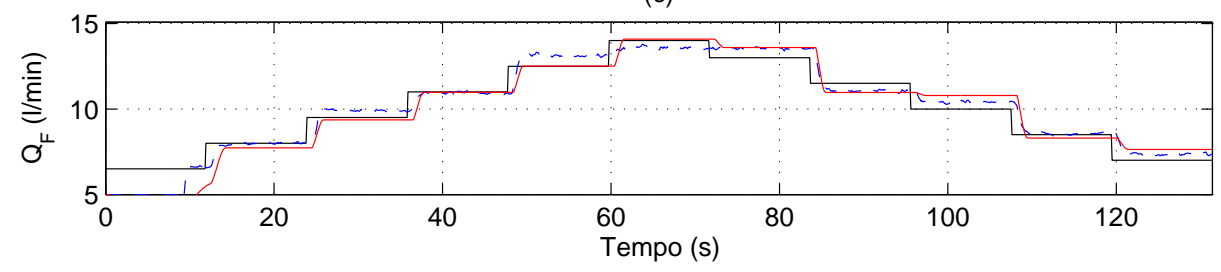

Figura 4.9: Respostas reais e de simulação do módulo de pulverização com controlador proporcional usando a ponta modelo ISO-11002.

\subsection{Ambiente de Simulação}

Adicionalmente, o desenvolvimento de um ambiente de simulação, com os modelos obtidos, na mesma linguagem de programação (Linguagem G ou Gráfica) utilizada na automação do sistema, permite que os códigos fonte ou programas desenvolvidos no LabVIEW para computador sejam transportados para LabVIEW Real-Time no PAC cRIO com poucas modificações.

Os modelos obtidos permitem através do Control Design and Simulation Module a implementação de um ambiente de simulação no LabVIEW para computador. O Control Design and Simulation Module possui algoritmos e funcionalidades para a modelagem e análise de sistemas dinâmicos lineares e não lineares, em tempo contínuo ou discreto, agilizando o processo de conversão das rotinas desenvolvidas para o hardware de destino (NATIONAL INSTRUMENTS, 2011). Neste trabalho, o uso do módulo de simulação reduziu significativamente o tempo necessário para a adaptação dos códigos e parâmetros dos controladores, que vinham sendo desenvolvidos com o auxílio do Matlab/Simulink, para o PAC cRIO.

O ambiente de simulação possibilitou a implementação, testes e ajuste de parâmetros dos controladores, que serão apresentados no próximo capítulo, para os módulo de 


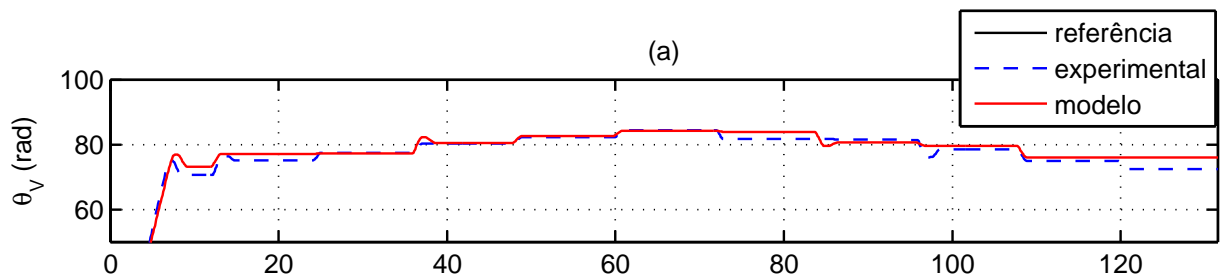

(b)

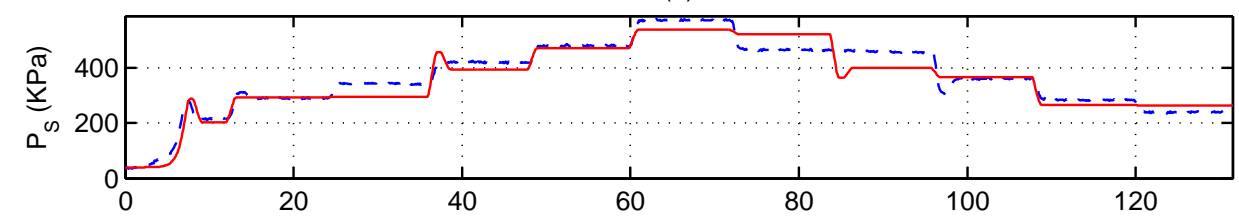

(c)

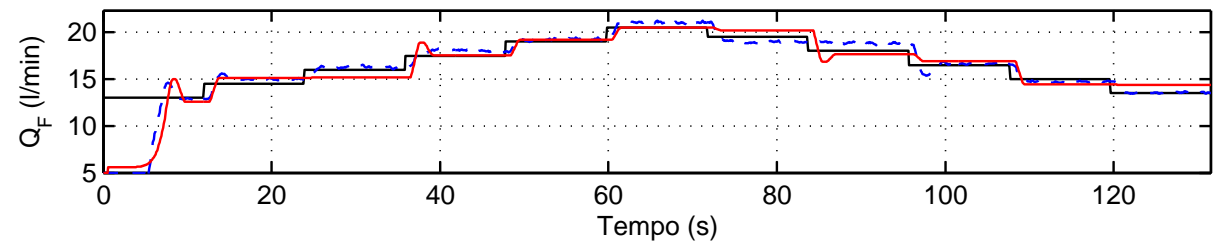

Figura 4.10: Respostas reais e de simulação do módulo de pulverização com controlador proporcional usando a ponta modelo ISO-11003.

injeção e de pulverização. Na Figura 4.13 é apresentado a interface gráfica usada para a simular o módulo de injeção e na Figura 4.14 é apresentada a interface gráfica usada para os testes dos controladores do módulo de pulverização. 


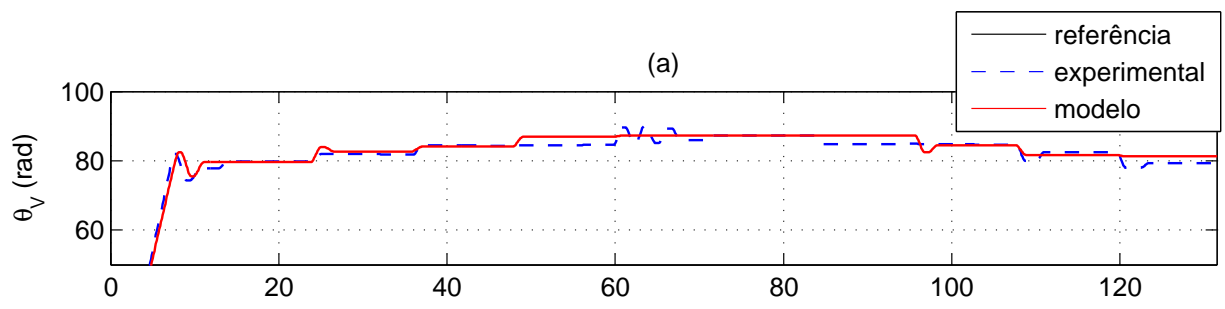

(b)

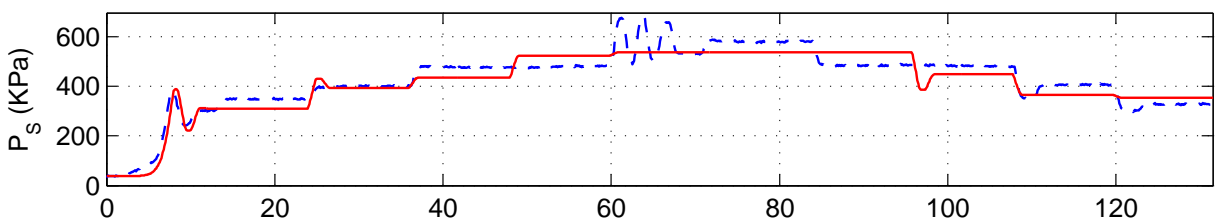

(c)

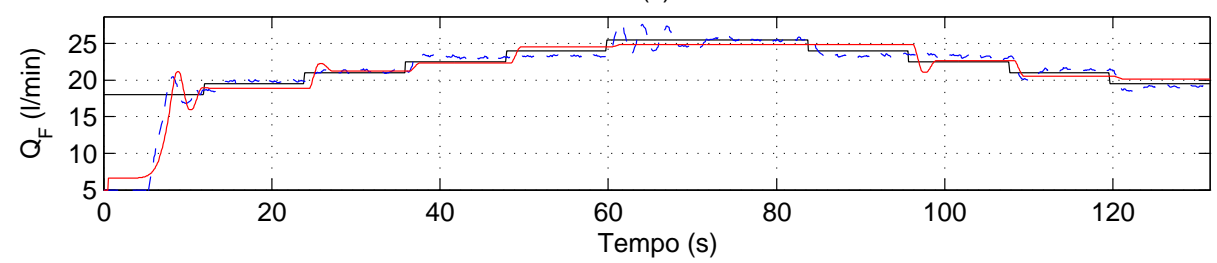

Figura 4.11: Respostas reais e de simulação do módulo de pulverização com controlador proporcional usando a ponta modelo ISO-11004.

(a)

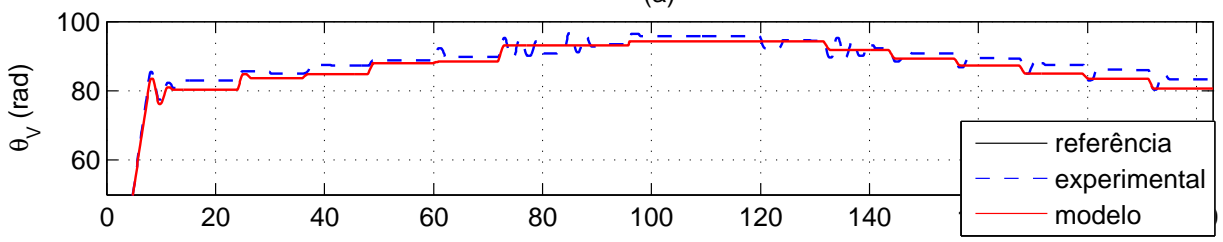

(b)

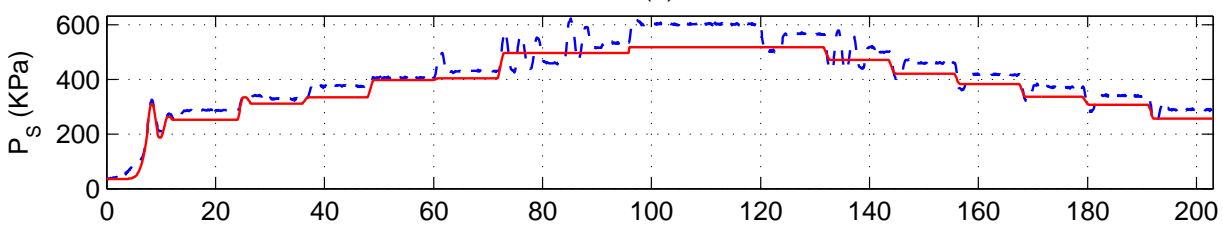

(c)

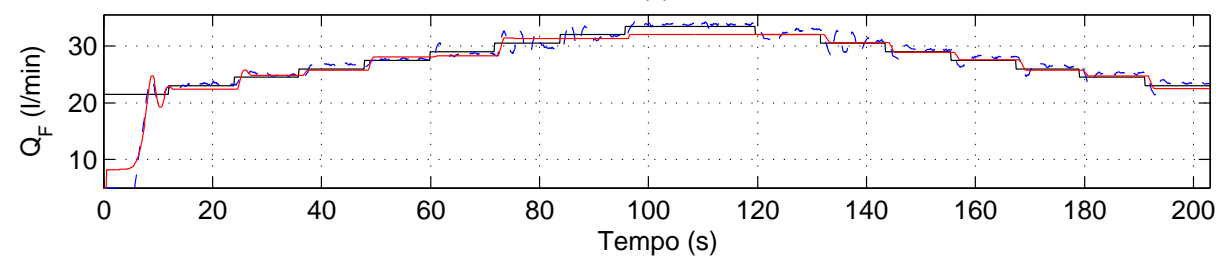

Figura 4.12: Respostas reais e de simulação do módulo de pulverização com controlador proporcional usando a ponta modelo ISO-11005. 


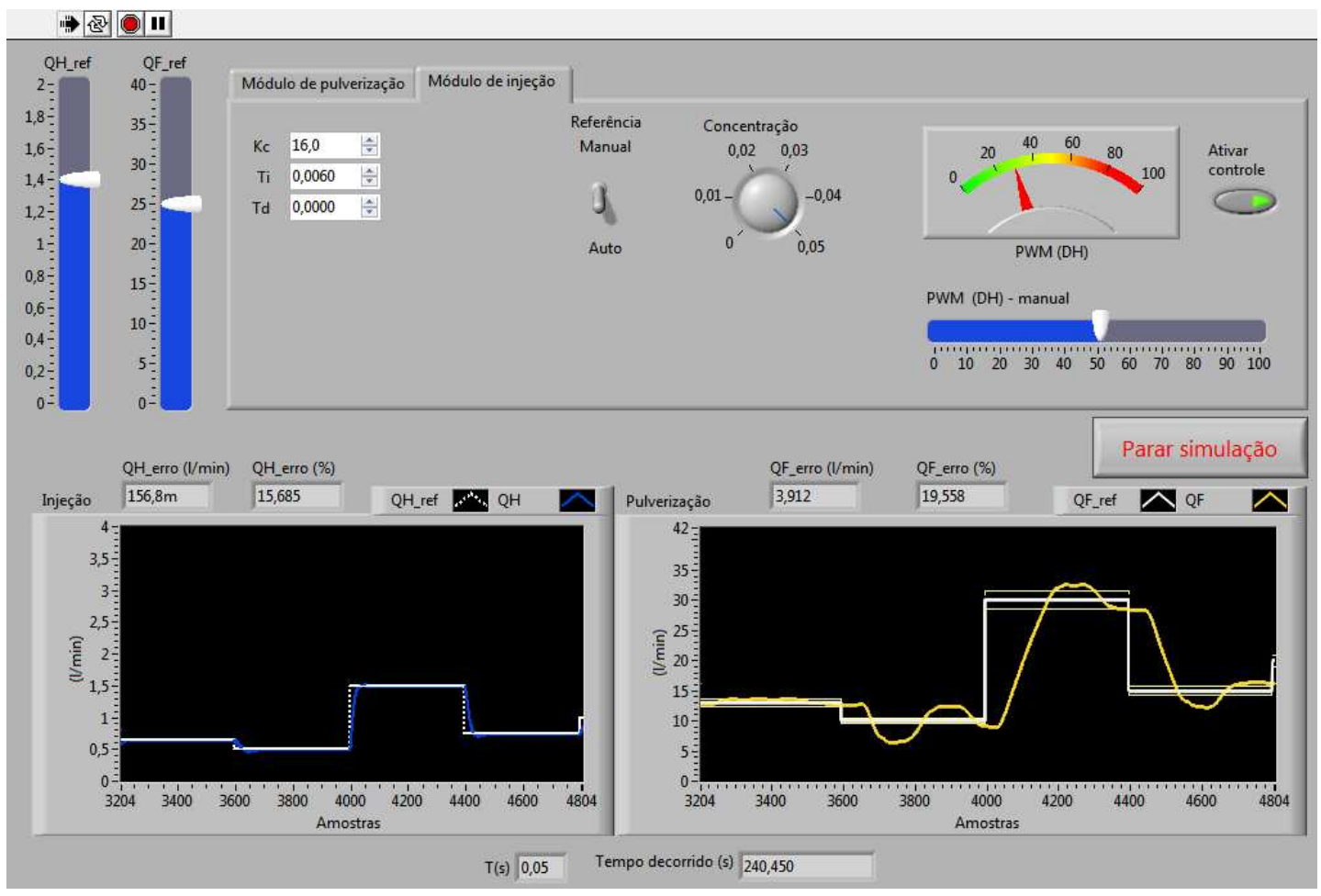

Figura 4.13: Ambiente de simulação mostrando a interface gráfica do controle de vazão do agroquímico.

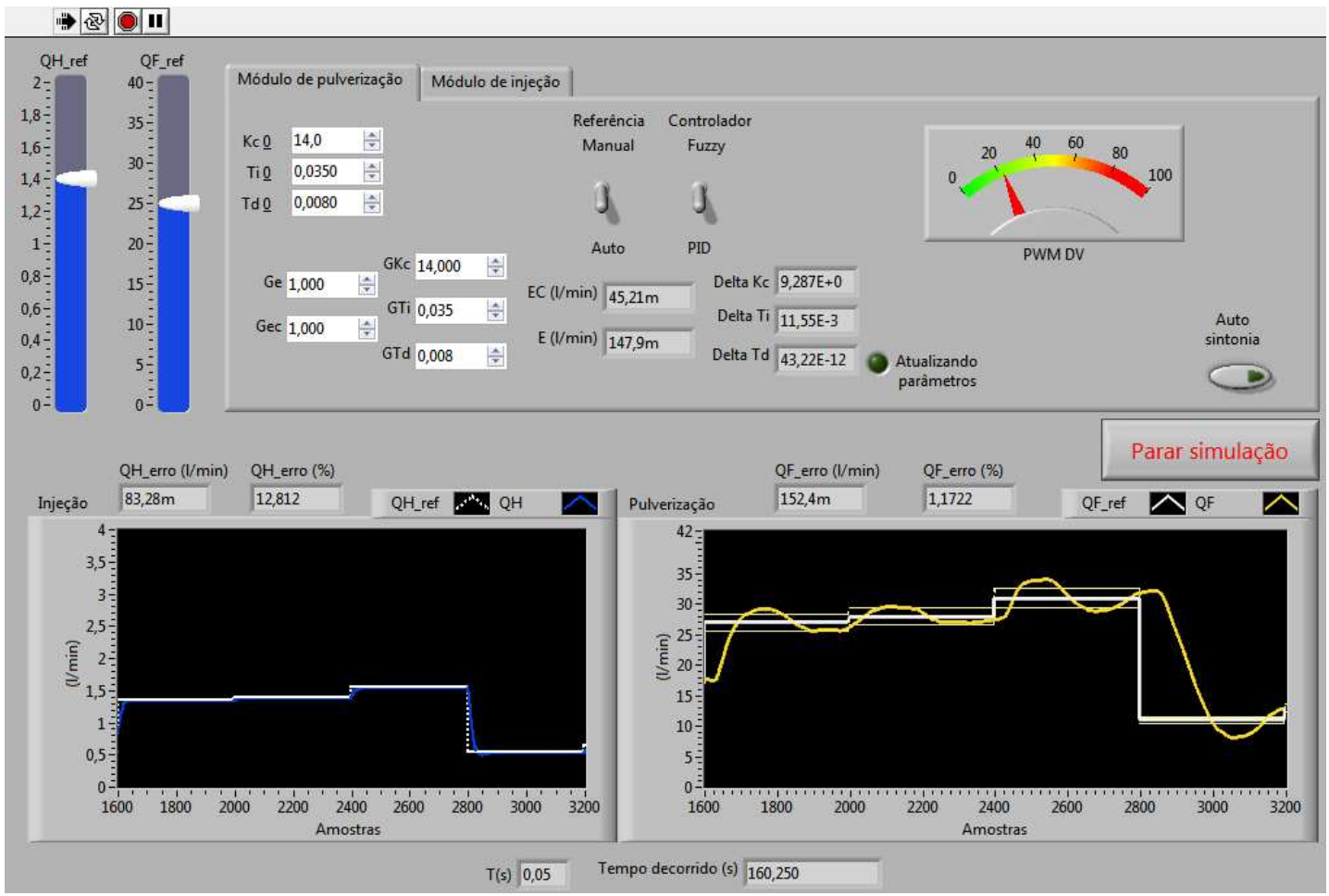

Figura 4.14: Ambiente de simulação mostrando a interface gráfica do controle de vazão da calda. 


\section{Capítulo 5}

\section{Controladores para os Módulos}

Os controladores utilizados em pulverizadores de barra a taxa variável devem apresentar um erro de menor ou igual a 5 por cento entre o valor da taxa real e da ajustada no controlador (ANTUNIASSI; BOLLER, 2011). Isso significa que o controlador deve possuir como característica de desempenho um erro de regime inferior a 5 por cento. Adicionalmente, esse deve apresentar um sobressinal pequeno e alta velocidade de resposta a fim de reduzir o erro de aplicação e o desperdício de agroquímicos. O valor de erro inferior a 5 por cento tem sido adotado como parâmetro de para avaliar o desempenho de controladores eletrônicos em implementos que visam a aplicação a taxa variada desde os primórdios da AP, no entanto, sua influência na eficiência da aplicação ainda não é bem determinada e pode variar dependendo da lavoura e do alvo.

Tendo como objetivo estas características, são implementados dois controladores: um para o módulo de injeção e outros dois para o módulo de pulverização. No módulo de injeção é utilizado um controlador proporcional-integral (PI). Para o módulo de pulverização são implementados e comparados dois controladores: um controlador PID convencional e um controlador adaptativo por escalonamento de ganho, que ajusta os parâmetros do PID através de um sistema fuzzy. Os controladores implementados para funcionamento no sistema de tempo real (RTOS) do PAC cRIO são desenvolvidos com o auxílio da ferramenta PID and Fuzzy Logic Toolkit do LabVIEW (NATIONAL INSTRUMENTS, 2009). 


\subsection{Definição do Período de Amostragem}

A taxa de amostragem, para o controle de um processo, deve ser escolhida de acordo com sua dinâmica. De modo geral o teorema da amostragem de Shannon diz que um sinal com banda limitada descrito no tempo pode ser reconstruído utilizando uma frequência de amostragem $\omega_{A}$, também conhecida por frequência de Nyquist, duas vezes maior que a maior frequência deste sinal.

Baseado no teorema de Shannon a frequência de amostragem $\omega_{A}$ deve satisfazer $\omega_{A}>2 \omega_{y}, \omega_{A}>2 \omega_{w}$ ou $\omega_{A}>2 \omega_{b m f}$, onde $\omega_{y}$ é a maior frequência do sinal medido, $\omega_{w}$ é a maior frequência de um sinal de distúrbio que o sistema de controle do processo em malha fechada deve responder e $\omega_{b m a}$ é a banda passante do sistema de controle do processo em malha fechada. O período de amostragem é dado então por $T=\frac{2 \pi}{\omega_{A}}$.

Na prática, devem ser considerados os efeitos do ruído, da resolução do conversor analógico-digital, das frequências naturais do processo e da perda de informações a fim de garantir a estabilidade e o desempenho da malha de controle. Abordagens empíricas, baseadas em observações experimentais e simulações, sugerem que: (i) seja adotada uma frequência de amostragem no mínimo 8 vezes maior que a banda passante do processo, (ii) o período de amostragem seja $1 / 2$ ou $1 / 3$ do tempo de subida $t_{r}$ para uma resposta ao degrau (HOUPIS; LAMONT, 1992), (iii) o período de amostragem $T$ seja 10 vezes menor que a constante de tempo dominante $\tau_{d}$ na resposta transitória do processo ou (iv) que a frequência de amostragem seja 10 vezes maior que a frequência natural $\omega_{n}$ do processo (LEIGH, 1985). As abordagens citadas são resumidas por:

$$
\begin{aligned}
& \omega_{A}>8 \omega_{b m a} \\
& \omega_{A}>\frac{6 \pi}{t_{r}} \\
& \omega_{A}>\frac{2 \pi}{10 \tau_{d}} \\
& \omega_{A}>10 \omega_{n} .
\end{aligned}
$$

O módulo de injeção, descrito por diagrama de blocos (Figura 4.1), é representado por um modelo linear que apresenta duas frequências naturais em $5,35 \mathrm{rad} / \mathrm{s}$ e $678 \mathrm{rad} / \mathrm{s}$, sendo a primeira referente a parte elétrica e a outra referente a parte mecânica do motor CC do módulo de injeção. Utilizando (5.1d) para obter a frequência de 
amostragem, um período de 117, 4 ms é obtido.

O módulo de pulverização apresenta diversas não linearidades, dificultando a determinação do período de amostragem através do modelo, assim é adotado um critério baseado na resposta experimental (5.1b). Através da resposta ao degrau apresentada na Figura 5.1 o tempo de subida para a faixa de 10 a $90 \%$ é $t_{r}=0,9 \mathrm{~s}$, assim para medir a vazão da calda deve ser utilizado um período de amostragem de no mínimo $300 \mathrm{~ms}$.

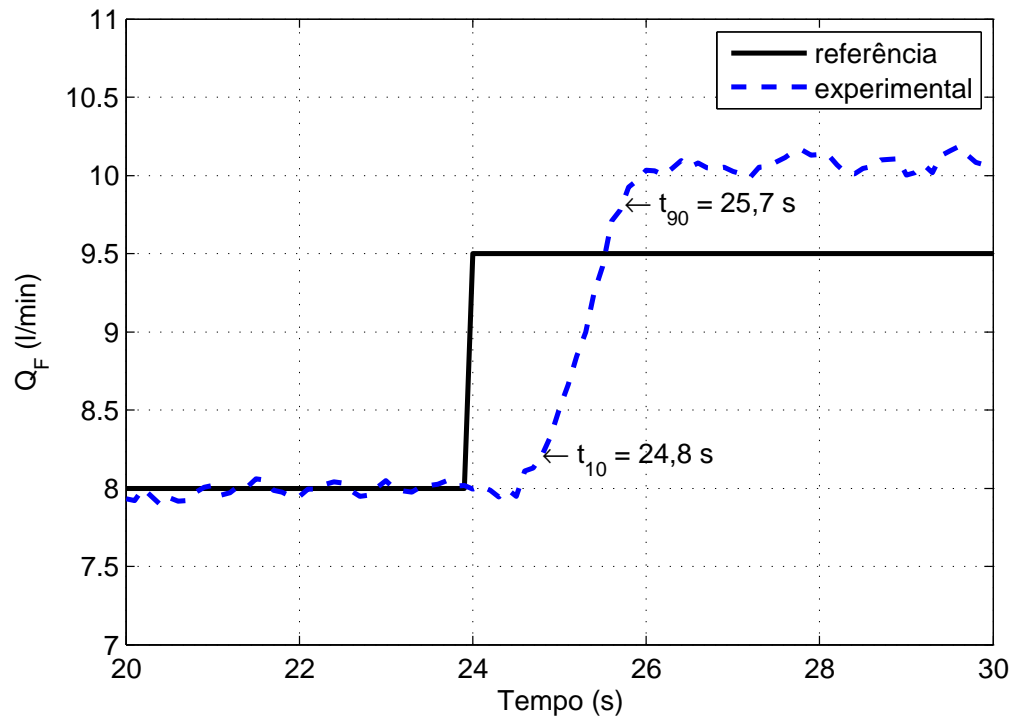

Figura 5.1: Resposta ao degrau do módulo de pulverização com controlador proporcional $\left(K_{C}=20\right)$ usando a ponta modelo ISO-11002.

Para o controle dos módulos do sistema de pulverização com injeção direta deve ser adotado um período de amostragem compatível com as variáveis medidas. Desta forma considerando que estas são: a velocidade angular $\omega_{H}$, no módulo de injeção $(T=117 \mathrm{~ms})$, e a vazão $Q_{F}$, no módulo de pulverização $(T=300 \mathrm{~ms})$ pode-se adotar um período de amostragem igual ou menor que o menor dos períodos obtidos. Assim, neste trabalho é adotado um período de amostragem $T=5010^{-3} \mathrm{~s}$.

\subsection{Controlador PID no LabVIEW}

O controlador PID, que surgiu por volta de 1930, ainda hoje é a solução mais comum para os problemas de controle encontrados na indústria (ASTROM; HAGGLUND, 2006; KATSUHIKO, 2003). A seguir são apresentados o controlador PID e a metodologia de auto-sintonia do PID and Fuzzy Logic Toolkit do LabVIEW. 
Como os controladores são implementados em rotinas determinísticas estes assumem forma discreta. A Figura 5.2 mostra o diagrama de blocos de um sistema de controle a malha fechada. Na figura estão representados a variável do processo $y$, a variável de referência $y_{r e f}$, a variável de controle $u$ e o ruído. Internamente ao controlador PID é utilizada uma base de tempo, nas ações integral e derivativa, dada em minutos:

$$
\Delta T_{P I D}=\frac{T}{60}
$$

onde $T$ é o período de amostragem ou de execução das rotinas de controle em segundos.

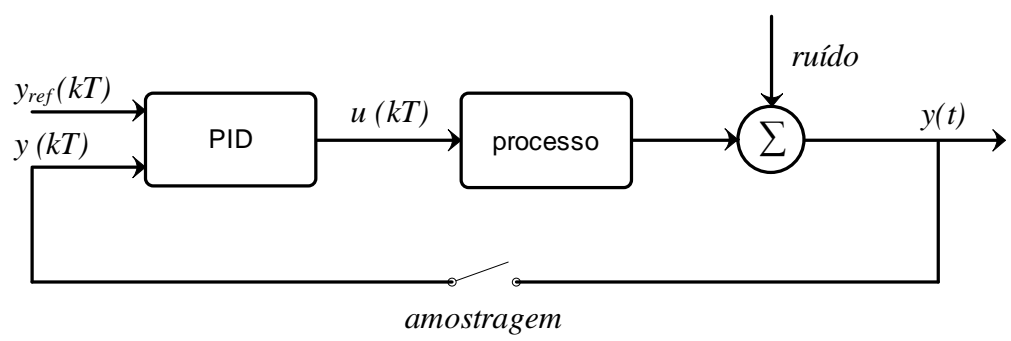

Figura 5.2: Diagrama de blocos de um sistema de controle a malha fechada.

A lei de controle na saída do PID é dada por:

$$
u(k T)=u_{p}(k T)+u_{i}(k T)+u_{d}(k T)
$$

onde $u_{p}(k T), u_{i}(k T)$ e $u_{d}(k T)$ representam respectivamente as ações proporcional, integral e derivativa parcial. O valor do erro $e(k T)$ para as ações proporcional e integral é dado pela diferença entre o valor da variável do processo $y(k T)$ e do valor da referência $y_{\text {ref }}(k T)$ por:

$$
e(k T)=y_{r e f}(k T)-y(k T) .
$$

Ação proporcional: refere-se a uma ação de controle proporcional a diferença entre o valor medido da variável do processo e um valor de referência desejado:

$$
u_{p}(k T)=K_{c} e(k T)
$$

As características do controle proporcional são que um elevado ganho $K_{c}$ leva a malha de controle para a instabilidade e o erro no regime estacionário não é zero. 
Ação integral: refere-se a uma ação de controle proporcional a integral do erro com o objetivo eliminar o erro no regime que ocorre somente com uma ação proporcional. Essa ação é implementada em sua forma discreta através de uma integração trapezoidal:

$$
u_{i}(k T)=\left\{\begin{array}{lll}
\frac{K_{c}}{T_{i}} \sum_{i=1}^{m}\left[\frac{e(i)-e(i-1)}{2}\right] \Delta T_{P I D}, & \text { se } & T_{i}>0 \\
0, & \text { se } & T_{i}=0
\end{array}\right.
$$

onde $T_{i}$ é dado em minutos. As características do controle integral são que quanto maior o tempo integrativo $T_{i}$ mais lento é o efeito da ação integral. No sentido oposto, maior é a velocidade de resposta e o sobressinal, o que leva a instabilidade na malha de controle.

Ação derivativa parcial: refere-se a uma ação de controle proporcional a diferença entre o erro atual e o erro anterior. Na prática a ação derivativa é implementada baseada na variável do processo $y(k T)$, evitando o efeito exagerado dessa ação de controle quando ocorrem mudanças abruptas na referência $y_{r e f}(k T)$. Essa ação derivativa parcial é dada por:

$$
u_{d}(k T)=-K_{c} \frac{T_{d}}{\Delta T_{P I D}}[y(k T)-y(k T-T)]
$$

onde $T_{d}$ é dado em minutos.

A ação derivativa pode ser interpretada com um preditor, devido a sua capacidade de gerar um sinal de controle proporcional a estimativa do erro no instante $T_{d}$ á frente do tempo atual. O objetivo da ação derivativa é melhorar a estabilidade em malha fechada, e quando combinada com as ações integral e proporcional esta possui como características a diminuição do sobressinal e o aumento da velocidade de resposta.

Características de implementação: o controlador PID do LabVIEW pode atuar como proporcional (P) se $T_{i}$ e $T_{d}$ são zero, como proporcional-integral (PI) se $T_{d}$ é zero ou como proporcional-derivativo $(\mathrm{PD})$ se $T_{i}$ é zero. A saída $u(k T)$ é limitada e seus 
limites são dados conforme a regra:

$$
u(k T)=\left\{\begin{array}{lll}
u_{\max }, & \text { se } & u(k T) \geq u_{\max } \\
u_{\min }, & \text { se } & u(k T) \leq u_{\min }
\end{array}\right.
$$

e os valores padrão são $u_{\min }=-100$ e $u_{\max }=100$.

Outra característica importante, não descrita no manual, é a reinicialização do integrador. A cada execução da rotina de controle é avaliado se houve alteração nos parâmetros do controlador, e caso afirmativo a ação integral retorna a zero, ou seja $u_{i}(k T)=0$.

\subsection{Auto-sintonia do PID no LabVIEW}

A auto-sintonia é uma metodologia onde o controlador é sintonizado automaticamente quando solicitado pelo usuário. Essas metodologias combinam métodos de determinação da dinâmica do processo e cálculo dos parâmetros do controlador. De modo geral elas envolvem a geração de um distúrbio no processo, a avaliação desse distúrbio e o cálculo dos parâmetros do controlador (ASTROM; HAGGLUND, 2006).

A técnica de auto-sintonia através de realimentação chaveada ${ }^{1}$ baseia-se na aplicação de um distúrbio na forma de uma onda quadrada na malha de controle, o que para muitos processos, devido a características não lineares, pode gerar um ciclo limite (ASTROM; HAGGLUND, 2006). A Figura 5.3 mostra o comportamento típico de um processo submetido a realimentação chaveada.

O método de auto-sintonia utilizado pela National Instruments é baseado na técnica de realimentação chaveada, proposta por Astrom e Hagglund (1984). A diferença entre as técnicas está no modo como a função de chaveamento é inserida na malha de controle. Enquanto no método de Åström o controlador que será sintonizado é substituído pela função de chaveamento (Figura 5.4), na metodologia da National o controlador continua na malha de controle (Figura 5.5).

O procedimento de auto-sintonia utilizado no PID auto-tune do LabVIEW, extraídos da patente (LUO; QIN; CHEN, , US 6081751), é composto pelas etapas mostradas

\footnotetext{
${ }^{1}$ em inglês: Relay Feedback
} 


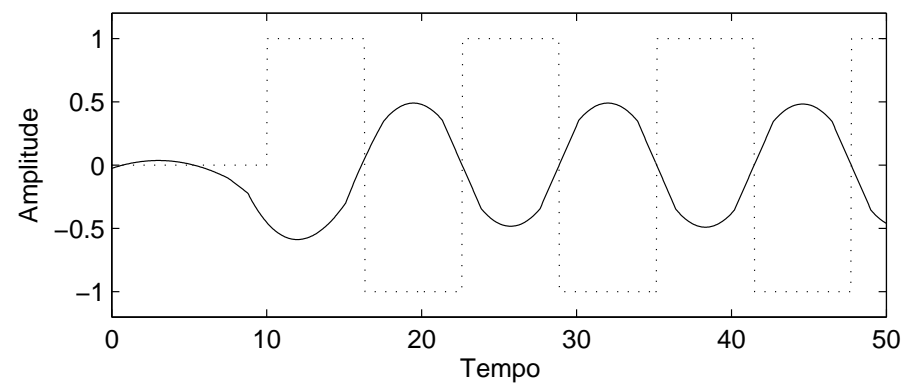

Figura 5.3: Função de chaveamento $u$ (linha pontilhada) e saída típica do processo y (linha sólida).

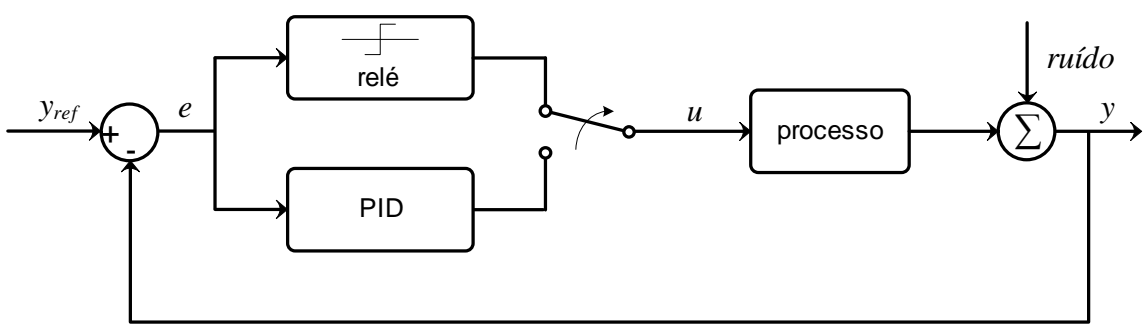

Figura 5.4: Malha de controle com a função de chaveamento no erro.

abaixo.

1. Implementação de um controlador estável, mesmo que mal sintonizado, do tipo P, PI ou PID.

2. Execução do sistema controle.

3. Início do procedimento de auto-sintonia.

4. Aplicação da função de chaveamento (chave na posição 2).

5. Inicio da oscilação sustentada.

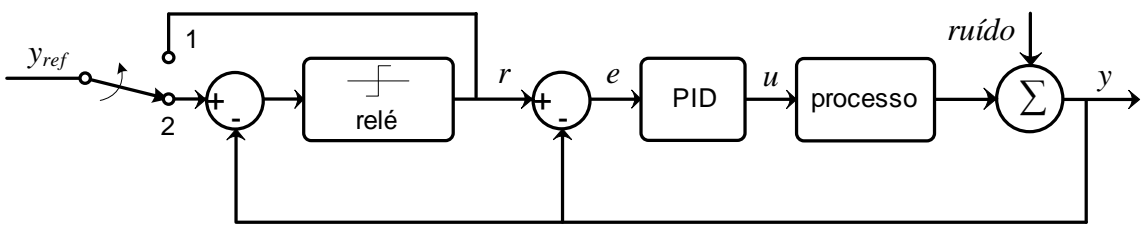

Figura 5.5: Malha de controle com a função de chaveamento na referência. 
6. Medidas do período e da amplitude da oscilação.

7. Cálculo dos novos parâmetros para o controlador.

8. Desacoplamento da função de chaveamento (chave na posição 1).

9. Validação, pelo usuário, dos novos parâmetros.

No início do procedimento de auto-sintonia, etapa 3, as seguintes operações são executadas pelo usuário:

- Escolher a amplitude do chaveamento $d$;

- Escolher quantas médias serão feitas;

- Selecionar o tipo do controlador desejado: (entre as opções P, PI ou PID);

- Selecionar a performance desejada: fast (coeficiente de amortecimento $\zeta=1 / 4$ ), normal (algum sobressinal) ou slow (sobressinal pequeno);

- Adicionalmente, pode ser estimado o ruído $n$ do processo.

A função de chaveamento é modelada como um ganho $K r$, assim o erro e na entrada do controlador, durante o experimento de chaveamento (chave na posição 2), é dado por:

$$
e=K r\left(y_{r e f}-y\right)-y
$$

O objetivo do experimento de chaveamento é determinar a frequência onde a entrada $u$ e a saída $y$, do processo tem fases opostas. Isto é feito na etapa 6 , onde é medido o período $T_{180}$ e a amplitude $a$ onde a variável de saída do processo $y$. A frequência de oscilação e o ganho do processo são calculados respectivamente por:

$$
\begin{aligned}
\omega_{180} & =\frac{2 \pi}{T_{180}} \\
K r_{180} & =\frac{\pi a}{4 d}
\end{aligned}
$$

onde $d$ é a amplitude da função de chaveamento.

Para um controlador existente do tipo $\mathrm{P}$, com ganho $K_{c}$, o processo de auto-sintonia 
identifica o ganho crítico $K_{u}$ e o período da oscilação $T_{u}$ :

$$
\begin{aligned}
K_{u} & =K_{c}\left(1+K r_{180}\right) \\
T_{u} & =T_{180} .
\end{aligned}
$$

Nesse caso, o cálculo dos parâmetros do controlador é baseado nas fórmulas de sintonia de Ziegler-Nichols apresentadas na Tabela 5.1(NATIONAL InSTRUMENTS, 2009).

Tabela 5.1: Fórmulas de sintonia quando o controlador é do tipo $\mathrm{P}$.

\begin{tabular}{lccc}
\hline $\begin{array}{l}\text { Controlador } \\
\text { desejado }\end{array}$ & $K_{c}$ & $T_{i}$ & $T_{d}$ \\
\hline fast & & & \\
\hline $\mathrm{P}$ & $0,50 K_{u}$ & - & - \\
$\mathrm{PI}$ & $0,40 K_{u}$ & $0,80 T_{u}$ & - \\
$\mathrm{PID}$ & $0,60 K_{u}$ & $0,50 T_{u}$ & $0,12 T_{u}$ \\
\hline normal & \multicolumn{5}{c}{} \\
\hline $\mathrm{P}$ & $0,20 K_{u}$ & - & - \\
$\mathrm{PI}$ & $0,18 K_{u}$ & $0,80 T_{u}$ & - \\
$\mathrm{PID}$ & $0,25 K_{u}$ & $0,50 T_{u}$ & $0,12 T_{u}$ \\
\hline slow & & & \\
\hline $\mathrm{P}$ & $0,13 K_{u}$ & - & - \\
$\mathrm{PI}$ & $0,13 K_{u}$ & $0,80 T_{u}$ & - \\
$\mathrm{PID}$ & $0,15 K_{u}$ & $0,50 T_{u}$ & $0,12 T_{u}$ \\
\hline & & &
\end{tabular}

Para um controlador existente do tipo PI ou PID, representado por:

$$
G_{c}(s)=K_{c}\left(1+\frac{1}{T_{i} s}\right)\left(\frac{T_{d} s+1}{\alpha T_{d} s+1}\right)
$$

onde $\alpha$ é um fator de ganho derivativo, o algoritmo de auto-sintonia identifica o os parâmetros do modelo:

$$
G_{p}(s)=\frac{e^{-\tau s}}{T_{p} s}
$$

sendo $\tau$ o tempo morto e $T_{p}$ a constante de tempo.

Quando é obtida a oscilação sustentada na malha de controle valem as seguintes relações:

$$
\begin{aligned}
\arg \left[(1+K r) G p\left(j \omega_{180}\right) G c\left(j \omega_{180}\right)\right] & =-\pi \\
\left|(1+K r) G p\left(j \omega_{180}\right) G c\left(j \omega_{180}\right)\right| & =1 .
\end{aligned}
$$


A partir de (5.15) e (5.16) são calculados o tempo morto e a constante de tempo, respectivamente por:

$$
\begin{aligned}
\tau & =\frac{\tan ^{-1}\left(T_{i} \omega_{180}\right)+\tan ^{-1}\left(T_{d} \omega_{180}\right)-\tan ^{-1}\left(\alpha T_{d} \omega_{180}\right)}{\omega_{180}} \\
T_{p} & =\frac{(1+K r) K_{c} \sqrt{T_{i}^{2} \omega_{180}^{2}+1} \sqrt{T_{d}^{2} \omega_{180}^{2}+1}}{T_{i} \omega_{180}^{2} \sqrt{\alpha^{2} T_{d}^{2} \omega_{180}^{2}+1}} .
\end{aligned}
$$

Nesse caso, o cálculo dos parâmetros do controlador é baseado nas fórmulas de sintonia de Ziegler-Nichols apresentadas na Tabela 5.2 (NATIONAL InSTRUMENTS, 2009).

Tabela 5.2: Fórmulas de sintonia quando o controlador é do tipo PI ou PID.

\begin{tabular}{lccc}
\hline $\begin{array}{l}\text { Controlador } \\
\text { desejado }\end{array}$ & $K_{c}$ & $T_{i}$ & $T_{d}$ \\
\hline fast & & & \\
\hline $\mathrm{P}$ & $1,00 T_{p} / \tau$ & - & - \\
$\mathrm{PI}$ & $0,90 T_{p} / \tau$ & $3,33 \tau$ & - \\
$\mathrm{PID}$ & $1,10 T_{p} / \tau$ & $2,00 \tau$ & $0,50 \tau$ \\
\hline normal & & & \\
\hline $\mathrm{P}$ & $0,44 T_{p} / \tau$ & - & - \\
$\mathrm{PI}$ & $0,40 T_{p} / \tau$ & $5,33 \tau$ & - \\
$\mathrm{PID}$ & $0,53 T_{p} / \tau$ & $4,00 \tau$ & $0,80 \tau$ \\
\hline slow & & & \\
\hline $\mathrm{P}$ & $0,26 T_{p} / \tau$ & - & - \\
$\mathrm{PI}$ & $0,24 T_{p} / \tau$ & $5,33 \tau$ & - \\
$\mathrm{PID}$ & $0,32 T_{p} / \tau$ & $4,00 \tau$ & $0,80 \tau$ \\
\hline
\end{tabular}

\subsection{Controladores Fuzzy no LabVIEW}

Esta seção é em sua maior parte baseada na referência National Instruments (2009), com o auxílio das referências Pedrycz e Gomide (2007), Ross (2005), Jantzen (2007). O PID and Fuzzy Logic Toolkit inclui a ferramenta Fuzzy System Designer para o desenvolvimento de controladores fuzzy do tipo Mamdani, composto pelas etapas de fuzzificação, de inferência baseada em regras linguísticas e de defuzzificação, cujo os relacionamentos são apresentados na Figura 5.6. É usado um exemplo hipotético, adaptado de Silva (17 ago. 2009, 04 dez. 2009), para descrever um controlador fuzzy.

Exemplo: A pressão de uma caldeira é regulada manualmente por um operador que atua em uma válvula de alívio $A b$. Considere o problema de regular a pressão interna dessa caldeira de modo automático e sem a medição direta da pressão. São 
conhecidos a temperatura $T$ e o volume de água $V$ dentro da caldeira.

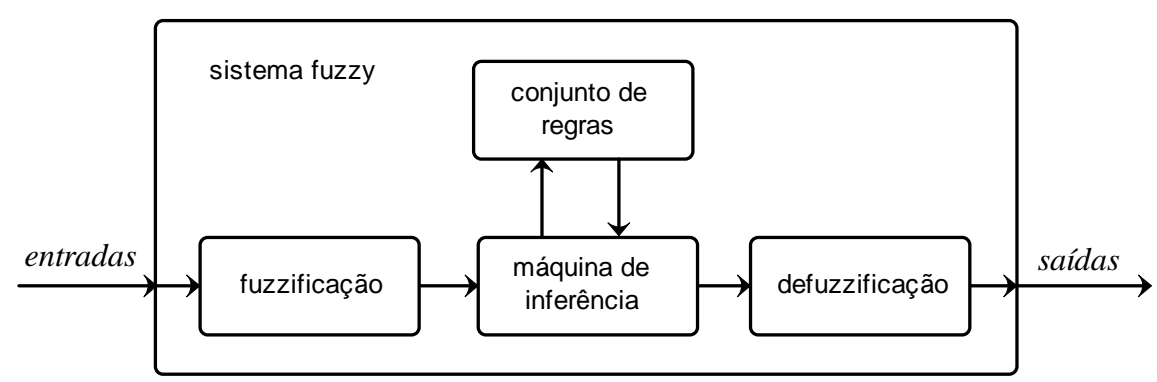

Figura 5.6: Componentes de um sistema de inferência fuzzy do tipo Mamdani.

Fuzzificação: é o processo usado para a transformação de um sinal ou valor pontual em termos da linguagem natural, isto é, em termos linguísticos. Uma variável linguística é uma variável cujos valores são nomes de conjuntos fuzzy (termos linguísticos ou termos fuzzy). O intervalo onde os termos fuzzy são definidos é o universo de discurso, representado aqui pela letra $\mathcal{U}$.

A função que define o grau de pertinência das variáveis linguísticas é a função de pertinência, representada aqui pela letra $\mu \in(0,1)$, e que neste trabalho foram usadas as dos tipos:

$$
\begin{aligned}
& \text { triangular } \quad \Lambda_{\wedge}(x ; a ; m ; b)=\left\{\begin{array}{lll}
0, & \text { se } & x \leq a \\
\left(\frac{x-a}{m-a}\right), & \text { se } & x \in[a, m] \\
\left(\frac{b-x}{b-m}\right), & \text { se } & x \in[m, b] \\
0, & \text { se } & x \geq b
\end{array}\right. \\
& \mu_{\Pi}(x ; a ; m ; n ; b)= \begin{cases}0, & \text { se } \quad x \leq a \\
\left(\frac{x-a}{m-a}\right), & \text { se } \quad x \in[a, m] \\
1, & \text { se } \quad x \in[m, n] \\
\left(\frac{b-x}{b-m}\right), & \text { se } \quad x \in[n, b] \\
0, & \text { se } \quad x \geq b\end{cases}
\end{aligned}
$$


onde $x$ é o valor pontual que será transformado no termo fuzzy e $a, m, n$ e $b$ são parâmetros das funções de pertinência. A Figura 5.7 ilustra a etapa de fuzzificação a partir de termos linguísticos através de funções de pertinência.

Exemplo (fuzzificação): Voltando ao exemplo, a Figura 5.7 mostra as entradas e a saída do sistema da caldeira. As variáveis são definidas por três funções de pertinência do tipo triangular ou trapezoidal, onde $\mathcal{U}_{T}=[100 ; 500], \mathcal{U}_{V}=[2 ; 10]$ e $\mathcal{U}_{A b}=[33 ; 100]$ são o universo de discurso da temperatura, do volume e da abertura da válvula de alívio, respectivamente.
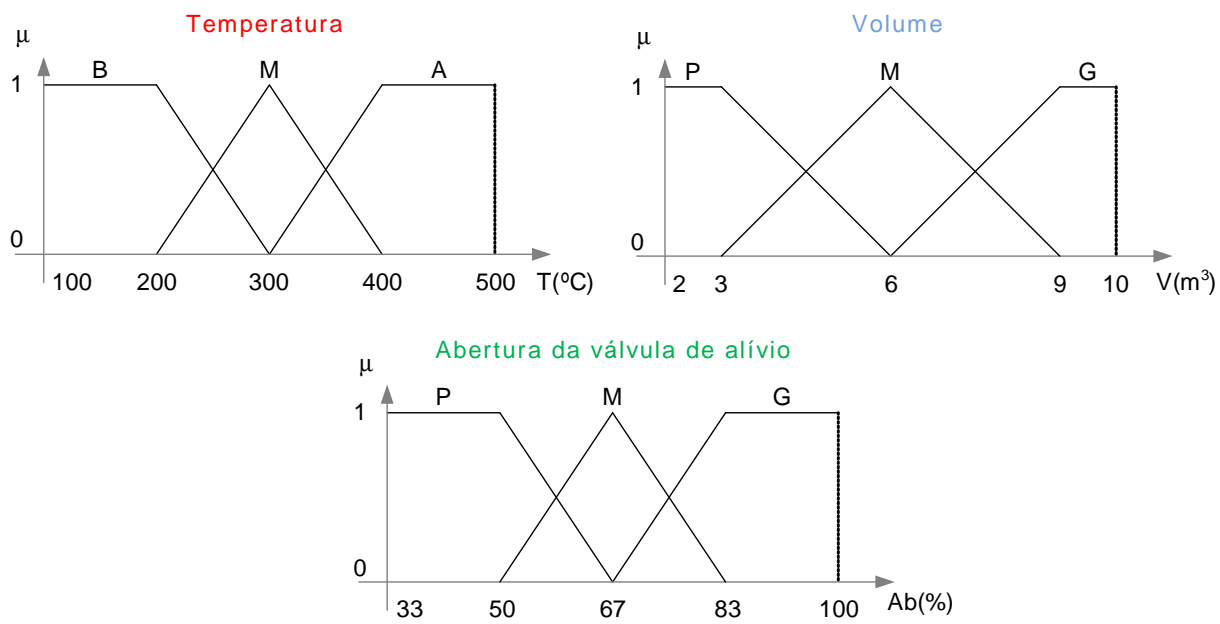

Figura 5.7: Exemplo: definições das funções de pertinência sendo $\mathrm{B}=$ baixa, $\mathrm{M}=$ média, $\mathrm{A}=$ alta, $\mathrm{P}=$ pequena, e $\mathrm{G}=$ grande.

Sejam os valores pontuais de entrada $450^{\circ} \mathrm{C}$ e $4 \mathrm{~m}^{3}$. A Figura 5.10 mostra que esse valor de temperatura possui um grau de pertinência 1 com o termo alta e zero com outros termos da variável temperatura, bem como o valor do volume possui diferentes graus de pertinência com os termos pequeno e médio.

Máquina de inferência e regras: são responsáveis pela inteligência artificial do controlador fuzzy. O mecanismo de inferência envolve o mapeamento do conhecimento sobre um determinado processo mediante um conjunto de regras do tipo "se (condição) então (ação)" para se obter um região fuzzy de saída. Para isso a máquina de inferência verifica quais os termos fuzzy estão ativos nas variáveis de entrada, encontra quais as regras ativadas por esses termos, determina quais os termos fuzzy serão ativados em cada variável de saída e agrega esses termos fuzzy para formar uma região de saída 


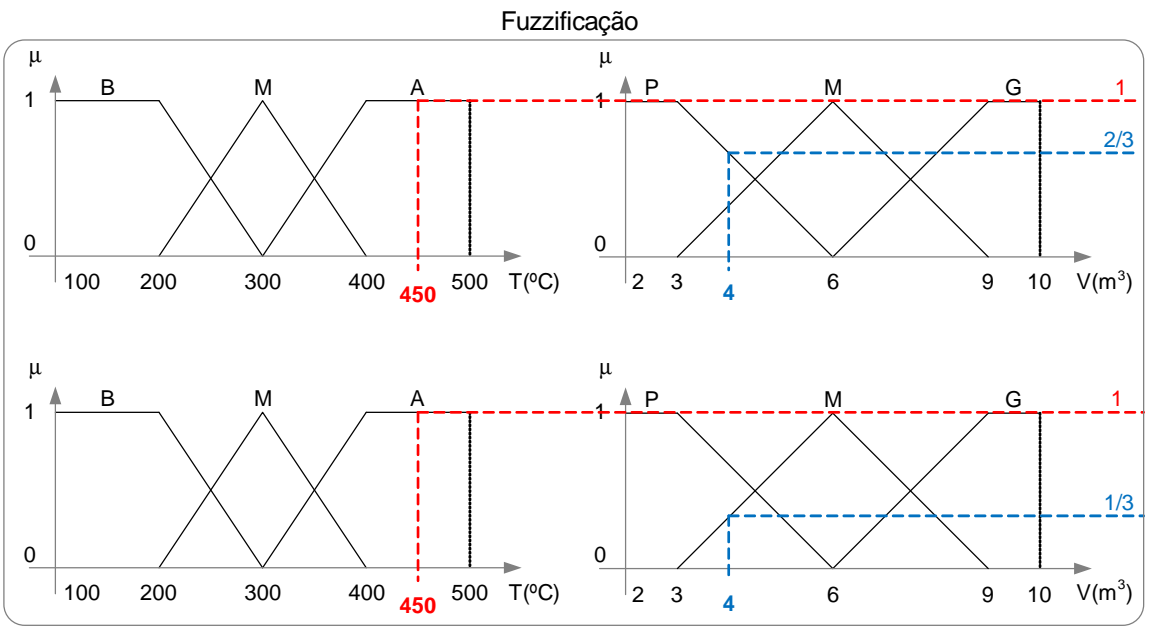

Figura 5.8: Exemplo: fuzzificação das variáveis de entrada.

para cada variável. Nesse processo o conjunto de regras descreve as relações entre as variáveis de entrada e saída baseado na linguagem natural.

Se uma regra tem mais de uma condição para descrever a relação das variáveis de entrada e saída são usados conectivos para compor o relacionamento lógico entre os termos das variáveis. Esses conectivos de composição são definidos por meio de operadores de intersecção ou união. Neste trabalho foi usado o conectivo de união:

$$
A N D(\text { Minimum }) \quad \mu A \cdot B=\min (\mu A, \mu B)
$$

onde A e B representam as variáveis de entrada.

Para cada regra ativada, pelos termos fuzzy de entrada, existe uma relação de implicação nos termos das variáveis de saída. A relação de implicação do tipo Minimum disponível no LabVIEW trunca o valor das funções de pertinência das variáveis de saída de acordo com o grau de ativação das regras pelas variáveis de entrada. Ao final do processo de inferência as funções de pertinência ativadas são agregadas através de um operador de união tipo máximo para formar a região fuzzy de saída.

Exemplo (máquina de inferência e regras): Voltando ao exemplo, o conhecimento do operador é modelado através de regras do tipo:

Se Temperatura é Alta e Volume é Pequeno então Abertura é Média;

Se Temperatura é Alta e Volume é Médio então Abertura é Grande. 
As regras obtidas a partir do conhecimento do operador, são representadas na Tabela 5.3. Para os valores escolhidos de temperatura e pressão são ativadas duas regras, destacadas em negrito na Tabela 5.3.

Tabela 5.3: Exemplo: base de regras para abertura da válvula de alívio.

\begin{tabular}{c|ccc}
\hline Volume & Pequeno & Médio & Grande \\
\hline Baixa & Pequena & Pequena & Média \\
Média & Pequena & Média & Grande \\
Alta & Média & Grande & Grande \\
\hline
\end{tabular}

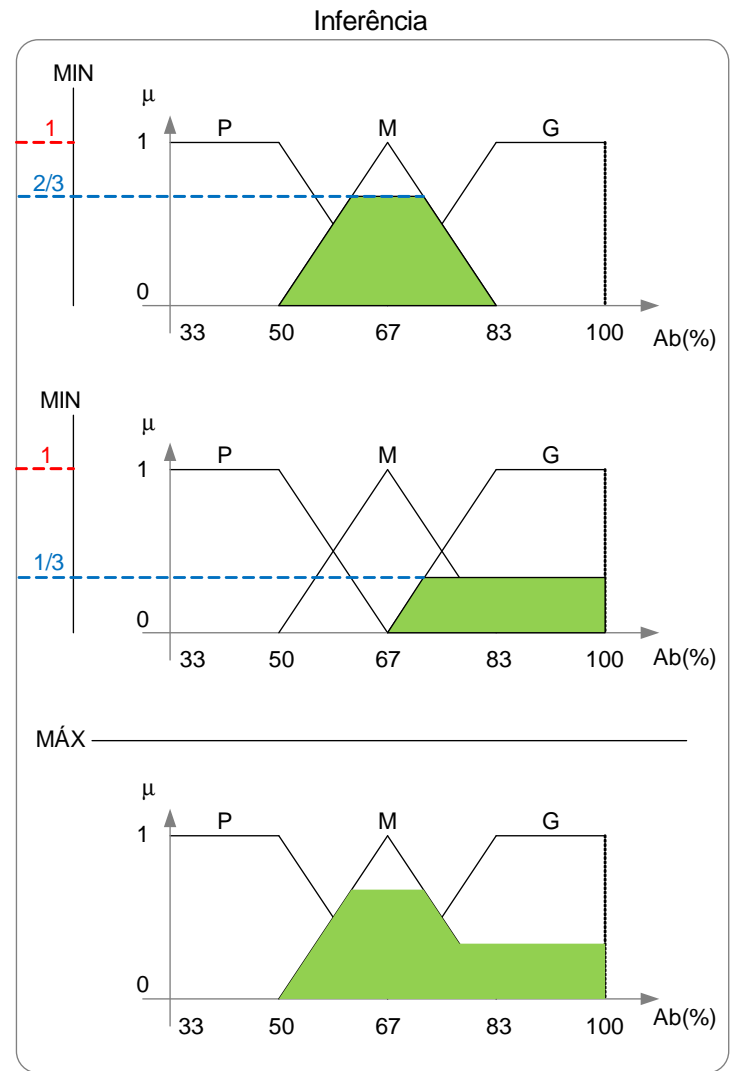

Figura 5.9: Exemplo: inferência da região fuzzy de saída através das funções MAX-MIN.

O grau de ativação de cada regra depende do relacionamento entre as variáveis de entrada, no caso é usado o conectivo e, assim a implicação na variável de saída pode ser dada por uma operação de mínimo (MIN), ou seja, o menor grau de pertinência será o grau de ativação da variável de saída. Esta operação é apresentada na Figura 5.9, onde verifica-se que cada regra ativada produz uma região fuzzy de saída (em verde). As regiões fuzzy de saída são agregadas por um operador de máximo (MAX) pra produzir 
uma única região fuzzy de saída.

Defuzzificação: é o processo pelo qual a região fuzzy de saída é transformada em um valor pontual, que é a saída do controlador fuzzy. Neste trabalho foi usado como método de defuzzificação o centro de área (CoA):

$$
C o A=\frac{\int_{\mathcal{U}_{\min }}^{\mathcal{U}_{\max }} \mu^{\prime}(x) x \mathrm{~d} x}{\int_{\operatorname{Uax}}^{\mathcal{U}_{\max }} \mu^{\prime}(x) \mathrm{d} x}
$$

onde $x$ é o valor da variável linguística, $\mathcal{U}_{\text {min }}$ e $\mathcal{U}_{\text {max }}$ representam respectivamente o início e final o universo de discurso da região de saída, composto das funções de pertinência ativadas na variável de saída, e $\mu^{\prime}(x)$ é o grau de pertinência em $x$ truncado pelo grau de ativação da regra.

Exemplo (defuzzificação): Voltando ao exemplo, uma vez que tem-se a região fuzzy de saída é necessário aplicar uma operação para se obter o valor de saída do controlador, esta operação de defuzzificação é realizada por estimadores fuzzy. Utilizando o centro de área pode-se obter este valor, cujo resultado é apresentado na Figura 5.10 .

Defuzzificação

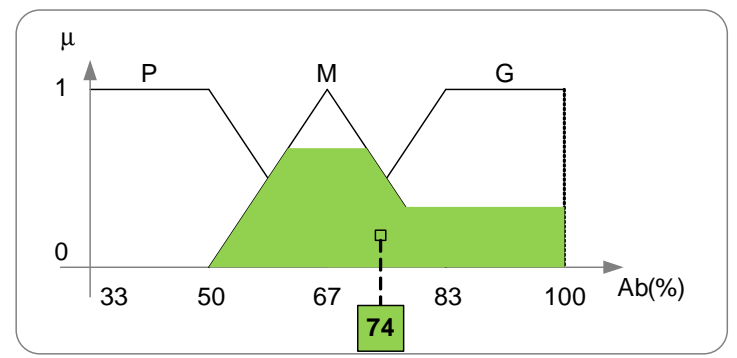

Figura 5.10: Exemplo: defuzzificação da variável de saída. 


\subsection{Controlador PI do Módulo de Injeção}

Para o módulo de injeção usando a técnica de realimentação chaveada e com ajuste manual (LI; ANG; CHONG, 2006) foi projetado um controlador PI. Inicialmente foi implementado um controlador proporcional com ganho $K_{c}=200$, e utilizando a técnica de realimentação chaveada com uma amplitude de chaveamento de 0,25 a fim de se obter um controlador com PI normal, cujos parâmetros resultantes foram $K c=96 \mathrm{e}$ $T_{i}=1,0410^{-2} \min$. A partir dos valores iniciais obtidos por auto-sintonia, foi feito o ajuste manual dos parâmetros e assim foram obtidos os valores dos parâmetros para o controlador PI do módulo de injeção $K c=16$ e $T_{i}=610^{-3} \mathrm{~min}$. Os resultados experimentais da implementação desse controlador são mostrados no próximo capítulo.

\subsection{Controladores do Módulo de Pulverização}

Devido as características do módulo de pulverização, apesar de ter sido implementado um sistema supervisório para evitar que ocorram acidentes devido ao excesso de pressão, é preferível o desenvolvimento dos controladores em um ambiente de simulação. Para isso foi usado o ambiente de simulação apresentado no capítulo anterior.

\subsubsection{Controlador PID}

Para o módulo de pulverização usando a técnica de realimentação chaveada e com ajuste manual (LI; ANG; CHONG, 2006) foi projetado um controlador PID. Inicialmente foi implementado um controlador proporcional com ganho $K_{c}=20$, e utilizando a técnica de realimentação chaveada para com amplitude de chaveamento de 0,8 a fim de se obter um controlador PID normal para as vazões de 15, 20 e $25 \ell / \mathrm{min}$. A Tabela 5.4 mostra os parâmetros obtidos na simulação. A partir dos valores iniciais obtidos por auto-sintonia, foi feito o ajuste manual dos parâmetros e assim foram obtidos os valores dos parâmetros $K_{c 0}=14, T_{i 0}=3,510^{-2} \min$ e $T_{d 0}=810^{-3} \min$ para o controlador PID do módulo de pulverização. Os resultados experimentais da implementação desse controlador são mostrados no próximo capítulo. 
Tabela 5.4: Parâmetros do PID obtidos por auto-sintonia do modelo do módulo de pulverização.

\begin{tabular}{clll}
\hline Vazão $(\ell /$ min $)$ & $K_{c}$ & $T_{i}($ min $)$ & $T_{d}($ min $)$ \\
\hline \multicolumn{4}{l}{ PID normal } \\
\hline 15 & 8,89 & 0,15 & $3,610^{-2}$ \\
20 & 7,33 & $6,0010^{-2}$ & 0,15 \\
25 & 7,26 & $6,0010^{-2}$ & $1,5010^{-2}$ \\
\hline
\end{tabular}

\subsubsection{Controlador PID Fuzzy Adaptativo por Escalonamento de Ganho}

Devido as características não lineares como a zona morta e a variação de parâmetros no tempo devido a curva da resistência hidráulica da válvula de controle VP1, o módulo de pulverização mostra-se promissor com relação a melhora de desempenho da malha de controle, assim é proposto o uso de um PID fuzzy adaptativo por escalonamento de ganho. O controlador implementado é apresentado no diagrama em blocos da Figura 5.11 .

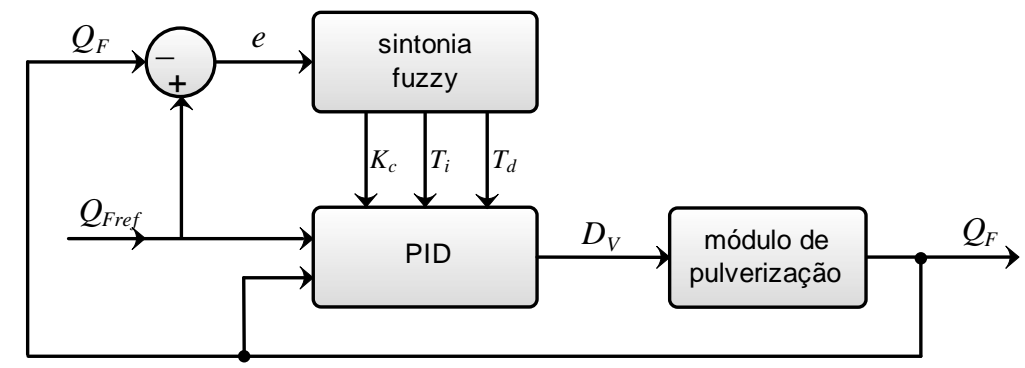

Figura 5.11: Diagrama em blocos do controlador PID fuzzy adaptativo implementado.

O bloco de sintonia fuzzy, composto por quatro estágios detalhados na Figura 5.12, tem como objetivo ajustar os valores dos parâmetros do controlador PID para melhorar o desempenho da malha de controle. A escolha dos estágios 1 a 3 seguem as propostas apresentadas por Pu e Zhang (2009), Bae et al. (2011), Liang, Jin e Liang (2008).

Estágio 1: é o estágio de entrada, responsável por ajustar os valores de entrada para o sistema fuzzy. Nesse estágio são calculados o erro $E$ e a variação do erro $E C$, variáveis de entrada do sistema fuzzy, como segue:

$$
\begin{aligned}
E & =G_{E}\left(Q_{F r e f}-Q_{F}\right) & & =G_{E} e(k T) \\
E C & =G_{E C} \frac{e(k T)-e(k T-T)}{T} & & =G_{E C} \Delta e(k T)
\end{aligned}
$$




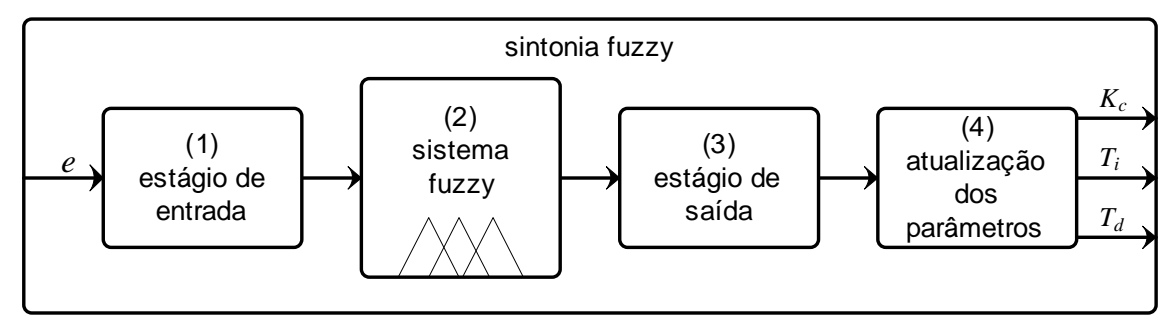

Figura 5.12: Diagrama em blocos do sistema de sintonia fuzzy.

onde $G_{E}$ e $G_{E C}$ são as constantes de ganho e $T=50 \mathrm{~ms}$ é o período de amostragem.

Estágio 2: é o estágio onde ocorre a inferência para a sintonia do parâmetros. O sistema fuzzy é implementado com duas entradas e três saídas conforme ilustrado na Figura 5.13. A cada iteração são calculados os valores das saídas $d K_{c}, d T_{i}$ e $d T_{d}$ baseado no erro $E$ e sua variação $E C$, como. Cada variável, de entrada ou saída, é representada por um conjunto fuzzy composto por sete termos linguísticos: negativo grande (NB), negativo médio (NM), negativo pequeno (NS), zero (ZO), positivo pequeno (PS), positivo médio $(\mathrm{PM})$ e positivo grande $(\mathrm{PB})$.

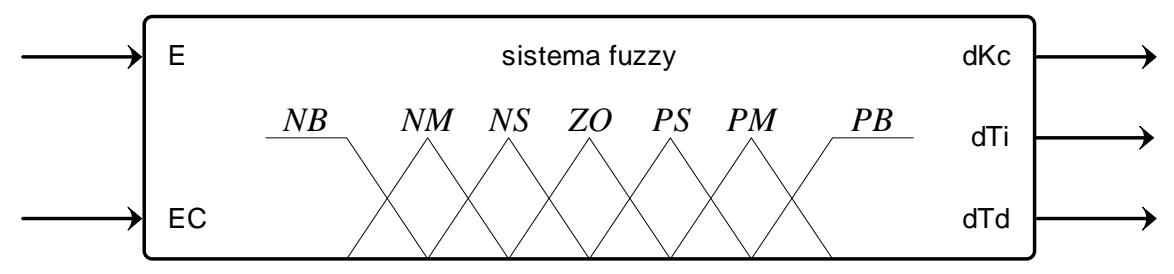

Figura 5.13: Representação do sistema fuzzy implementado.

Na Tabela 5.5 são mostrados os conjuntos fuzzy que representam as variáveis de entrada e saída, seu universo de discurso $\mathcal{U}$ e as variáveis linguísticas pertencentes a cada conjunto. A seguir são apresentadas em (5.25) a (5.27) as funções de pertinência que representam as variáveis de entrada $E$ e $E C$ e as de saída $d K_{c}, d T_{i}$ e $d T_{d}$. 
Tabela 5.5: Conjuntos fuzzy de entrada e saída.

\begin{tabular}{c|lcc}
\hline & Nome & $\mathcal{U}$ & Funções de pertinência \\
\hline variáveis & $\mathrm{E}$ & $(-41 ; 41)$ & $\{\mathrm{NB}, \mathrm{NM}, \mathrm{NS}, \mathrm{ZO}, \mathrm{PS}, \mathrm{PM}, \mathrm{PB}\}$ \\
de entrada & $\mathrm{EC}$ & $(-150 ; 150)$ & $\{\mathrm{NB}, \mathrm{NM}, \mathrm{NS}, \mathrm{ZO}, \mathrm{PS}, \mathrm{PM}, \mathrm{PB}\}$ \\
\hline variáveis & $d K_{c}$ & $(-1 ; 1)$ & $\{\mathrm{NB}, \mathrm{NM}, \mathrm{NS}, \mathrm{ZO}, \mathrm{PS}, \mathrm{PM}, \mathrm{PB}\}$ \\
de & $d T_{i}$ & $(-1 ; 1)$ & $\{\mathrm{NB}, \mathrm{NM}, \mathrm{NS}, \mathrm{ZO}, \mathrm{PS}, \mathrm{PM}, \mathrm{PB}\}$ \\
saída & $d T_{d}$ & $(-1 ; 1)$ & $\{\mathrm{NB}, \mathrm{NM}, \mathrm{NS}, \mathrm{ZO}, \mathrm{PS}, \mathrm{PM}, \mathrm{PB}\}$ \\
\hline
\end{tabular}

$$
\begin{aligned}
& E= \begin{cases}N B, & \mu_{\prod^{(x}}(-42 ;-42 ;-10 ;-7) \\
N M, & \mu_{\bigwedge}(x ;-10 ;-7 ;-4) \\
N S, & \mu_{\bigwedge}(x ;-7 ;-4 ;-2) \\
Z O, & \mu_{\bigwedge}(x ;-4 ; 0 ; 4) \\
P S, & \mu_{\bigwedge}(x ; 2 ; 4 ; 7) \\
P M, & \mu_{\bigwedge}(x ; 4 ; 7 ; 10) \\
P B, & \mu_{\Pi}(x ; 7 ; 10 ; 42 ; 42)\end{cases}
\end{aligned}
$$

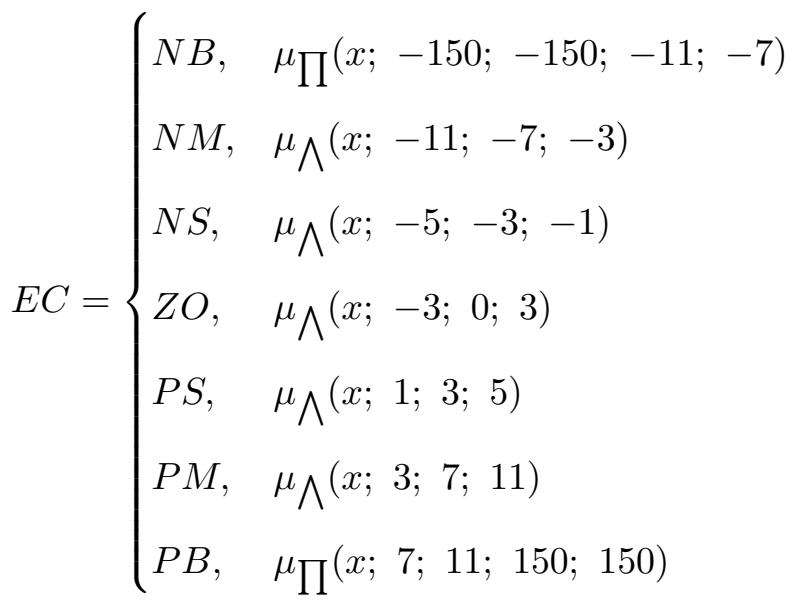




$$
d K_{c}, d T_{i}, d T_{d}= \begin{cases}N B, & \mu_{\bigwedge}(x ;-2,00 ;-1,00 ;-0,66) \\ N M, & \mu_{\bigwedge}(x ;-1,00 ;-0,66 ;-0,33) \\ N S, & \mu_{\bigwedge}(x ;-0,66 ;-0,33 ; 0,00) \\ Z O, & \mu_{\bigwedge}(x ;-0,33 ; 0,00 ; 0,33) \\ P S, & \mu_{\bigwedge}(x ; 0,00 ; 0,33 ; 0,66) \\ P M, & \mu_{\bigwedge}(x ; 0,33 ; 0,66 ; 1,00) \\ P B, & \mu_{\bigwedge}(x ; 0,66 ; 1,00 ; 2,00)\end{cases}
$$

Com as variáveis de entrada e saída definidas é elaborado o conjunto de regras que relacionam as entradas com as saídas. Utilizando o ambiente de simulação, com base na experiência acumulada durante a modelagem do sistema foi desenvolvido através de tentativa e erro o conjunto de regras apresentado na Tabela 5.6, onde é utilizado o conectivo $A N D($ Minimum).

Tabela 5.6: Base de regras.

\begin{tabular}{|c|c|c|c|c|c|c|c|c|}
\hline $\mathrm{EC}$ & $\mathrm{E}$ & NB & $\mathrm{NM}$ & NS & $\mathrm{ZO}$ & PS & $\mathrm{PM}$ & $\mathrm{PB}$ \\
\hline \multirow{3}{*}{ NB } & $K_{c}$ & $\mathrm{NB}$ & $\overline{\mathrm{PM}}$ & $\mathrm{ZO}$ & NB & $\mathrm{ZO}$ & $\mathrm{NS}$ & $\overline{\mathrm{PB}}$ \\
\hline & $T_{i}$ & $\mathrm{ZO}$ & $\mathrm{NM}$ & $\mathrm{ZO}$ & $\mathrm{ZO}$ & $\mathrm{ZO}$ & $\mathrm{PB}$ & NB \\
\hline & $T_{d}$ & $\mathrm{ZO}$ & $\mathrm{NM}$ & $\mathrm{ZO}$ & $\mathrm{ZO}$ & $\mathrm{ZO}$ & NM & $\mathrm{PB}$ \\
\hline \multirow{3}{*}{$\mathrm{NM}$} & $K_{c}$ & $\mathrm{~PB}$ & $\overline{\mathrm{PM}}$ & $\mathrm{ZO}$ & NM & $\mathrm{ZO}$ & $\mathrm{NS}$ & $\overline{\mathrm{PB}}$ \\
\hline & $T_{i}$ & NB & $\mathrm{NM}$ & $\mathrm{ZO}$ & $\mathrm{ZO}$ & $\mathrm{ZO}$ & $\mathrm{PB}$ & NB \\
\hline & $T_{d}$ & $\mathrm{~PB}$ & $\mathrm{NM}$ & $\mathrm{ZO}$ & $\mathrm{ZO}$ & $\mathrm{ZO}$ & $\mathrm{NM}$ & PB \\
\hline \multirow{3}{*}{$\mathrm{NS}$} & $K_{c}$ & $\mathrm{~PB}$ & $\mathrm{PM}$ & $\mathrm{ZO}$ & PB & $\mathrm{ZO}$ & $\mathrm{NS}$ & $\overline{\mathrm{PB}}$ \\
\hline & $T_{i}$ & $\mathrm{NB}$ & $\mathrm{NM}$ & $\mathrm{ZO}$ & $\mathrm{ZO}$ & $\mathrm{ZO}$ & $\mathrm{PB}$ & NB \\
\hline & $T_{d}$ & $\mathrm{~PB}$ & $\mathrm{NM}$ & $\mathrm{ZO}$ & $\mathrm{ZO}$ & $\mathrm{ZO}$ & NM & $\mathrm{PB}$ \\
\hline \multirow{3}{*}{$\mathrm{ZO}$} & $K_{c}$ & $\mathrm{~PB}$ & $\mathrm{PM}$ & $\mathrm{ZO}$ & $\mathrm{PM}$ & $\mathrm{ZO}$ & $\mathrm{NS}$ & $\overline{\mathrm{PB}}$ \\
\hline & $T_{i}$ & NB & $\mathrm{NM}$ & $\mathrm{ZO}$ & $\mathrm{ZO}$ & $\mathrm{ZO}$ & $\mathrm{PB}$ & NB \\
\hline & $T_{d}$ & $\mathrm{~PB}$ & $\mathrm{NM}$ & $\mathrm{ZO}$ & $\mathrm{ZO}$ & $\mathrm{ZO}$ & NM & $\mathrm{PB}$ \\
\hline \multirow{3}{*}{ PS } & $K_{c}$ & $\mathrm{~PB}$ & $\overline{\mathrm{PM}}$ & $\mathrm{ZO}$ & PB & $\mathrm{ZO}$ & $\mathrm{NS}$ & $\overline{\mathrm{PB}}$ \\
\hline & $T_{i}$ & $\mathrm{NB}$ & $\mathrm{NM}$ & $\mathrm{ZO}$ & $\mathrm{ZO}$ & $\mathrm{ZO}$ & $\mathrm{PB}$ & NB \\
\hline & $T_{d}$ & $\mathrm{~PB}$ & $\mathrm{NM}$ & $\mathrm{ZO}$ & $\mathrm{ZO}$ & $\mathrm{ZO}$ & NM & $\mathrm{PB}$ \\
\hline \multirow{3}{*}{$\mathrm{PM}$} & $\overline{K_{c}}$ & $\mathrm{~PB}$ & $\mathrm{PM}$ & $\mathrm{ZO}$ & $\mathrm{NM}$ & $\mathrm{ZO}$ & $\mathrm{NS}$ & $\overline{\mathrm{PB}}$ \\
\hline & $T_{i}$ & $\mathrm{NB}$ & $\mathrm{NM}$ & $\mathrm{ZO}$ & $\mathrm{ZO}$ & $\mathrm{ZO}$ & $\mathrm{PB}$ & NB \\
\hline & $T_{d}$ & $\mathrm{~PB}$ & $\mathrm{NM}$ & $\mathrm{ZO}$ & $\mathrm{ZO}$ & $\mathrm{ZO}$ & NM & PB \\
\hline \multirow{3}{*}{$\mathrm{PB}$} & $K_{c}$ & $\mathrm{~PB}$ & $\mathrm{PM}$ & $\mathrm{ZO}$ & NB & $\mathrm{ZO}$ & $\mathrm{NS}$ & $\overline{\mathrm{PB}}$ \\
\hline & $T_{i}$ & $\mathrm{NB}$ & $\mathrm{NM}$ & $\mathrm{ZO}$ & $\mathrm{ZO}$ & $\mathrm{ZO}$ & $\mathrm{PB}$ & NB \\
\hline & $T_{d}$ & $\mathrm{~PB}$ & $\mathrm{NM}$ & $\mathrm{ZO}$ & $\mathrm{ZO}$ & $\mathrm{ZO}$ & NM & $\mathrm{PB}$ \\
\hline
\end{tabular}

Para cada par de valores de $E$ e $E C$, o sistema fuzzy determina o valor das saídas 
através do método de defuzzificação $C o A$. As variáveis de saída do sistema fuzzy podem ser representadas com uma função das entradas e das regras:

$$
d K_{c}=F_{1}(E, E C), d T_{i}=F_{2}(E, E C) \text { e } d T_{d}=F_{3}(E, E C)
$$

onde $F_{1}$ a $F_{3}$ são funções que mapeiam as variáveis de saída, e além disto, as saídas das variáveis só são válidas $\left(d K_{c} \neq 0, d T_{i} \neq 0\right.$ e $\left.d T_{d} \neq 0\right)$ se os valores das variáveis de entrada estão representadas em seus respectivos universos de discurso $E \in \mathcal{U}_{E}$ e $E C \in \mathcal{U}_{E C}$.

Através da combinação dos valores assumidos nas variáveis de entrada $E$ e $E C$ é mapeada, através da funções $F_{1}$ a $F_{3}$, as superfícies que representam o comportamento do sistema para cada variável de saída. Essas superfícies são apresentadas respectivamente nas Figuras 5.14 a 5.16. Note que as superfícies são definidas no intervalo $(-1,1)$, o valor de variação dos parâmetros do controlador PID é obtido no estágio seguinte, pela multiplicação das superfícies pelos respectivos valores escalares dos ganhos de saída.

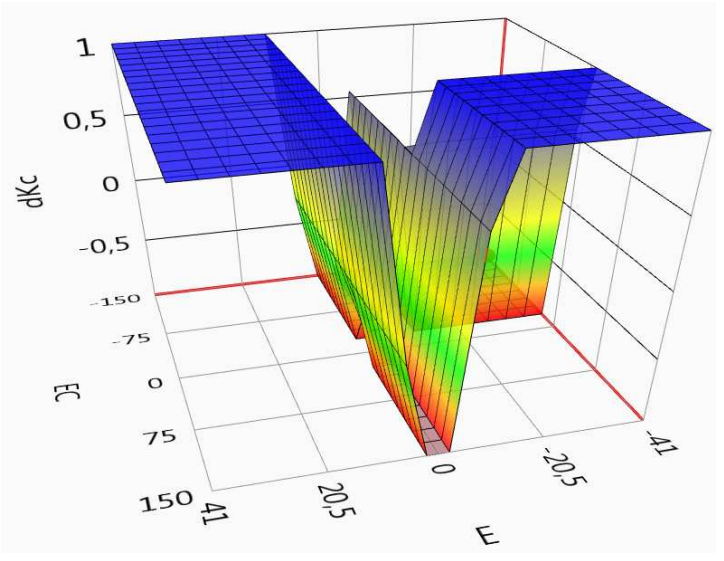

Figura 5.14: Superfície de ajuste do parâmetro $K_{c}$.

Estágio 3: é o estágio onde são calculados os valores da variação dos parâmetros do controlador PID. A partir das variáveis de saída do sistema fuzzy representadas pelas 


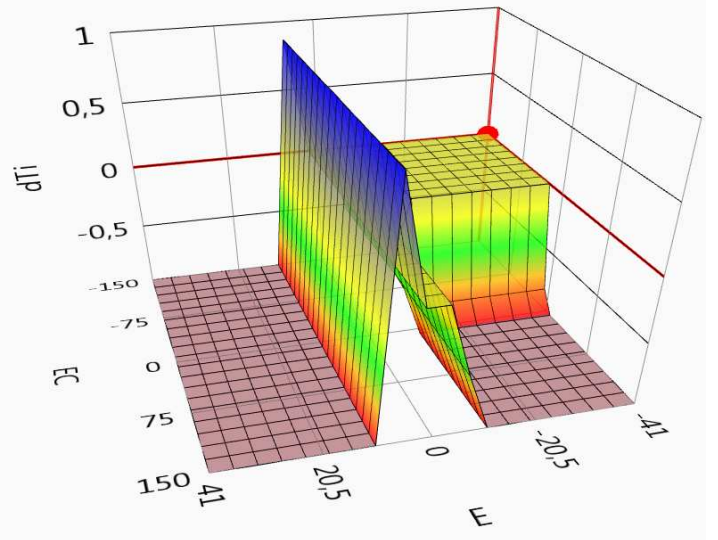

Figura 5.15: Superfície de ajuste do parâmetro $T_{i}$.

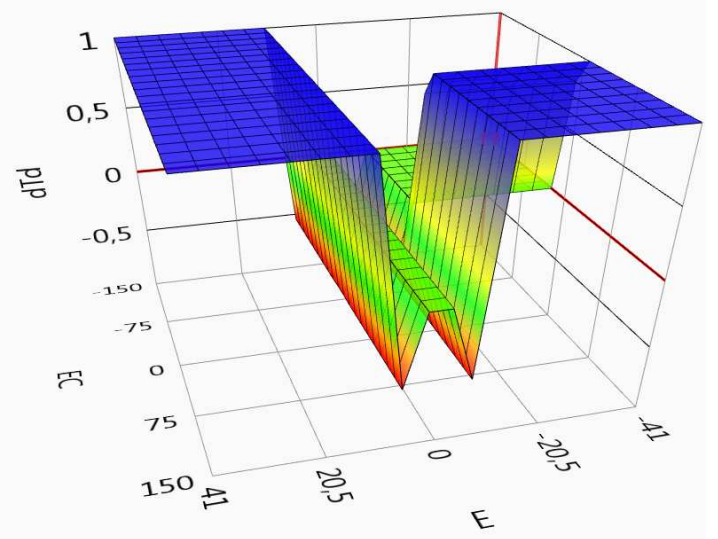

Figura 5.16: Superfície de ajuste do parâmetro $T_{d}$.

Figuras 5.14 a 5.16 a variação dos parâmetros do controlador PID é dada por:

$$
\begin{aligned}
\Delta K_{c}(k T) & =G_{K C} d K_{c}, \\
\Delta T_{i}(k T) & =G_{T I} d T_{i}, \\
\Delta T_{d}(k T) & =G_{T D} d T_{d},
\end{aligned}
$$

onde $G_{K C}=14, G_{T I}=3,510^{-2}$ e $G_{T D}=810^{-3}$ são ganhos do estágio e devem ser no máximo os valores ajustados no PID, a fim de evitar a instabilidade da malha de controle.

Estágio 4: é o estágio onde é verificado se os valores calculados do estágio anterior 
serão atualizados no controlador. Conforme descrito anteriormente, a variação dos parâmetros $K_{c}, T_{i}$ ou $T_{d}$ durante a execução da rotina do PID acarreta na reinicialização do integrador, levando o controlador a atuar somente como PD. Isso implica em uma malha de controle incapaz de eliminar o erro estacionário.

Para contornar esse problema é implementado o Algoritmo 1, que atua na atualização dos parâmetros. Através de condições de restrição na variação dos parâmetros que irão ser aplicados no controlador PID. Basicamente o algoritmo avalia se a variação dos parâmetros do PID calculadas pelo sistema fuzzy é maior que um dado limiar. Caso afirmativo os parâmetros são atualizados e caso contrário são mantidos os últimos parâmetros atualizados. Através de ensaios, utilizando a plataforma de simulação desenvolvida, são testados valores de limiar variando de 0,1 a 0,9 vezes o valor dos ganhos ajustados no estágio anterior, em intervalos de 0,1. A partir desses ensaios foi determinado que adotando o valor de limiar de 0,1 vezes o valor dos ganhos de saída do estágio 3 , se obtém uma malha de controle com maior desempenho.

O Algoritmo 1, representado através do esquema na Figura 5.17, recebe como entradas os valores das variáveis de saída do sistema fuzzy $\Delta K_{c}(k T), \Delta T_{i}(k T)$ e $\Delta T_{d}(k T)$, os valores dos ganhos aplicados as variáveis de saída do Estágio $3 G_{K C}, G_{T I}$ e $G_{T D}$ e os valores dos parâmetros ajustados para o controlador PID $K_{c 0}, T_{i 0}$ e $T_{d 0}$, verifica para cada variável se a diferença do valor absoluto entre as variáveis de saída são maiores que os limiares $k 0, i 0$ e $d 0$ e caso afirmativo atualiza os valores dos parâmetros do controlador.

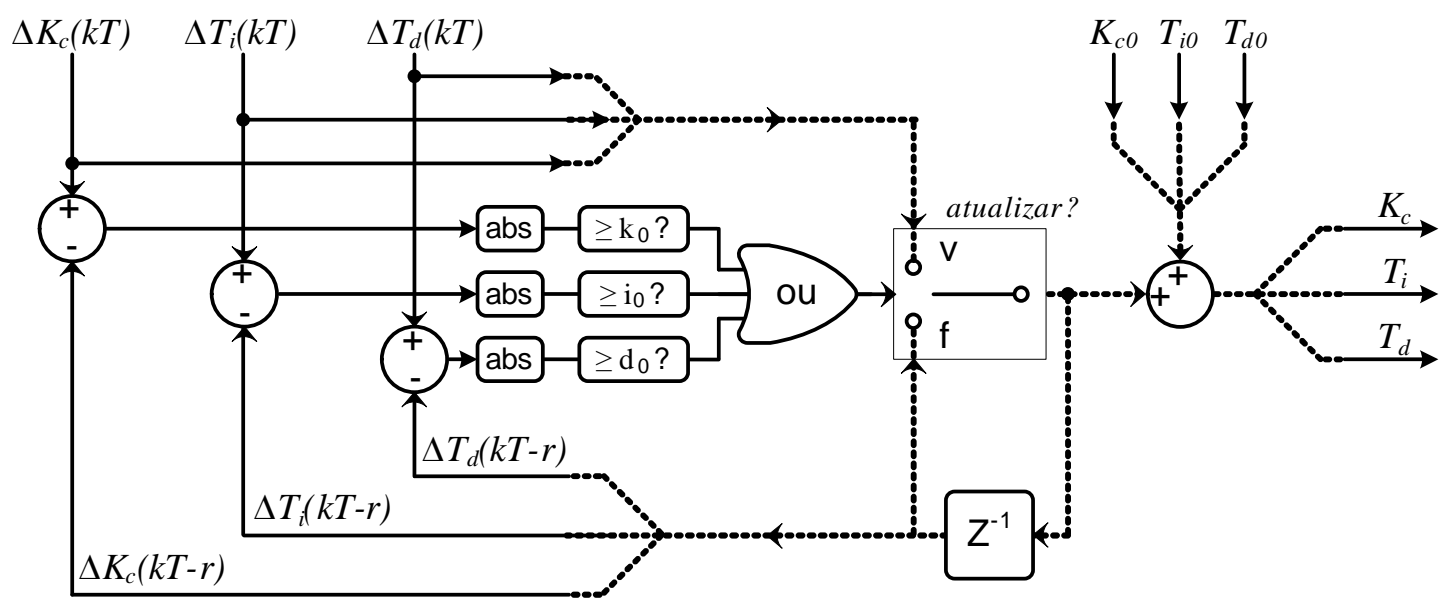

Figura 5.17: Esquema de avaliação e atualização dos parâmetros do controlador PID. 


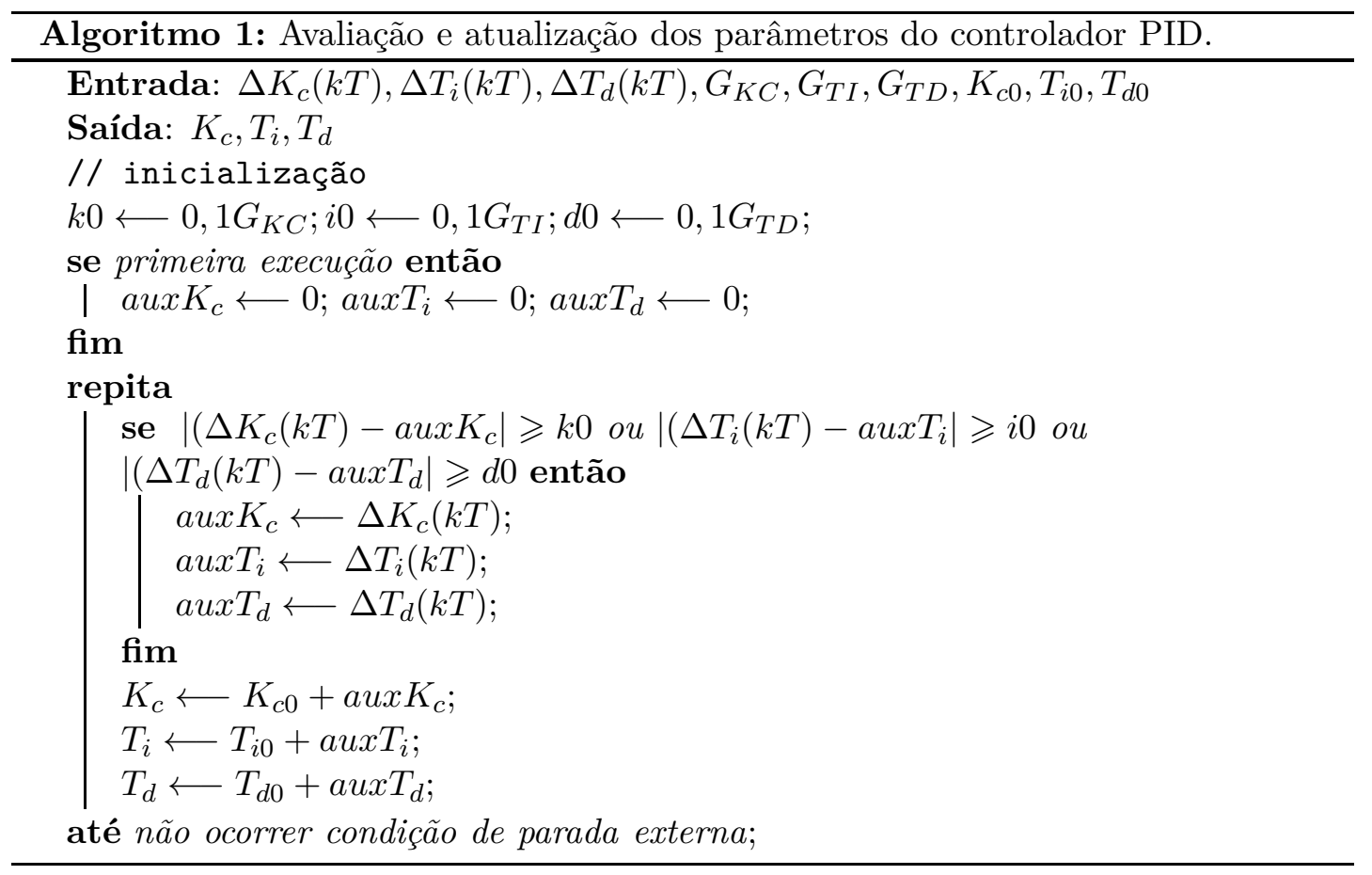

Conforme apresentado neste capítulo, pode-se resumir o projeto do controlador PID fuzzy por escalonamento de ganho nos seguintes passos:

1. Projetar um controlador PID que estabilize a malha de controle;

2. Determinar o universo de discurso das variáveis de entrada;

3. Ajustar as funções de pertinência das variáveis de entrada;

4. Elaborar uma base de regras;

5. Ajustar os ganhos de saída com valores numericamente inferiores aos parâmetros do controlador projetado. 


\section{Capítulo 6}

\section{Resultados Experimentais}

Tradicionalmente o desempenho de um controlador PID é avaliado através de análise visual do erro de seguimento de uma referência ou através de critérios como o erro absoluto integral IAE ${ }^{1}$ dada por (6.1) (OVIEDO; BOELEN; OVERSCHEE, 2006), onde quanto menor é o seu valor melhor o desempenho do controlador (ASTROM; HAGGLUND, 2006). Neste trabalho além do IAE é empregada a norma $\mathcal{L}^{2}$ dada por (6.2), que mede a raiz quadrática média do erro, assim valores pequenos da norma representam menor erro no seguimento da trajetória de referência, e portanto, maior desempenho do controlador (WHITCOMB; RIZZI; KODITSCHEK, 1993).

$$
\begin{gathered}
I A E=\sum_{k=1}^{N}|e(k)| \Delta T \\
\mathcal{L}^{2}[e(k)]=\left(\frac{1}{N} \sum_{k=1}^{N} e(k)^{2}\right)^{1 / 2}
\end{gathered}
$$

onde $e(k)$ é o erro de aplicação em $\ell / \min , \mathrm{N}$ é o número de amostras e $\Delta T$ é o período de amostragem em minutos.

O objetivo do ensaio apresentado a seguir é avaliar o desempenho dos controladores implementados, mantendo constante a relação entre a vazão da calda e a vazão do agroquímico, ou seja, a concentração da mistura deve ser constante. O ensaio é realizado utilizando água em ambos os reservatórios de agroquímico e de água. São utilizadas as pontas de pulverização ISO 11005, por propiciarem uma pressão no sistema hidráulico

\footnotetext{
${ }^{1}$ do inglês: integral absolute error
} 
inferior a $600 k P a$ para uma ampla faixa de vazão da calda.

É definida uma referência para a vazão da calda $Q_{F r e f}$, conforme mostra a Figura 6.1(a). A vazão de referência para o agroquímico é calculada em tempo real por $Q_{H r e f}=$ 0,055 $Q_{\text {Fref }}$. Essa relação é baseada nas recomendações da bula Roundup original da Monsanto, um herbicida não seletivo a base de Glifosato.

O formato da curva utilizada com referência para os controladores foi elaborado para simular duas situações distintas: (i) mudanças abruptas na taxa de aplicação devido a mudança do grau de infestação por plantas invasoras e (ii) variação na velocidade de deslocamento do veículo pulverizador. A referência para a vazão da calda, entre 0 e $300 \mathrm{~s}$, tem como objetivo testar a resposta dos controladores para diferentes amplitudes de degraus tanto de subida como de descida. Isso simula o efeito do aumento e da diminuição da taxa de aplicação. Para o tempo a partir de $300 s$ a referência de vazão tem como objetivo simular o aumento e a diminuição da velocidade de deslocamento do pulverizador.

Para o módulo de pulverização os resultados experimentais são mostrados na Figura 6.1. Os gráficos indicam que durante as transições da referência, de 0 a $300 s$, ambos os controladores não atendem os requisitos de erro na taxa de aplicação. Isso é decorrente do tempo de resposta válvula de controle VP1. Para as rampas, partir de $300 \mathrm{~s}$, os gráficos indicam um melhor desempenho do PID fuzzy durante a rampa de subida e para a descida o PID apresentou melhores resultados. De modos geral fica evidente que o controlador PID fuzzy apresentou melhores resultados, o que pode ser confirmado pelos índices de desempenho mostrados na Tabela 6.1. 
(a)

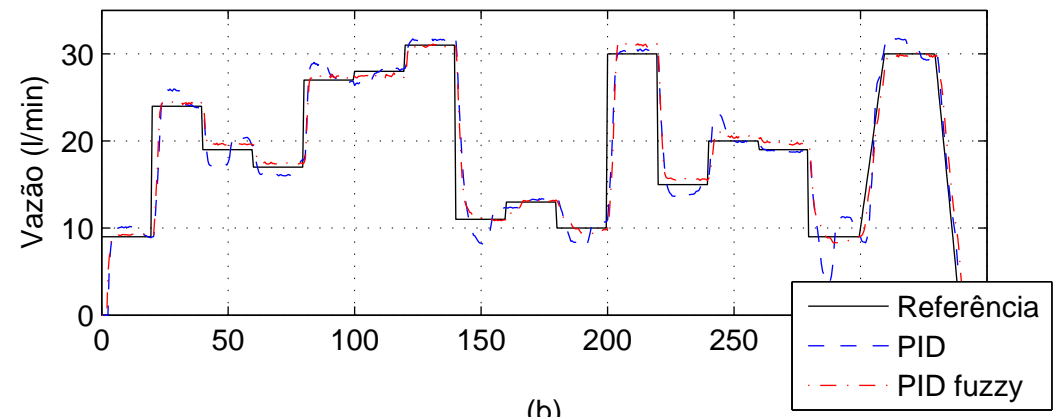

(b)

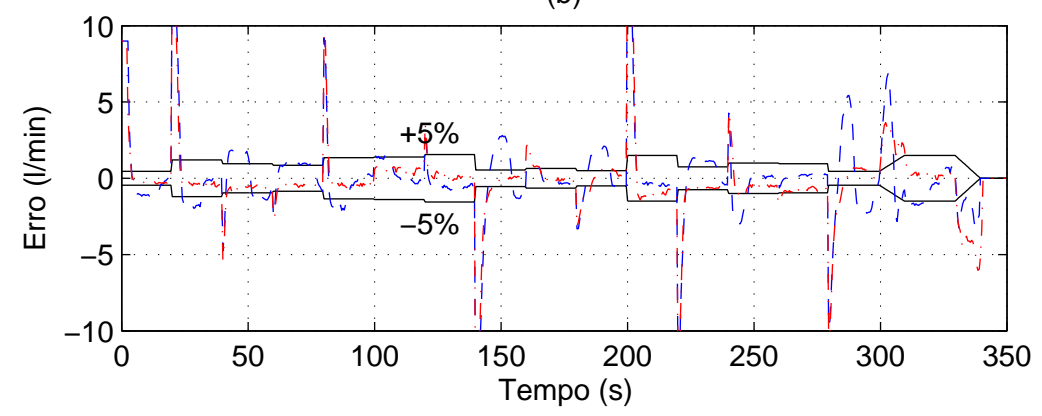

Figura 6.1: Respostas dos controladores PID e PID fuzzy do módulo de pulverização. (a)Vazão da calda $Q_{F}$ e (b) Erro de aplicação com relação a referência, onde as linhas contínuas indicam a faixa de erro de $\pm 5 \%$.

Tabela 6.1: Desempenho dos controladores implementados para o módulo de pulverização.

\begin{tabular}{lccc}
\hline Índice de desempenho & PID & PID fuzzy & Melhora $(\%)$ \\
\hline IAE & $9,06 \ell$ & $7,28 \ell$ & 25 \\
$\mathcal{L}^{2}$ & $2,99 \ell /$ min & $2,88 \ell /$ min & 4 \\
\hline
\end{tabular}

Na Figura 6.2 são apresentados os valores dos parâmetros do controlador PID fuzzy por escalonamento de ganho. Na Figura 6.3 é apresentada as curvas da pressão $P_{S}$ no sistema para os controladores PID e PID fuzzy por escalonamento de ganho. 
(a)

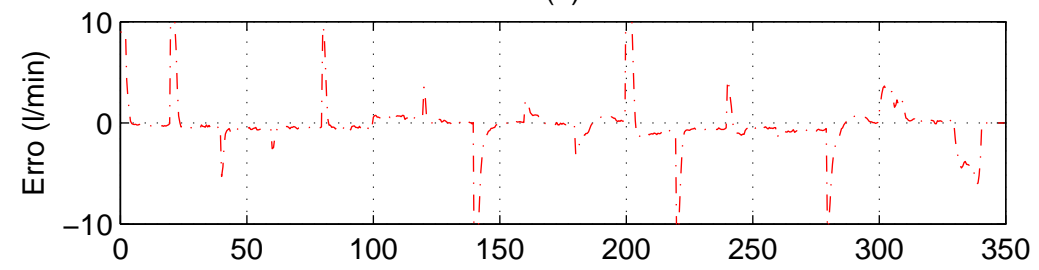

(b)

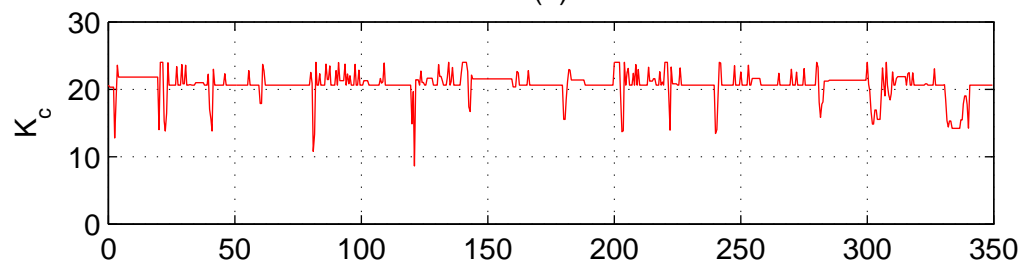

(c)

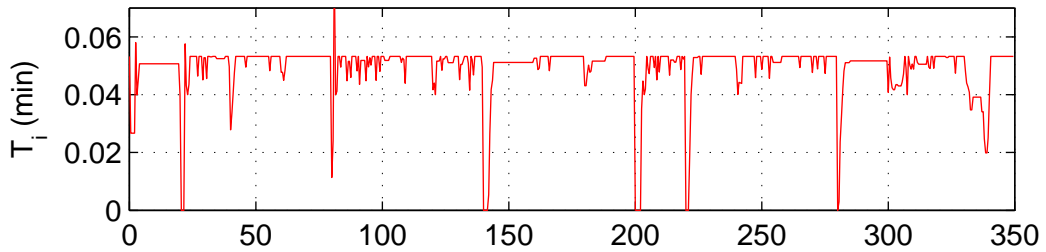

(d)

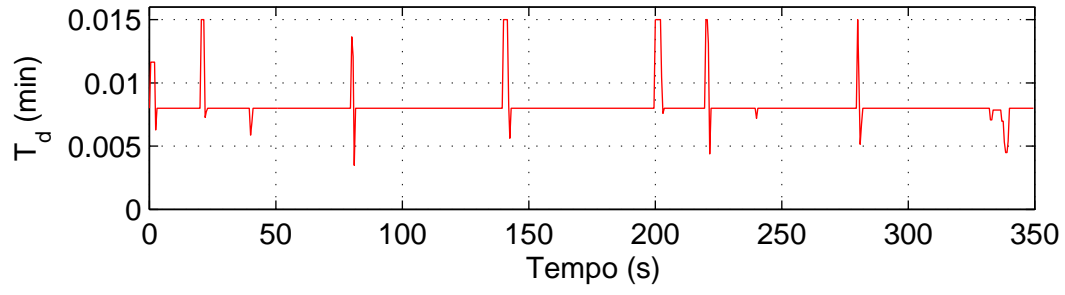

Figura 6.2: Adaptação de parâmetros do controlador PID fuzzy por escalonamento de ganho. (a) A variável de entrada $E$. (b) a (d) Os parâmetros atualizados no controlador PID fuzzy $K_{c}, T_{i}$ e $T_{d}$. 


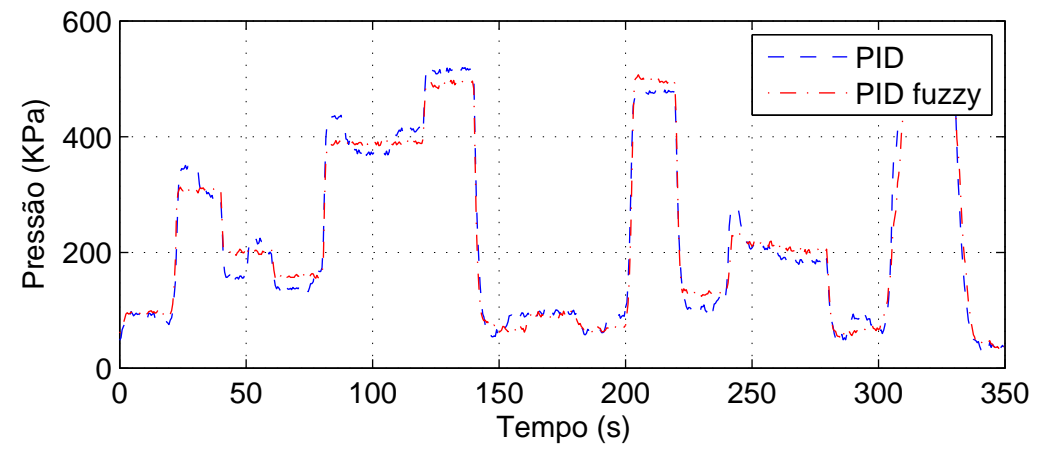

Figura 6.3: Respostas da pressão $P_{S}$ do sistema com os controladores PID e PID fuzzy por escalonamento de ganho do módulo de pulverização.

Para o módulo de injeção os resultados experimentais são mostrados na Figura 6.4. Os gráficos indicam que, exceto para transições de referências muito abruptas, o módulo de injeção apresenta um erro menor que 5\%. O controlador implementado foi capaz de seguir a referência para as duas consições de operação propostas. Esse desempenho pode ser verificado através dos índices mostrados na Tabela 6.2.

(a)
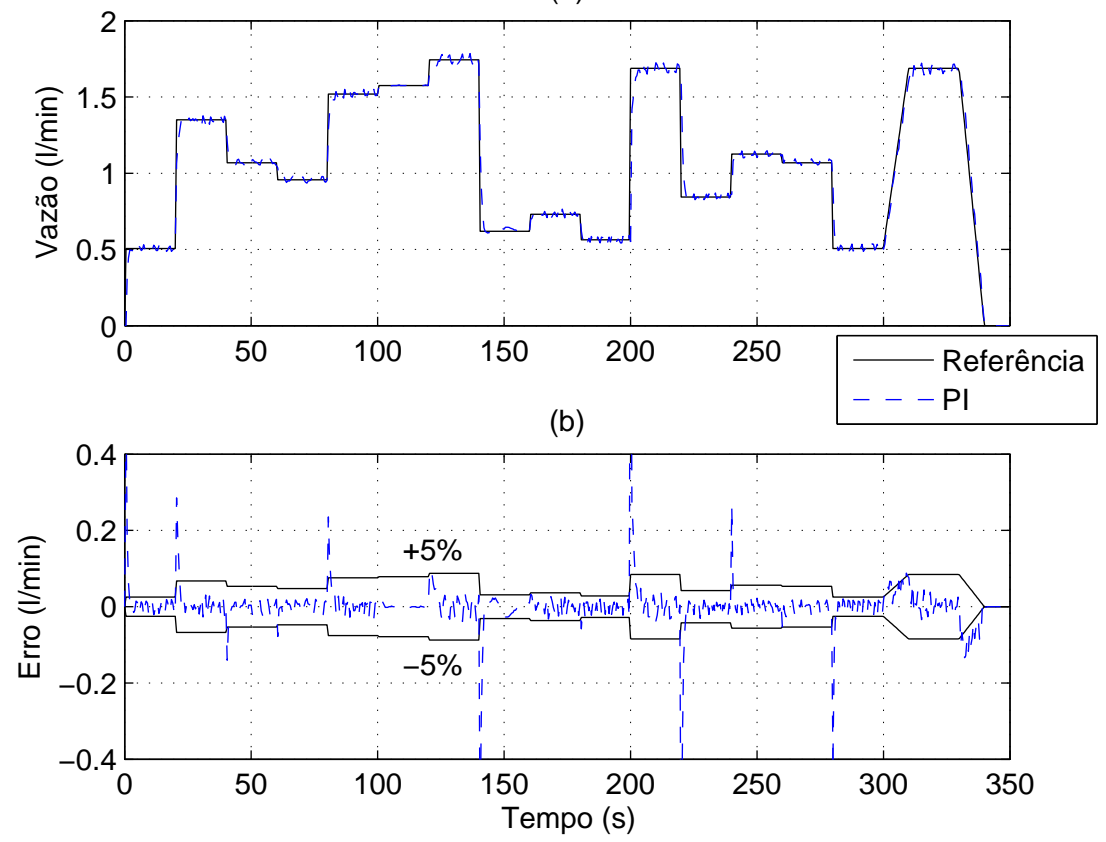

Figura 6.4: Respostas do controlador PI do módulo de injeção. (a)Vazão $Q_{H}$ e (b) Erro de aplicação com relação a referência, onde as linhas contínuas indicam a faixa de erro de $\pm 5 \%$. 
Tabela 6.2: Desempenho do controlador implementado para o módulo de injeção.

\begin{tabular}{lc}
\hline Índice de desempenho & PI \\
\hline IAE & $1,1810^{-1} \ell$ \\
$\mathcal{L}^{2}$ & $4,6810^{-2} \ell /$ min \\
\hline
\end{tabular}




\section{Capítulo 7}

\section{Conclusões}

Neste trabalho foi implementado a automação de um sistema de pulverização em taxa variada com injeção direta de agroquímicos. Para isto, é utilizada uma bancada de pulverização que se mostrou como uma importante ferramenta para o desenvolvimento e testes de sistemas de pulverização.

Os circuitos desenvolvidos para a instrumentação do sistema montado na bancada de pulverização, mostraram-se confiáveis durante as etapas de modelagem e testes do sistema, não apresentando problemas como superaquecimento, queima de componentes, ou outros que acarretem em mal funcionamento do sistema. O PAC-cRIO 9073 apresentou capacidade de executar diferentes tarefas sem prejuízo as ações de controle, possibilitando ainda ser embarcado para uso em campo. A utilização dos modelos para o desenvolvimento de um ambiente de simulação, em LabVIEW para PC, possibilitou a compreensão da interação entre os diferentes elementos do sistema de pulverização, a implementação e testes dos controladores desenvolvidos, bem como a transferência dos códigos desses controladores para o PAC-cRIO com poucas modificações.

Os resultados experimentais mostram que para regular a vazão do agroquímico, no módulo de injeção, um controlador do tipo PI apresenta resultados satisfatórios, com um erro de aplicação total de $1,1810^{-1} \ell$ e um erro quadrático médio de $4,6810^{-2} \ell /$ min para a faixa de operação de 0,5 a 1,8 $/$ /min. Para regular a vazão da mistura, no módulo de pulverização, o controlador PID fuzzy por escalonamento de ganho apresentou desempenho superior ao controlador PID convencional. Com relação ao erro total de aplicação houve uma melhora de $25 \%$ e quanto ao erro quadrático médio a melhora de 
desempenho é de $4 \%$ na faixa de operação de 10 a $32 \ell /$ min. Desta forma, conclui-se que o controlador PID fuzzy por escalonamento de ganho apresenta potencial aplicação para regular a vazão em sistemas de pulverização. 


\section{Capítulo 8}

\section{Propostas para Trabalhos Futuros}

A bancada de pulverização, utilizada neste trabalho, foi compartilhada para o desenvolvimento de outros trabalhos visando o estudo dos efeitos do atraso de transporte, do transiente de concentração e do espectro de gotas na qualidade da aplicação. A implementação de controladores avançados como o controlador preditivo baseado em modelo e a implementação de uma plataforma móvel para avaliar o espectro de gotas simulando o movimento do pulverizador já vem sendo consideradas.

Outros trabalhos têm explorado as características das pontas de pulverização visando extender a faixa de operação do pulverizador sem precisar trocar as pontas. Neste sentido, os bicos de pulverização PWM tem apresentado resultados promissores, sendo capazes do controle individual da vazão das pontas e mantendo o tamanho das gotas para uma ampla faixa de pressão. Apesar dos benefícios, esta tecnologia ainda não vem sendo adotada extensivamente devido a relação custo benefício.

Considerando as tecnologias recentes como bicos PWM e a experiência acumulada neste trabalho são propostas para trabalhos futuros:

- o desenvolvimento de bicos PWM de baixo custo bem como um controlador para esses bicos;

- o estudo da influência da realimentação pelo retorno da válvula de três vias no transiente da concentração da mistura de agroquímico e água;

- o estudo comparativo entre o controle da vazão da mistura pela válvula de três vias e o controle da rotação da bomba de mistura; 
- o estudo do uso do aumento da vazão de injeção por um curto período de tempo visando aumentar a velocidade de resposta do transiente de concentração (o transiente da concentração depende da vazão da mistura). 


\section{Apêndice A}

\section{Diagramas Esquemáticos}

Este apêndice contém os diagramas esquemáticos dos circuitos usados na instrumentação do sistema de pulverização. Os diagramas esquemáticos estão listados a seguir:

1. Diagrama esquemático da placa de interface com o inversor de frequência (Figura A.1).

2. Diagrama esquemático dos circuitos de acionamento das válvulas VP1, VP2, VS1 e VS2 (Figura A.2).

3. Diagrama esquemático dos circuitos do amplificador de potência, condicionamento de sinal e alimentação do encoder do módulo de injeção (Figura A.3).

4. Diagrama esquemático da placa de acionamento da bomba de descarte e ligações dos sensores de nível e do fluxômetro (Figura A.4). 


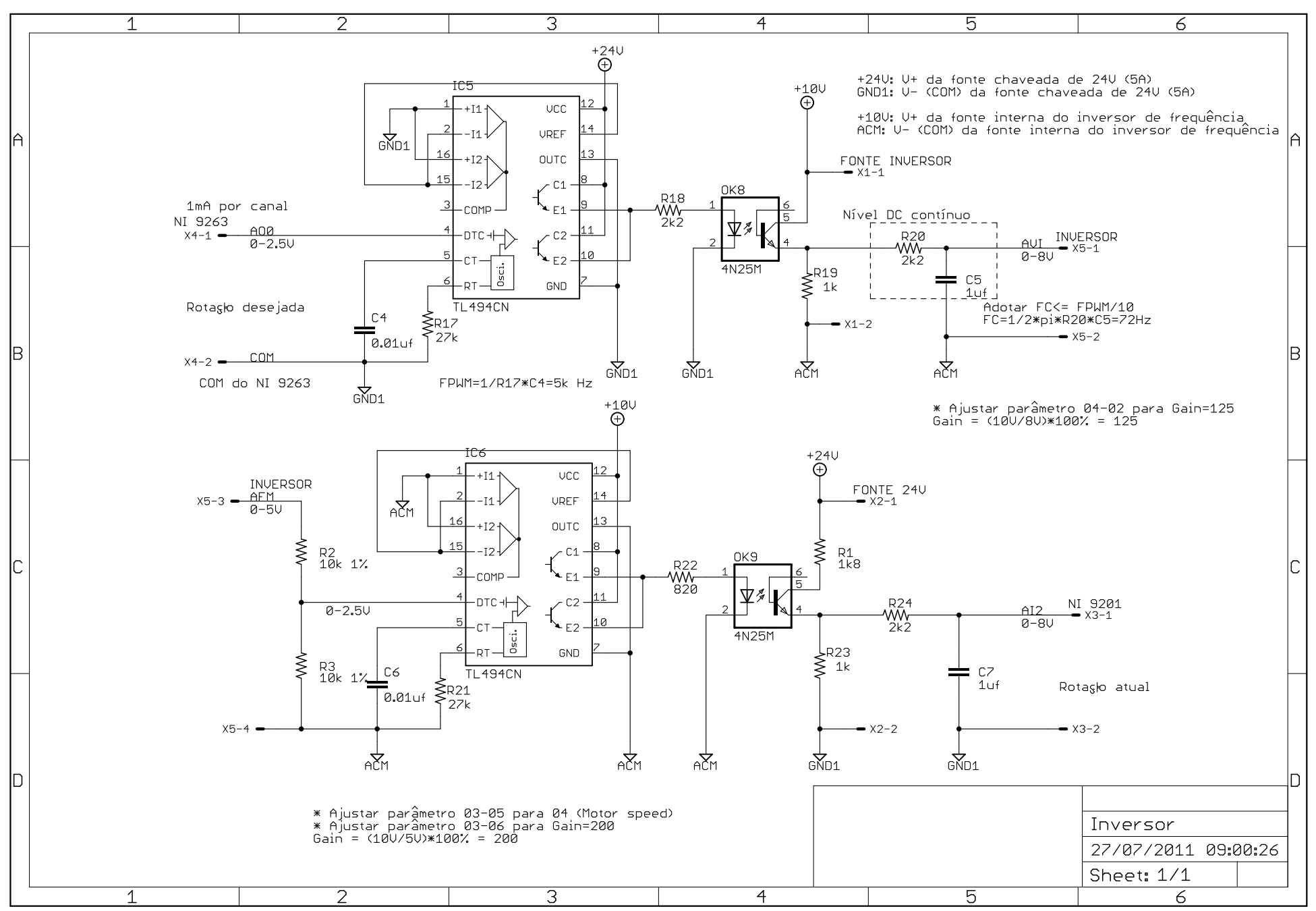

Figura A.1: Diagrama esquemático da placa de interface com o inversor de frequência. 


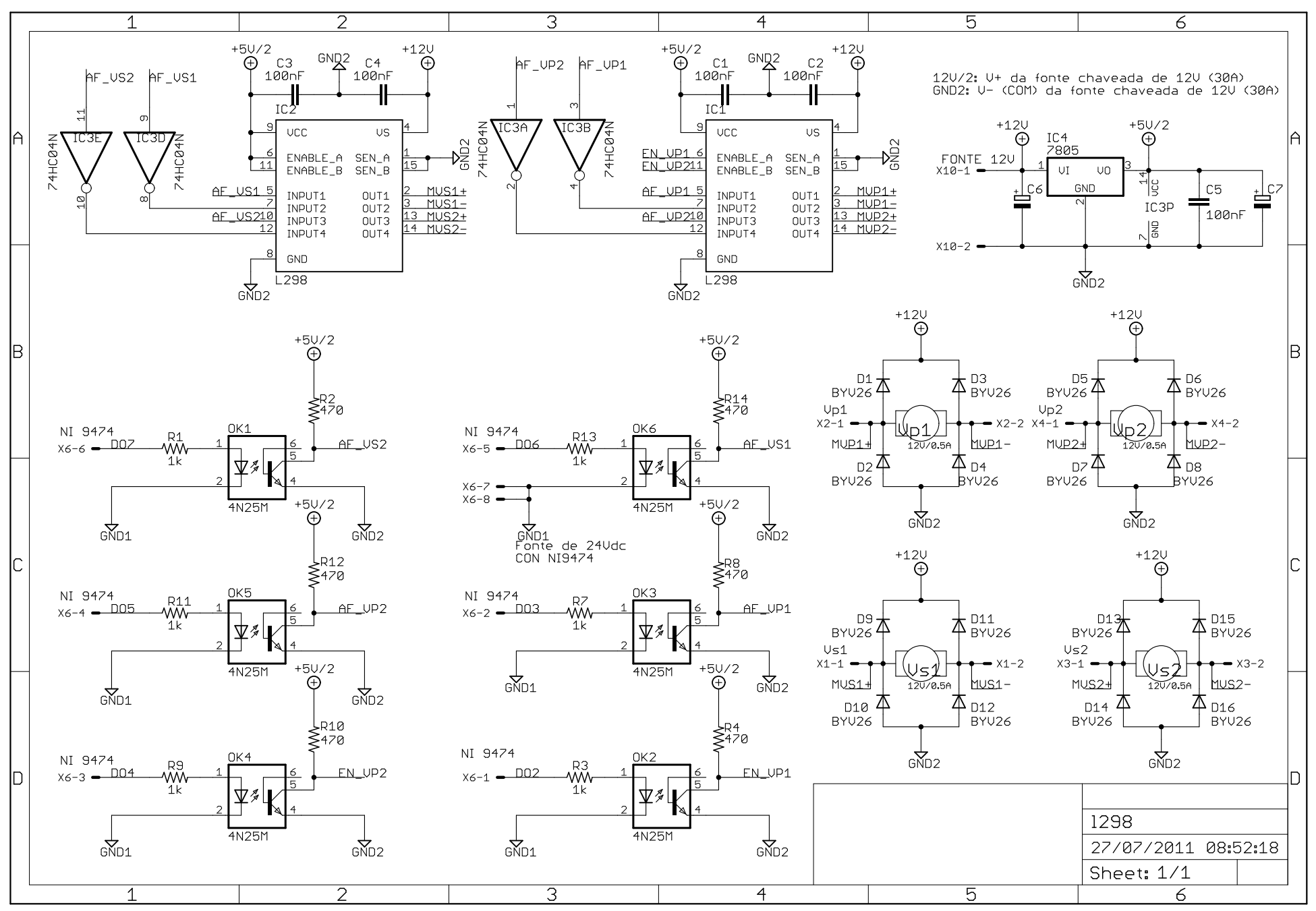

Figura A.2: Diagrama esquemático dos circuitos de acionamento das válvulas VP1, VP2, VS1 e VS2. 


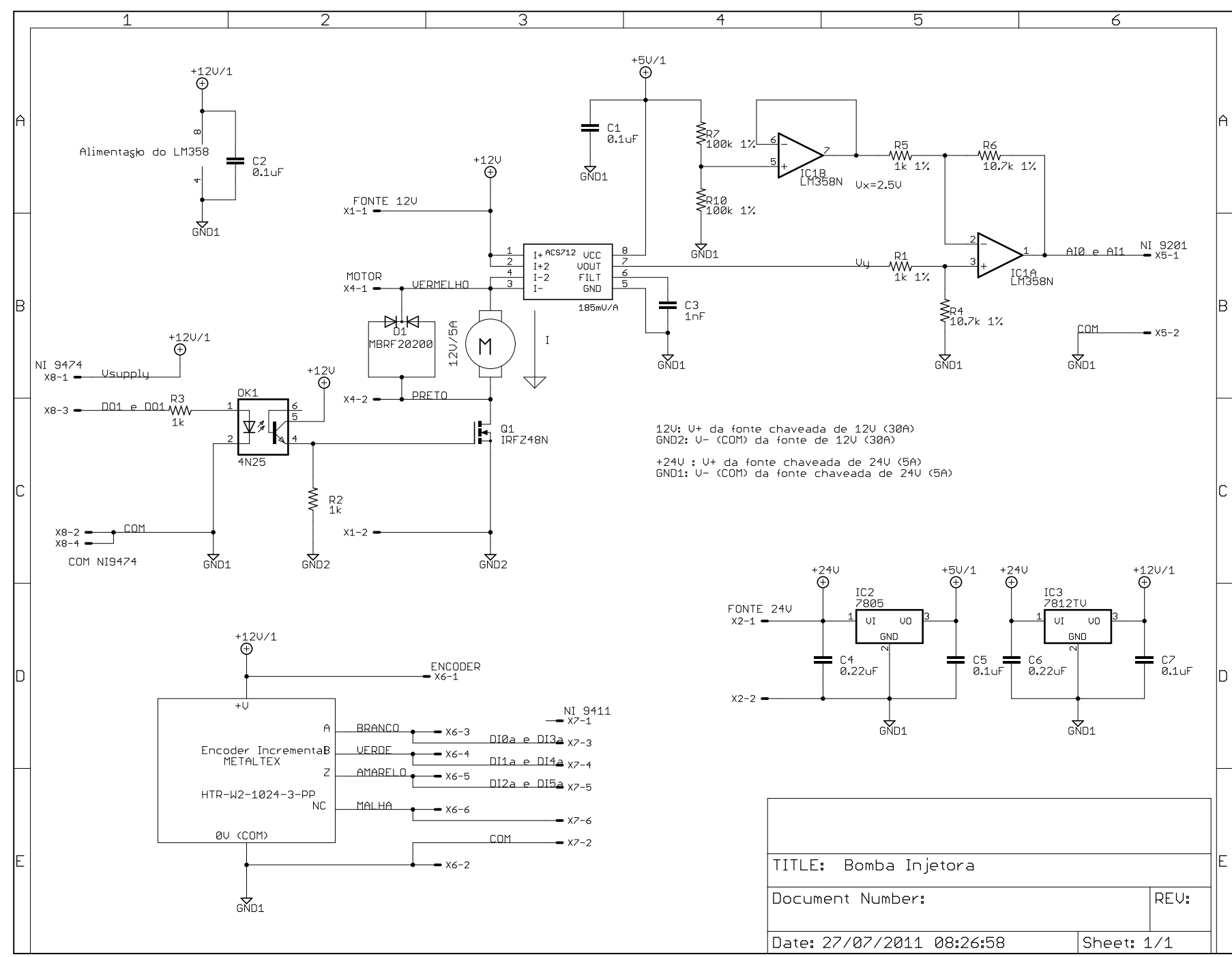

Figura A.3: Diagrama esquemático dos circuitos do amplificador de potência, condicionamento de sinal e alimentação do encoder do módulo de injeção. 


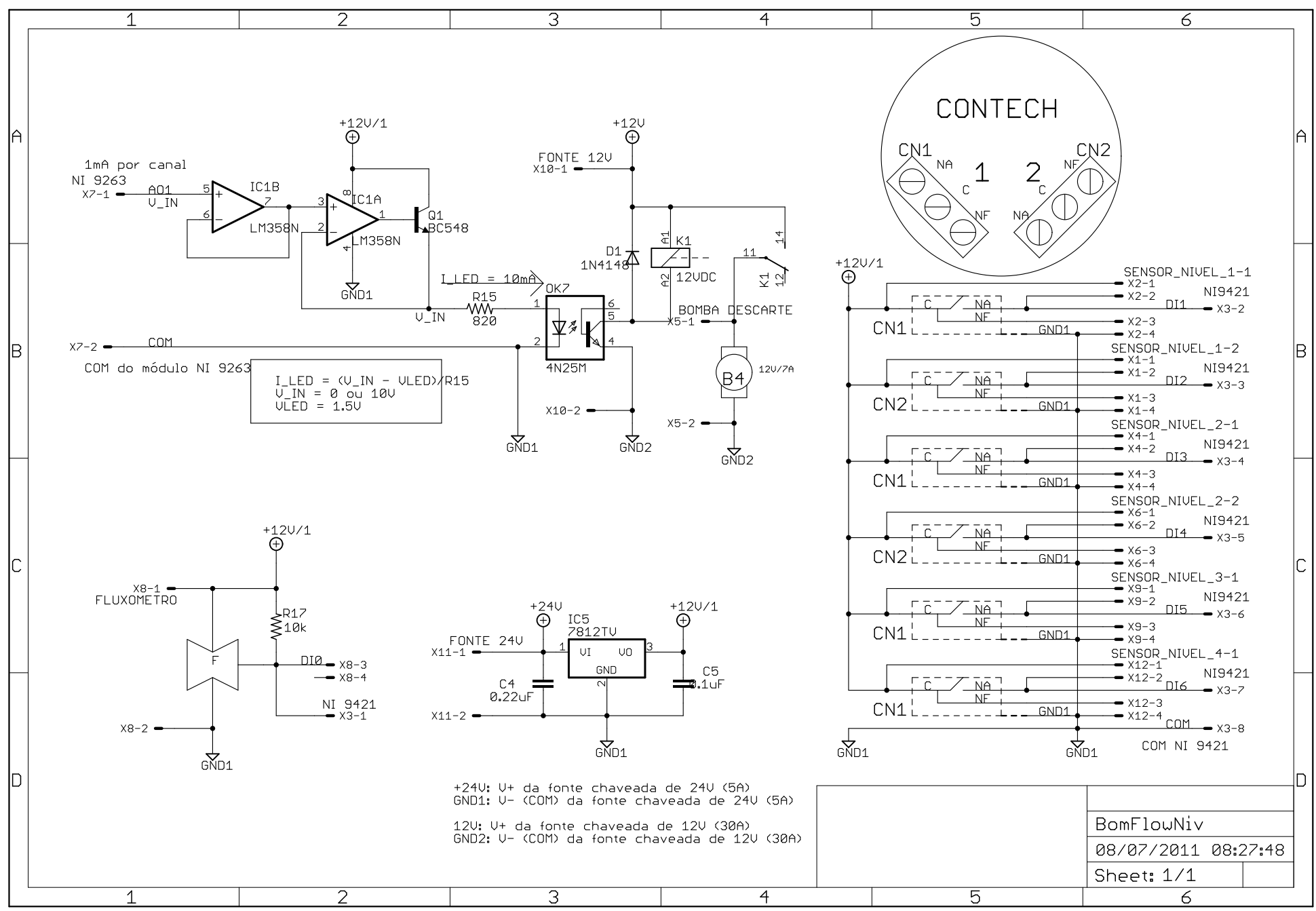

Figura A.4: Diagrama esquemático da placa de acionamento da bomba de descarte e ligações dos sensores de nível e do fluxômetro. 


\section{Referências Bibliográficas}

AMADO, T. J. C. et al. Projeto aquarius-cotrijal: pólo de agricultura de precisão. Plantio Direto, v. 91, n. 15, p. 39-47, 2006.

ANDREI, E. Compêndio de Defensivos Agrícolas. 7. ed. São Paulo: Andrei Ed. Ltda, 2005.

ANTUNIASSI, U. R.; BOLlER, W. (Ed.). Tecnologia de Aplicação para Culturas Anuais. Passo Fundo: Aldeia Norte, 2011.

ANTUNIASSI, U. R.; GANDOLFO, M. A.; SIQUEIRA, J. L. Inspeção de pulverizadores de barras. In: ANTUNIASSI, U. R. (Ed.). Tecnologia de Aplicação para Culturas Anuais. Passo Fundo: Aldeia Norte, 2011. p. 83-102.

ANTUNIASSI, U. R. et al. Performance of a flow control system for aquatic herbicide application using an airboat sprayer. In: ASAE Annual International Meeting. Las Vegas: American Society of Agricultural and Biological Engineers, 2003. p. No 031068.

ASTROM, K. J.; HAGGLUND, T. Automatic tuning of simple regulators with specifications on phase and amplitude margins. Automatica, v. 20, n. 5, p. 645-651, 1984.

ASTROM, K. J.; HAGGLUnD, T. Advanced PID Control. Research Triangle Park: ISA - The Instrumentation, Systems, and Automation Society, 2006.

BAE, K. et al. Fuzzy gain scheduling for magnetic levitation control. In: The 21st International Conference on Magnetically Levitated Systems and Linear Drives. Daejeon - Korea: Korea Institute of Machinery and Materials, 2011. p. SOCP-01. 
BAIO, F. H.; ANTUNIASSI, U. R. Sistemas de controle eletrônico e navegação para pulverizadores. In: ANTUNIASSI, U. R. (Ed.). Tecnologia de Aplicação para Culturas Anuais. Passo Fundo: Aldeia Norte, 2011. p. 123-140.

BOLLER, W.; RAETANO, C. G. Bicos e pontas de pulverização de energia hidráulica, regulagens e calibração de pulverizadores de barras. In: ANTUNIASSI, U. R. (Ed.). Tecnologia de Aplicação para Culturas Anuais. Passo Fundo: Aldeia Norte, 2011. p. 51-65.

BOUSE, L. F.; CARLTON, J. B.; MORRISON, R. K. Aerial application of insect egg parasites. Transactions of the ASAE, v. 24, p. 1093-1098, 1981.

CAVENAGHI, A. L. Tecnologia de aplicação de herbicidas. In: ANTUNIASSI, U. R. (Ed.). Tecnologia de Aplicação para Culturas Anuais. Passo Fundo: Aldeia Norte, 2011. p. 203-217.

CHEN, C.-K.; SHIH, M.-C. Pid-type fuzzy control for anti-lock brake systems with parameter adaptation. JSME International Journal Series C Mechanical Systems, Machine Elements and Manufacturing, v. 47, n. 2, p. 675-685, 2004 .

CHEN, G.; PHAM, T. T. Introduction to Fuzzy Sets, Fuzzy Logic, and Fuzzy Control Systems. Boca Raton, Florida: CRC Press, 2001.

COELHO, A. M. Agricultura de Precisão: manejo da variabilidade espacial e temporal dos solos e culturas. Sete Lagoas: Embrapa Milho e Sorgo, 2005. Relatório técnico (Documentos - Edição: 46), 59 p.

CRUVINEL, P. E. et al. Bancada automatizada para ensaios e desenvolvimento de pulverizadores de agrotóxicos, aplicadores de fertilizantes líquidos e maturadores em culturas agrícolas sob manejo baseado em agricultura de precisão. In:

INAMASU, R. Y. et al. (Ed.). Agricultura de Precisão: um Novo Olhar. São Carlos, SP: Embrapa Instrumentação, 2011. p. 96-100.

CUNHA, J. P. R. da. Simulação da deriva de agrotóxicos em diferentes condições de pulverização. Ciência e agrotecnologia, v. 32, n. 5, p. 1616-1621, 2008.

DICKE, D.; KüHBAUCH, W. Temporal dynamics of weed populations in arable fields using long-term site-specific weed control. In: 15th Australian Weeds 
Conference, Papers and Proceedings: Managing weeds in a changing climate. Victoria: Weed Management Society of South Australia, 2006. p. $375-378$.

ESS, D. R.; PARSONS, S. D.; MEDLIN, C. R. Implementing Site-Specific Management: Sprayer Technology - Controlling Application Rate and Droplet Size Distribution On The Go. IN: Purdue University, 2001. Tech. Report (SSM-5-W), 7 p.

FERREIRA, C. R. R. P. T.; CAMARGO, M. L. B.; VEGRO, C. L. R. Defensivos agrícolas: comercialização recorde em 2011 e expectativas de acréscimo nas vendas em 2012. Análises e Indicadores do Agronegócio, v. 7, n. 7, p. 5, 2012.

GARCIA, C. Modelagem e Simulação de Processos Industriais e de Sistemas Eletromecânicos. 2. ed. São Paulo: Editora da Universidade de São Paulo, 2005.

GERHARDS, R.; OEBEL, H. Practical experiences with a system for site-specific weed control in arable crops using real-time image analysis and gps-controlled patch spraying. Weed Research, v. 46, n. 3, p. 185-193, 2006.

HOUPIS, C. H.; LAMONT, G. B. Digital Control Systems. 2nd. ed. Singapore: McGraw-Hill Higher Education, 1992.

HUGHES, T. A. Measurement and Control Basics. 3. ed. Research Triangle Park: ISA Press, 2002.

HUI, W.; YONGBO, Y.; MEIYU, L. Fuzzy-pid control in the application of multi-purpose vehicles of the road snow plowing. In: Proceedings of the 2009 International Conference on Web Information Systems and Mining. Washington DC, USA: IEEE Computer Society, 2009. p. 246-250.

INAMASU, R. Y. et al. (Ed.). Agricultura de Precisão: um Novo Olhar. São Carlos, SP: Embrapa Instrumentação, 2011.

JANG, J. O. A deadzone compensator of a dc motor system using fuzzy logic control. IEEE Transactions on Systems, Man, and Cybernetics, Part C: Applications and Reviews, v. 31, n. 1, p. 42-48, 2001. 
JANTZEN, J. Foundations of Fuzzy Control. 2. ed. Chippenham: John Wiley and Sons, 2007.

JUNIOR, A. R. et al. Variabilidade espacial e temporal de atributos químicos do solo e da produtividade da soja num sistema de agricultura de precisão. Engenharia na Agricultura, v. 14, n. 3, p. 156-169, 2006.

KATSUHIKO, O. Engenharia de Controle Moderno. 4. ed. São Paulo: Prentice Hall Brasil, 2003.

KIM, H.-M. A design for elevator group controller of building using adaptive dual fuzzy algorithm. Journal of Mechanical Science and Technology, The Korean Society of Mechanical Engineers, v. 15, p. 1664-1675, 2001.

KROPFF, M. J.; LAAR, H. H. van (Ed.). Modelling Crop-Weed Interactions. Wallingford: CAB International, 1993.

LAMMERS, P. S.; VONDRICKA, J. Evaluation of a carrier control valve for a direct nozzle injection system. Biosystems Engineering, v. 103, n. 1, p. 43-48, 2008.

LAMMERS, P. S.; VONDRICKA, J. Direct injection sprayer. In: OERKE, E.-C. et al. (Ed.). Precision Crop Protection - the Challenge and Use of Heterogeneity. Bonn - Germany: Springer, 2010. p. 295-309.

LEIGH, J. R. Applied Digital Control: Theory, design and implementation. Hertfordshire: Prentice Hall International (UK) Ltd., 1985.

LI, Y.; ANG, K. H.; CHONG, G. PID control system analysis and design. IEEE Control Systems, v. 26, n. 1, p. $32-41,2006$.

LIAN, S. H.; MESSOM, C.; KONG, Y. P. Fuzzy hybrid PID controller of a steam heated dryer. In: Fuzzy Systems Conference Proceedings. Seoul, South Korea: IEEE International, 1999. v. 3, p. 1707-1711.

LIANG, Y.; JIN, H.; LIANG, L. Fuzzy-PID controlled lift feedback fin stabilizer. Journal of Marine Science and Application, Harbin Engineering University, v. 7 , p. 127-134, 2008. 
NATIONAL INSTRUMENTS CORPORATION (AUSTIN TX). Rongfu Luo, S. Joe Qin e Dapang Chen. System and method for closed loop autotuning of PID controllers. US Pat. US 6081751, 03 apr. 1998, 27 jun. 2000.

MAMDANI, E.; ASSILIAN, S. An experiment in linguistic synthesis with a fuzzy logic controller. International Journal of Man-Machine Studies, v. 7, n. 1, p. 1-13, 1975.

MANTOVANI, E. C. Desenvolvimento, ajustes e aplicação de técnicas de agricultura de precisão para o aumento de eficiência e redução de impactos ambientais de sistemas de produção agrícola sob plantio direto. Sete Lagoas: Embrapa Milho e Sorgo, 1999-2002. Relatório técnico (Projeto PRODETAB 030-01/99), v.1 p.

MANTOVANI, E. C. Agricultura de precisão na Embrapa. 2006. Disponível em: $<$ http://fatecpompeia.edu.br/arquivos/arquivos/projeto_agricultura_de_precisaojunho_2006.pdf>. Acesso em: 20-09-2012.

MANTOVANI, E. C.; QUEIROZ, D. M.; DIAS, G. P. Máquinas e operações utilizadas na agricultura de precisão. In: SILVA, F. M. da (Ed.). Mecanização e Agricultura de Precisão. Poços de Caldas, MG: UFLA/SBEA, 1998. p. $109-157$.

MAZOYER, M. et al. História das Agriculturas no Mundo: do Neolítico à Crise Contemporânea. São Paulo: UNESP, 2010.

MENEGATTI, L. A. A.; MOLIN, J. P. A cana e a agricultura de precisão. Idea News, v. 5, n. abril, p. 18-23, 2004.

MERCALDI, H. V. et al. Modelo do módulo de injeção direta de herbicidas para aplicação em taxa variada. In: Conferência Brasileira de Dinâmica e Controle - DINCON 2011. Aguas de Lindóia - SP: Sociedade Brasileira de Automática e Sociedade Brasileira de Matemática Aplicada e Computacional, 2011a. p. 511-515.

MERCALDI, H. V. et al. Modelagem de um sistema de injeção direta de herbicida em taxa variável para aplicação em culturas agrícolas. In: INAMASU, R. Y. et al. 
(Ed.). Agricultura de Precisão: um Novo Olhar. São Carlos, SP: Embrapa Instrumentação, 2011b. p. 101-105.

MERRITT, H. E. Hydraulic Control Systems. New York - London - Sidney: John Wiley and Sons Inc., 1967.

MOLIN, J. Controle minucioso. Cultivar Máquinas, Pelotas, v. 3, n. abril, p. 18-21, 2004 .

MOLIN, J. P. Agricultura de precisão. parte 1: o que é e estado da arte em sensoriamento. Engenharia Agrícola, v. 17, n. 2, p. 97-107, 1997.

NATIONAL INSTRUMENTS. LabVIEW: PID and Fuzzy Logic Toolkit User Manual. Austin, Texas, Jun 2009.

NATIONAL INSTRUMENTS. NI Tutorial 11281: What is the LabVIEW Control Design and Simulation Module. Austin, Texas, Mar 2011.

NATSHEH, E.; BURAGGA, K. A. Comparison between conventional and fuzzy logic pid controllers for controlling dc motors. International Journal of Computer Science Issues, v. 7, n. 5, p. 128-134, 2010.

OERKE, E.-C. et al. (Ed.). Precision Crop Protection - the Challenge and Use of Heterogeneity. Bonn - Germany: Springer, 2010.

OliveirA, V. A.; AGUIAR, M. L.; VARGAS, J. B. Sistemas de Controle: Aulas de Laboratório. São Carlos: EESC-USP, 2005.

OVIEDO, J.; BOELEN, T.; OVERSCHEE, P. van. Robust advanced pid control (rapid): Pid tuning based on engineering specifications. Control Systems, IEEE, v. 26, n. 1, p. 15-19, 2006.

PAICE, M. E. R.; MILLER, P. C. H.; BODLE, J. D. An experimental sprayer for the spatially selective application of herbicides. Agricultural Engineering Research, v. 60, n. 2, p. 107-116, 1995.

PAICE, M. E. R.; MILLER, P. C. H.; DAY, W. Control requirements for spatially selective herbicide sprayers. Computers and Electronics in Agriculture, v. 14, n. 2-3, p. 163-177, 1996. 
PEDRYCZ, W.; GOMIDE, F. Fuzzy Systems Engineering: Toward

Human-Centric Computing. New Jersey: Wiley-IEEE Press, 2007.

PIERCE, F. J.; NOWAK, P. Aspects of precision agriculture. Advances in Agronomy, v. 67, n. -, p. 1-85, 1999.

PU, L.; ZHANG, X. dong. An intelligent fuzzy-pid control system for high-speed solenoid valve. In: Fourth International Conference on Innovative Computing, Information and Control (ICICIC). Kaohsiung: IEEE, 2009. p. $504-507$.

QUEIROS, L. R. Desenvolvimento de um Sistema de Controle para Aplicação a Taxa Variada e em Tempo Real de Fitorreguladores na Cultura do Algodoeiro. Tese (Doutorado) - Universidade Estadual De Campinas, Campinas, 2010.

QueIroZ, D. M. de; DIAS, G. P.; MANTOVAni, E. C. Agricultura de precisão na produção de grãos. 2006. Disponível em: <ftp://www.ufv.br/Dea/Disciplinas/Daniel/AP_GPS_ENG_432/palestra_vicosa.RTF >. Acesso em: 20-09-2012.

RAETANO, C. G. Introdução ao estudo da tecnologia de aplicação de produtos fitossanitários. In: ANTUNIASSI, U. R. (Ed.). Tecnologia de Aplicação para Culturas Anuais. Passo Fundo: Aldeia Norte, 2011. p. 15-26.

REIS, G. B. Simulação e Controle do Processo de Produção de Levedura. Dissertação (Mestrado) — UFSCar, São Carlos, SP, 2009.

RESENDE Álvaro V. et al. Agricultura de precisão no brasil: Avanços, dificuldades e impactos no manejo e conservação do solo, segurança alimentar e sustentabilidade. In: XVIII Reunião Brasileira de Manejo e Conservação do Solo e da Água. Teresina - PI: Embrapa Meio-Norte, 2010. p. id:23283.

RIID, A.; RUSTERN, E. Fuzzy logic in control: truck backer-upper problem revisited. In: The 10th IEEE International Conference on Fuzzy Systems. Melbourne, Vic.: IEEE, 2001. v. 1, p. 513-516.

ROCKWELL, A. D.; AYERS, P. D. A variable rate, direct nozzle injection field sprayer. Applied Engineering in Agriculture, v. 12, n. 5, p. 531-538, 1996. 
ROSS, T. J. Fuzzy Logic with Engineering Applications. 2. ed. Chichester: John Wiley and Sons, 2005.

ROSSETO, F. R. Controlador Fuzzy para um Sistema de Aplicação de Herbicidas a Taxa variável. Dissertação (Mestrado) - EESC-USP, São Carlos, SP, 2008.

SHIRATSUCHI, L. S.; FONTES, J. R. A. Tecnologia de Aplicação de Herbicidas. Planaltina: Embrapa, 2002. Relatório técnico (Documentos - Edição: 78), 30 p.

SILVA, I. N. Sistemas fuzzy: SEL5755-2/4. Notas de Aula. 17 ago. 2009, 04 dez. 2009.

STEWARD, B. L.; HUMBURG, D. S. Modeling the raven scs-700 chemical injection system with carrier control with sprayer simulation. Transactions of the ASAE, v. 43 , n. 2 , p. $231-245,2000$.

SUDDUTH, K. A.; BORGELT, S. C.; HOU, J. Performance of a chemical injection sprayer system. Applied Engineering in Agriculture, v. 11, n. 3, p. 343-348, 1995.

SUMATHI, S.; PANEERSELVAM, S. Computational Intelligence Paradigms: Theory and Aapplications using MATLAB. 1. ed. Boca Raton: CRC Press, 2010 .

TIMMERMANN, C.; GERHARDS, R.; KüHBAUCH, W. The economic impact of site-specific weed control. Precision Agriculture, v. 4, p. 249-260, 2003.

WALKER, J. T.; BANSAL, R. K. Development and characterization of variable orifice nozzles for spraying agro-chemicals. Precision Agriculture, p. Paper No 99-1008, 1999.

WEIS, M. et al. Precision farming for weed management: techniques. Gesunde Pflanzen, v. 60, n. 4, p. 171-181, 2008.

WERNER, V. et al. Aplicação de fertilizantes a taxa variável em agricultura de precisão variando a velocidade de deslocamento. Revista Brasileira de Engenharia Agrícola e Ambiental, v. 11, n. 6, p. 658 - 663, 2007. 
WHITCOMB, L.; RIZZI, A.; KODITSCHEK, D. Comparative experiments with a new adaptive controller for robot arms. IEEE Transactions on Robotics and Automation, v. 9, n. 1, p. 59-70, 1993.

WILES, T. L.; SHARP, D. G.; MATTHEWS, G. A. Guidelines On Standards For Agricultural Pesticide Application Equipment And Related Test Procedures: volume two vehicle-mounted and trailed sprayers. Rome: FAO, 2001. Tech. Report, 50 p.

YADAV, S.; TIWARI, J. P.; NAGAR, S. K. Digital control of magnetic levitation system using fuzzy logic controller. International Journal of Computer Applications, v. 41, n. 21, p. 27-31, 2012.

YIN, Z. et al. The application of adaptive PID control in the spray robot. In: International Conference on Intelligent Computation Technology and Automation. Shenzhen, Guangdong: IEEE, 2011. p. 528-531.

ZADEH, L. Fuzzy sets. Information Control, v. 8, p. 338-353, 1965.

ZADEH, L. A. Outline of a new approach to the analysis of complex systems and decision processes. IEEE Transactions on Systems, Man and Cybernetics, v. 3, n. 1, p. 28-44, 1973.

ZHANG, N.; WANG, M.; WANG, N. Precision agriculture - a worldwide overview. Computers and Electronics in Agriculture, v. 36, n. 2-3, p. 113 - 132, 2002.

ZHU, H. et al. Mixture uniformity in supply lines and spray patterns of a laboratory injection sprayer. Applied Engineering in Agriculture, v. 14, n. 3, p. 223-230, 1998. 